$$
\begin{gathered}
\text { Universidade de São Paulo } \\
\text { FFCLRP - Departamento de Física }
\end{gathered}
$$

Pós-graduação em Física aplicada à Medicina e Biologia

JEAM HAROLDO OLIVEIRA BARBOSA

\title{
Quantificação da deposição de ferro no cérebro usando ressonância magnética: um estudo em pacientes com doença de Parkinson.
}

Dissertação apresentada à Faculdade de Filosofia, Ciências e Letras de Ribeirão Preto da Universidade de São Paulo, como parte das exigências para a obtenção do título de Mestre em Ciências, Área: Física aplicada à Medicina e Biologia.

Ribeirão Preto - SP

2013 
JEAM HAROLDO OLIVEIRA BARBOSA

\section{Quantificação da deposição de ferro no cérebro usando ressonância magnética: um estudo em pacientes com doença de Parkinson.}

Dissertação apresentada à Faculdade de Filosofia, Ciências e Letras de Ribeirão Preto da Universidade de São Paulo, como parte das exigências para a obtenção do título de Mestre em Ciências.

\section{Área de Concentração:}

Física aplicada à Medicina e Biologia.

Orientador:

Carlos Ernesto Garrido Salmon.

Versão corrigida

Versão original disponível na FFCLRP - USP

Ribeirão Preto - SP

2013 
Autorizo a reprodução e divulgação total ou parcial deste trabalho, por qualquer meio convencional ou eletrônico, para fins de estudo e pesquisa, desde que citada a fonte.

\section{FICHA CATALOGRÁFICA}

Barbosa, Jeam Haroldo Oliveira

Quantificação da deposição de ferro no cérebro usando ressonância magnética: um estudo em pacientes com doença de Parkinson. / Jeam Haroldo Oliveira Barbosa; orientador Carlos Ernesto Garrido Salmon. Ribeirão Preto - SP, 2013.

160 f.:il.

Dissertação (Mestrado - Programa de Pós-graduação em Física aplicada à Medicina e Biologia) - Faculdade de Filosofia, Ciências e Letras de Ribeirão Preto da Universidade de São Paulo, 2013.

1. Ressonância Magnética. 2. Suceptibilidade. 3. Relaxometria. 4. Parkinson 5. Ferro. 
Nome: Barbosa, Jeam Haroldo Oliveira

Título: Quantificação da deposição de ferro no cérebro usando ressonância magnética: um estudo em pacientes com doença de Parkinson.

Dissertação apresentada à Faculdade de Filosofia, Ciências e Letras de Ribeirão Preto da Universidade de São Paulo, como parte das exigências para a obtenção do título de Mestre em Ciências.

Aprovado em:

\section{Banca Examinadora}

Prof(a). Dr(a).

Instituição:

Julgamento:

Assinatura:

Prof(a). Dr(a).

Instituição:

Julgamento:

Assinatura:

Prof(a). Dr(a).

Instituição:

Julgamento:

Assinatura: 


\section{Agradecimentos}

Aos meus pais Luiz Carlos e Elizabeth por terem me concedido o dom da vida e todo o cuidado que tiveram comigo até esta etapa de minha vida. Saibam que quando eu tentava explicar o que eu estava estudando conseguia aprender mais ainda. Obrigado por me ouvirem sempre com toda paciência e amor.

A minha amada Thamiris pelo apoio, compreensão e paciência por ter me esperado estudar em muitos dias e finais de semana. Esta vitória também é sua. Obrigado por fazer a distância entre nós a mais curta possível com suas palavras e mensagens de amor.

Ao Prof. Dr. Carlos Garrido agradeço por ter me orientado como aluno de mestrado e mais do que isso acreditado em mim. Sou muito grato pela paciência e por tudo que me ensinou: incluindo ciência e vida. Obrigado por ter incentivado e aberto todas as portas do mundo científico.

Aos alunos do laboratório Inbrain, muito obrigado! Sem vocês não seria tão prazeroso fazer ciência. Vocês acreditaram em mim e me apoiaram em tudo, aulas de inglês, atividade física e muitos almoços. Obrigado por poder dividir com vocês momentos de alegria e aflição.

Ao meus amigos da república Moita, obrigado por me incentivarem. O companheirismo de todos vocês foi muito importante. Em especial ao meu amigo Antonio Carlos da Silva Senra Filho por ter compartilhado todo o seu aprendizado científico e pessoal. Agradeço e digo que não esquecerei da república Moita.

Ao Prof. Dr. E. M. Haacke muito obrigado. Mesmo com toda a fama e influência me recebeu em seu laboratório e na sua casa em Detroit nos Estados 
Unidos sem saber quem eu era. Cuidou de mim como um filho, muito obrigado mesmo.

Ao professor Vitor Túmas e sua equipe do ambulatório extra piramidal do Hospital das Clínicas da Faculdade de Medicina de Ribeirão Preto, muito obrigado. Sem a sua colaboração este trabalho não teria sentido para a população em geral.

A professora Sílvia do Espírito Santo e o pessoal do seu laboratório LACCA, muito obrigado. Criamos uma grande amizade e muitas experiências valiosas.

Aos funcionários e técnicos do Departamento de Física que sempre estiveram presentes para resolver minhas dúvidas e me ajudar até como voluntários da pesquisa.

Em especial, ao meu pai do céu. Agradeço à Deus pela vida de cada pessoa acima. Agradeço a saúde que foi meu principal combustível para a conclusão deste trabalho e de mais um sonho. 
“ 'Tentar' não existe.

Faça.

Ou não faça."

Mestre Yoda 


\section{Resumo}

BARBOSA, J. H. O. Quantificação da deposição de ferro no cérebro usando ressonância magnética: um estudo em pacientes com doença de Parkinson.. 2013. 160 f. Dissertação (Mestrado - Programa de Pós-graduação em Física aplicada à Medicina e Biologia) - Faculdade de Filosofia, Ciências e Letras de Ribeirão Preto, Universidade de São Paulo, Ribeirão Preto - SP, 2013.

A capacidade do ferro, presente no corpo humano, em aceitar e doar elétrons o torna essencial para homeostase celular e várias reações biológicas. Contudo, o excesso deste metal no cérebro pode gerar efeitos deletérios através da produção de espécies reativas de oxigênio que causam o estresse oxidativo. Este estresse aparece como possível causa de doenças neurodegenerativas, caracterizadas por um aumento significativo da concentração de ferro em certas regiões do cérebro. Detectar e quantificar a deposição de ferro in vivo no cérebro torna-se de extrema relevância para entender diversas doenças neurodegenerativas. Neste estudo avaliamos a sensibilidade e a especificidade das principais técnicas de Ressonância Magnética in vivo para estimar o conteúdo de ferro depositado no cérebro. Foram estudados um grupo de 16 sujeitos saudáveis e outro de 14 pacientes com doença de Parkinson. Mapas de relaxometria (R2 e R2*) e susceptibilidade (QSM) foram estimados a partir de imagens adquiridas numa maquina de RM de 3.0T. Embora todos os mapas 
tenham apresentado correlação linear $\left(\mathbf{r}^{2}=0,7\right)$ com o acumulo de ferro reportado in vitro nas regiões do núcleo da base, apenas os mapas R2 e QSM apresentaram estatisticamente aumento significativo $(\mathbf{p}<0,05)$ para certas regiões do cérebro parkinsoniano (substância negra, núcleo rubro e globo pálido). O mapa QSM apresentou maior sensibilidade e especificidade para diferenciar pacientes com a doença quando comparados a sujeitos saudáveis por meio da análise da curva ROC. Concluímos que os mapas de relaxometria e susceptibilidade magnética podem estimar de forma indireta o conteúdo de ferro no cérebro, apesar de apresentarem dependências diferentes com a concentração deste metal. Observamos também que os valores de sususceptibilidade magnética obtidos com imagens de baixa resolução $(1,0 \times 1,0 \times 2,0 \mathrm{~mm})$ não apresentaram mudanças significativas em relação aos obtidos com imagens de alta resolução $(0,5 \times 0,5 \times 2,0 \mathrm{~mm})$. Logo, sugerimos a aquisição de imagens com baixa resolução para o processamento do mapa QSM . A analise de múltiplos valores de tempo de relaxação $\mathrm{T} 2$ determinou apenas um valor para cada região do núcleo da base para ambos grupos, este resultado foi aparentemente afetado pela relação sinal ruído.

Palavras-chave: $\quad$ 1. Ressonância Magnética. 2. Suceptibilidade. 3. Relaxometria. 4. Parkinson 5. Ferro. 


\section{Abstract}

BARBOSA, J. H. O. Quantification of iron deposition in the brain using magnetic resonance: a study in patients with Parkinson's disease.. 2013. 160 f. Dissertation (M.Sc. - Postgraduate program in Physics applied to Medicine and Biology) - Faculty of Philosophy, Sciences and Literature, University of São Paulo, Ribeirão Preto - SP, 2013.

The capacity of the iron present in the human body to accept and donate electrons makes it essential for cellular homeostasis and various biological reactions. However, an excess of the metal in the brain can produce deleterious effects through the production of reactive oxygen species that cause oxidative stress. This stress can be the possible cause of neurodegenerative diseases which present a significant increase in iron concentration in certain brain regions. To detect and quantify iron deposition in the brain in vivo has high potential for understanding neurodegenerative diseases. In this study we evaluated the sensitivity and specificity of the main Magnetic Resonance technique in vivo to estimate the content of iron deposited in the brain. Were studied a group of 16 controls and 14 patient with Parkinson disease. Relaxometry map (R2 and R2*) and magnetic susceptibility map QSM were estimated by images obtained of scanner of Magnetic Resonance of 3T. Although all maps have presented linear correlation $\left(r^{2}=0.7\right)$ with the accumulation of iron reported in vitro regions of basal ganglia, only the R2 and QSM maps showed significant 
increase $(p<0.05)$ for certain regions of the parkinsonian brain (substantia nigra, red nucleus, and globus pallidus). The QSM map showed higher sensitivity and especificity for differentiate patients with the disease when compared with controls by the analysis of curve ROC. We conclude that magnetic susceptibility and relaxometry maps may estimate indirect the content of brain iron, although having different dependencies with the concentration of this metal. We also observed that the values of magnetic sususceptibilidade obtained with low resolution images $(1,0 \times 1,0 \times 2,0 \mathrm{~mm})$ showed no significant change compared to those obtained with high-resolution images $(0,5 \times 0,5 \times 2$, 0mm). So, we suggest the acquisition of images with low resolution to process QSM map. The analyse of multiple relaxation time T2 determined just one value for basal ganlies in both groups, these results were apparently affected by rate noise signal.

Key-words: 1. Magnetic Resonance. 2. Suceptibility. 3. Relaxometry. 4. Parkinson's Disease 5. Iron. 


\section{Lista de Figuras}

1.1 Metaloproteínas envolvendo ferro e grupo heme . . . . . . . . 4

1.2 Representação da molécula de mioglolbina . . . . . . . . . . . . 5

1.3 Representação ilustrativa de proteínas envolvidas no armazenamento de ferro . . . . . . . . . . . . . . 6

1.4 Imagem de microscopia eletrônica dos núcleos de ferritina e hemossiderina . . . . . . . . . . . . . . 7

1.5 Processo de transporte de ferro para o interior da célula partindo da transferrina . . . . . . . . . . . . . . . 9

1.6 Cortes transversais contendo os gânglios da base . . . . . . . . . 11

1.7 Estresse oxidativo . . . . . . . . . . . . . . . . . 18

2.1 Método histoquímico de Pers'l stain aplicado nos núcleos da base de um cadáver . . . . . . . . . . . . . . . . 22

2.2 Representação do efeito do íon de ferro paramagnético na distorção do campo magnético local. . . . . . . . . . . . . . . . 24

2.3 Imagens axiais do cérebro ponderadas em T2 . . . . . . . . . . 24

2.4 Mapas de relaxometria do cérebro por ressonância magnética nuclear. . . . . . . . . . . . . . . 25

2.5 Imagens ponderadas em SWI. . . . . . . . . . . . . . . . . 28

2.6 Mapas de susceptibilidade magnética. . . . . . . . . . . . . 30

2.7 Acúmulo de ferro com o avanço da idade em regiões anatômicas. 33

2.8 Dependência do valor de R2* com o avanço da idade. . . . . . . . 34

3.1 Espectro de susceptibilidade magnética. . . . . . . . . . . . . . 38 
3.2 Susceptibilidade magnética do fígado de acordo com o acúmulo de ferro. . . . . . . . . . . . . . . . . . 41

3.3 Representação do problema para o cálculo do campo magnético. . 43

3.4 Regiões de descontinuidade da função kernel inversa $\left(F(k)^{-1}\right)$. . 46

3.5 Representação das componentes de campo para uma imagem 2D. 48

3.6 Comparação do filtro SHARP com o filtro passa alta para uma imagem in vivo. . . . . . . . . . . . . . . . . . 50 50

3.7 Resultados do processamento do filtro baseado em geometria. . . 53

3.8 Representação da função $\mathrm{F}(\mathrm{k})$. . . . . . . . . . . . . . . . . . . . 54

3.9 Representação 3D das singularidades geradas pela aplicação de filtros $F(k)$. . . . . . . . . . . . . . . 57

4.1 Exemplo de imagens de uma fatia da região dos núcleos da base adquiridas com uma sequencia Spin Eco mudando o tempo ao eco de 12 em $12 \mathrm{~ms} . \ldots \ldots$. . . . . . . . . . . . . . . 64

4.2 Exemplo de imagens de uma fatia da região dos núcleos da base adquiridas com uma sequencia Gradiente Eco com múltiplos ecos (4 ecos, $\mathrm{TE}=12,24,36,48 \mathrm{~ms}) . \quad \ldots \ldots$. . . . . . . . . . 64

4.3 Etapas para o processamento do mapa de susceptibilidade magnética. . . . . . . . . . . . . . 67

4.4 Tela principal do programa SMART (v1.1 2012) . . . . . . . . . . 70

4.5 Exemplo de regiões segmentadas sobre diferentes fatias do mapa de susceptibilidade magnética. . . . . . . . . . . . . 73

5.1 Análise inter-observador . . . . . . . . . . . . . . . . 77

5.2 Análise intra-observador. . . . . . . . . . . . . . . . . . 77

5.3 Correlação linear entre R2 e acúmulo de ferro estimado considerando o efeito idade. . . . . . . . . . . . 80

5.4 Correlação linear entre R2* e acúmulo de ferro estimado considerando o efeito idade. . . . . . . . . . . . 8 80 
5.5 Correlação linear entre $\Delta \chi$ e acúmulo de ferro estimado considerando o efeito idade. . . . . . . . . . . . . . 80

5.6 Correlação linear entre R2 e $\Delta \chi$ nas diferentes regiões avaliadas neste estudo. . . . . . . . . . . . . . . . 83

5.7 Correlação linear entre R2* e $\Delta \chi$ nas diferentes regiões avaliadas neste estudo.

5.8 Correlação linear entre R2 com R2* nas diferentes regiões avaliadas neste estudo. . . . . . . . . . . . . . . . . 84

5.9 Exemplos de mapas de R2 . . . . . . . . . . . . . . 85

5.10Exemplos de mapas de R2* . . . . . . . . . . . . . . . 86

5.11 Exemplos de mapas de $\Delta \chi \ldots \ldots$. . . . . . . . . . 87

5.12Valores médios e desvio padrão de R2 dos controles e pacientes com doença de Parkinson. . . . . . . . . . . . . . . . . . 88

5.13Valores médios e desvio padrão de R2* dos controles e pacientes com doença de Parkinson. . . . . . . . . . . . . . . 89

5.14Valores médios e desvio padrão de $\Delta \chi$ dos controles e pacientes com doença de Parkinson. . . . . . . . . . . . . . . . 89

5.15Valores de R2 para a região da $\mathrm{SN}$ (a) e RN (b) para controles e pacientes em relação à idade. . . . . . . . . . . . . . . . . . . . . 93

5.16Valores de $\Delta \chi$ para a região da SN (a) e GP (b) para controles e pacientes em relação a idade. . . . . . . . . . . . . . . 93

5.17Curva ROC para os mapas de $\mathrm{R} 2$, R2* e QSM da região da substância negra $(\mathrm{SN})$. . . . . . . . . . . . . . . . . . . . 94

5.18Curva ROC para os mapas de R2, R2* e QSM da região do núcleo rubro $(\mathrm{RN}) . \ldots \ldots \ldots$. . . . . . . . . . . . . . . . . . . . . . . . .

5.19Curva $R O C$ para os mapas de R2, R2* e QSM da região do globo pálido (GP). . . . . . . . . . . . . . . . . . . 95

5.20 Mapas de QSM obtidos de imagens com alta e baixa resolução para um controle e um paciente com doença de Parkinson. . . . . 97 
5.21Correlação linear entre valores médios de susceptibilidade magnética dos núcleos da base por meio do processamento de imagens com baixa e alta resolução. . . . . . . . . . . . . . . 97

5.22 Valores médios e desvio padrão dos valores de susceptibilidade magnética. . . . . . . . . . . . . . . . . . . . 98

5.23Análise de múltiplos T2 para sujeito controle. . . . . . . . . . . . 100

5.24Análise de múltiplos T2 para pacientes com doença de Parkinson. 100

5.25Dependência do cálculo de múltiplos T2 para a determinação dois valores de T2 simulados. . . . . . . . . . . . . . . . . . . . . 101

A.1 Esboço da sequência de Gradiente Eco. . . . . . . . . . . . . 117

A.2 Diagrama da evolução dos spins durante uma sequência de Gradiente Eco. . . . . . . . . . . . . . . . . . . . . . 117

A.3 Representação do sinal complexo. . . . . . . . . . . . . . . 118

A.4 Máscara de filtro espacial com coeficientes arbitrários. . . . . . . 119

A.5 Imagem de $9 \times 9$ pixels. . . . . . . . . . . . . . . . . . . . . . 119

A.6 Aplicação de filtro espacial passa alta. . . . . . . . . . . . . . 120

A.7 Representação pictórica do processo de geração da máscara da fase. . . . . . . . . . . . . . . . . . . . 122

A.8 Obtenção da imagem SWI. . . . . . . . . . . . . . . . . . . . . 123

A.9 Imagem mIP das imagens de magnitude e SWI. . . . . . . . . . . 123

A.10Diagrama das etapas do processamento da imagem de SWI. . . . 124

B.1 A convolução de duas funções. . . . . . . . . . . . . . . . . 125

C.1 Aceite do comitê de ética da FFCLRP _ . . . . . . . . . . 136

D.1 Aceite do comitê de ética do HC . . . . . . . . . . . . 138 


\section{Lista de Tabelas}

1.1 Distribuição de ferro em adultos saudáveis. . . . . . . . . . . . . 2

1.2 Conteúdo de ferro total por unidade de peso de tecido úmido em regiões cerebrais de sujeitos saudáveis. . . . . . . . . . . 10

1.3 Conteúdo de ferritina por unidade de peso de tecido úmido em regiões cerebrais. . . . . . . . . . . . . . . . . 12

1.4 Regiões cerebrais que apresentaram aumento significativo de ferro em pacientes com doença de Parkinson, através de técnicas in vitro. . . . . . . . . . . . . . . . . . . . 15

1.5 Regiões cerebrais que apresentaram aumento significativo das taxas de relaxação R2 e R2* em pacientes com doença de Parkinson. 16

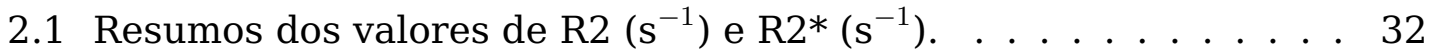

3.1 Susceptibilidade magnética de alguns materiais fracamente magnéticos e tecidos biológicos. . . . . . . . . . . . . . 39

4.1 Principais informações sobre os pacientes com doença de Parkinson e os controles avaliados. . . . . . . . . . . . . 61

4.2 Principais informações sobre os pacientes com doença de Parkinson avaliados.

5.1 Coeficientes de regressão linear obtidos e encontrados na literatura. . . . . . . . . . . . . . . . . . . 881

5.2 Resultado do teste $\mathrm{t}$ de Student para o gurpo controle e de paciente com doença de Parkinson. . . . . . . . . . . . . . 90 


\section{Lista de Abreviaturas}

FFCLRP Faculdade de Filosofia Ciências e Letras de Ribeirão Preto.

USP Universidade de São Paulo.

T2 Tempo de relaxação transversal.

T2* Tempo de relaxação transversal estrela.

R2 Taxa de relaxação transversal.

R2* Taxa de relaxação transversal estrela.

SWI Sigla em inglês de Susceptibility Weighted Imaging.

TfR Receptores de transferrina.

DMT1 Transportador de metal divalente 1.

Apo-TF Apotransferrina e receptores de transferrina.

RNA Sigla em inglês de ácido ribonucleíco citoplasmático.

IRPs Regulador de proteínas com ferro.

AAS Sigla em inglês de espectroscopia por absorção atômica.

AS Sigla em inglês de espectrofotometria por absorção atômica.

NAA Sigla em inglês de análise por ativação com nêutrons.

ICP Sigla em inglês de plasma indutivamente acoplado. 
RMN Ressonância Mangética Nuclear.

SHARP Sigla em inglês Sophisticated Harmonic Artefact Reduction.

COSMOS Sigla em inglês Calculation of Susceptibility Through Multiple Orientation Sampling.

TE Tempo ao eco.

TR Tempo de repetição.

SN Substância Negra.

RN Sigla em inglês de Núcelo Rubro

GP Globo Pálido

PUT Putâmen

CN Sigla em inglês de Núcleo Caudado

THA Sigla em inglês de Tálamo

WM Sigla em inglês de Substância Branca

GM Sigla em inglês de Substância Negra

$\Delta \chi \quad$ Susceptibilidade magnética relativa

CCI Coeficiente de Correlação intra-classe

ROC Sigla em inglês Receiver Operating Characteristic 


\section{Lista de Símbolos}

$\vec{H} \quad$ Vetor campo magnético externo aplicado.

$\vec{B} \quad$ Vetor campo magnético.

$\vec{M} \quad$ Magnetização.

$\vec{M}_{0} \quad$ Magnetização inerente.

$\overleftrightarrow{\chi} \quad$ Tensor de susceptibilidade mangnética.

$\chi \quad$ Susceptibilidade magnética.

$Y \quad$ Fração de oxigenação das células vermelhas.

Hct Fração de eritrócitos presentes no sangue.

$\chi_{o x i} \quad$ Susceptibilidade magnética da hemoglobina oxigenada.

$\chi_{\text {deoxi }} \quad$ Susceptibilidade magnética da hemoglobina deoxigenada.

$\chi_{\text {plasma }} \quad$ Susceptibilidade magnética do plasma.

$\chi_{\text {sangue }} \quad$ Susceptibilidade magnética do sangue.

$\Delta Y \quad$ Variação do nível de oxigenação do sangue.

$\Delta \chi \quad$ Variação de susceptibilidade magnética do sangue ou susceptibilidade magnética relativa (Depende do contexto).

$\mu_{0} \quad$ Permeabilidade magnética absoluta.

$\gamma \quad$ Razão giro-magnética. 


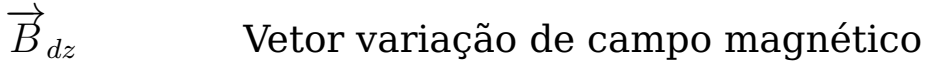

$\phi \quad$ Valor de fase.

TF Transformada de Fourier.

$T F^{-1} \quad$ Transformada Inversa de Fourier.

$\Delta^{2} \quad$ Operador Laplaciano.

$\delta \quad$ Impulso unitário .

P $\quad$ Módulo do momento de dipolo.

$\alpha \quad$ Limiar ou parâmetro de regularização (Depende do contexto).

$\beta \quad$ Parâmetro de regularização. 


\section{Prefácio}

Esta dissertação descreve os resultados obtidos no mestrado do aluno Jeam Haroldo Oliveira Barbosa sobre orientação do Prof. Dr. Carlos Ernesto Garrido Salmon na FFCLRP-USP. O tema principal abordado é a implementação e seleção da técnica de Imagem por Ressonância Magnética mais adequada para quantificar a deposição de ferro no cérebro humano. A seguir maiores detalhes do conteúdo da dissertação.

De forma introdutória abordamos no capítulo 1 detalhes sobre o conteúdo e a distribuição de ferro no organismo humano, em específico no cérebro humano. Posteriormente mostramos a relação do acúmulo de ferro com a doença neurodegenerativa de Parkinson.

No capítulo 2 apresentamos as técnicas de quantificação ou estimativa da concentração de ferro no cérebro in vitro e in vivo. Além disso, descrevemos algumas variáveis associadas à deposição de ferro no cérebro (idade, gênero e sexo).

Apresentamos no capítulo 3 a definição de susceptibilidade magnética e a classificação dos tecidos considerando esta propriedade física. Adicionalmente, descrevemos o mapa quantitativo de susceptibilidade magnética (QSM) recentemente proposto pela literatura científica (2008) e ainda não descrito no Brasil.

O capítulo 4 contém os principais aspectos metodológicos usados nesta pesquisa. Nele consideramos a casuística, as imagens adquiridas com seus respectivos parâmetros, o processamento dos mapas de R2, R2* e QSM, a segmentação e análise estatística adotada.

No capítulo 5 apresentamos os nossos resultados obtidos com os 
voluntários saudáveis e pacientes com doença de Parkinson e as respectivas discussões.

Em resumo, este trabalho objetiva quantificar a concentração de ferro no cérebro de controles e pacientes com doença de Parkinson através da combinação de diferentes parâmetros obtidos a partir de imagens de RMN (R2, R2* e QSM). Dentre o objetivo definimos os objetivos específicos:

- Implementação das técnicas Spin Eco, Gradiente Eco e do processamento QSM na estimativa da concentração de ferro para controles e pacientes com doença de Parkinson.

- Co-relacionar as medidas quantitativas das diferentes técnicas de imagem (R2, R2* e QSM) com o acúmulo de ferro.

- Avaliação de sensibilidade e especificidade das técnicas de imagem (R2, R2* e QSM) e sua combinação referente à diferenciação entre pacientes e controles. 


\section{Sumário}

Lista de Figuras $\quad$ xi

Lista de Tabelas $\quad$ xv

$\begin{array}{ll}\text { Lista de Abreviaturas } & \text { xvi }\end{array}$

Lista de Símbolos $\quad$ xviii

Prefacio $\quad \mathbf{x x}$

1 Revisão da distribuição de ferro no organismo humano 1

1.1 Conteúdo de ferro no organismo humano . . . . . . . . . . . . 2

1.2 Distribuição de ferro no cérebro . . . . . . . . . . . . . . . 9

1.3 Acúmulo de ferro no cérebro e doenças neurodegenerativas (Doença de Parkinson) . . . . . . . . . . . . . . . 15

2 Metodologia de quantificação de ferro no cérebro 20

2.1 Medidas in vitro . . . . . . . . . . . . . . . . . . 20

2.2 Medidas in vivo . . . . . . . . . . . . . . . . . . 23

2.2.1 Relaxometria R2 e R2* . . . . . . . . . . . 25

2.2.2 Imagem por susceptibilidade magnética . . . . . . . . 28

2.3 Variáveis associadas à distribuição de ferro no cérebro de indivíduos normais . . . . . . . . . . . . . . . . 31

3 Mapa de Susceptibilidade Magnética 36

3.1 Introdução . . . . . . . . . . . . . . . . 36

3.2 Susceptibilidade Magnética e classificações . . . . . . . . . . . 37 
3.3 Mapa quantitativo de susceptibilidade magnética (QSM) . . . . . 41

3.3.1 Relação teórica . . . . . . . . . . . . . . . . . 42

3.3.2 Pré processamento da imagem de fase . . . . . . . . . . . 47

3.3.3 Cálculo do mapa de susceptibilidade magnética . . . . . . . 53

4 Materiais e Métodos $\quad 59$

4.1 Casuística . . . . . . . . . . . . . . . . . 59

4.2 Aquisição das imagens . . . . . . . . . . . . . . . . . . 62

4.3 Processamento dos Mapas . . . . . . . . . . . . . . . 63

4.3.1 Mapa de Relaxometria . . . . . . . . . . . . . . 63

4.3.2 Mapa de Susceptibilidade Magnética . . . . . . . . . 66

4.4 Segmentação das regiões de interesse . . . . . . . . . . . . . 72

4.5 Análises estatísticas . . . . . . . . . . . . . . . 73

5 Resultados e Discussões $\quad 76$

5.1 Análise estatística da segmentação . . . . . . . . . . . . 76

5.2 Correlação linear entre R2, R2* e QSM com o acúmulo de ferro 79

5.3 Correlação linear entre R2 com QSM, R2* com QSM, R2 com R2* nos sujeitos controles . . . . . . . . . . . . . . . 83

5.4 Mapas de R2, R2* e QSM para controles e pacientes com doença de Parkinson . . . . . . . . . . . . . . . . . . . 85

5.5 Efeito da resolução da imagem no mapa de QSM . . . . . . . . . . 96

5.6 Análise de diferentes valores de T2 . . . . . . . . . . . . . 99

6 Conclusões $\quad 102$

$\begin{array}{ll}\text { Referências Bibliográficas } & \mathbf{1 0 4}\end{array}$

Apêndice A - Processamento da imagem SWI 116

Apêndice B - Teorema da Convolução 125

Anexo A - Termo de consentimento livre e esclarecido para sujeito controle 
xxiv

Anexo B - Termo de consentimento livre e esclarecido para sujeito paciente

Anexo C - Aceite do Comitê de Ética da FFCLRP

135

Anexo D - Aceite do Comitê de Ética do Hospital das Clínicas 


\section{Capítulo}

\section{Revisão da distribuição de ferro no organismo humano}

A habilidade do ferro em aceitar e doar elétrons o torna imprescindível para homeostase celular e diversas reações biológicas. É componente essencial para a formação da molécula heme e participa da formação de diversas proteínas como transferrina, ferritina e hemossiderina.

A síntese de heme é controlada por mecanismos enzimáticos e de degradação, e esse controle tem que ser rigoroso, uma vez que o excesso de ferro pode ter efeito deletério, gerando espécies reativas de oxigênio que causam estresse oxidativo (reação de Fenton). A ação desses radicais sobre proteínas, lipídios e DNA causam graves lesões celulares (ANDREWS, 1999; WIJAYANTI; KATZ; IMMENSCHUH, 2004; HENTZE; MUCKENTHALER; ANDREWS, 2004).

Comunidades de pesquisa em geral acreditam que a habilidade de detectar e quantificar regiões cerebrais com acúmulo de ferro apresenta um elevado potencial no estudo de doenças neurodegenerativas possibilitando entender a patogênese e monitorar a progressão, seja em condições normais ou ante um tratamento. Haacke e colaboradores, em um trabalho de revisão (HAACKE et al., 2005), exemplificam patologias com um comprovado acúmulo de ferro como: Hallervorden-Spatz, Hemocromatose, Talassemia, Anemia, Infarto Cerebral, Hemorragia Crônica, Esclerose Múltipla, doença de Alzheimer, Huntington, doença de Parkinson, AIDS e Síndrome de Down. Esta 
diversidade de patologias associadas a este metal é altamente dependente da distribuição e funcionalidade do mesmo no corpo humano.

\subsection{Conteúdo de ferro no organismo humano}

O ferro é o metal de transição mais abundante do nosso corpo. Homens adultos saudáveis têm cerca de 3000 a 4000mg de ferro distribuídos no corpo (Tabela 1.1).

\begin{tabular}{|c|c|c|c|c|c|}
\hline Região & Célula & $\begin{array}{l}\text { Molécula } \\
\text { associada }\end{array}$ & $\begin{array}{l}\text { Função } \\
\text { fundamental }\end{array}$ & Quantidade (mg) & $\begin{array}{l}\text { Quantidade } \\
\text { relativa (\%) }\end{array}$ \\
\hline Sangue & eritrócitos & hemoglobina & transporte $\mathrm{O}_{2}$ & 2680 & 66,0 \\
\hline Fígado & hepatócitos & $\begin{array}{l}\text { ferritina e } \\
\text { hemossiderina }\end{array}$ & $\begin{array}{l}\text { armazenamento } \\
F e^{+3}\end{array}$ & 1000 & 24,6 \\
\hline $\begin{array}{l}\text { Músculo } \\
\text { (geral) }\end{array}$ & $\begin{array}{l}\text { células } \\
\text { musculares }\end{array}$ & mioglobina & $\begin{array}{l}\text { transporte } \\
\text { reserva de } \mathrm{O}_{2}\end{array}$ & 153 & 3,7 \\
\hline Medula Óssea & $\begin{array}{l}\text { eritroblastos } \\
\text { e mácrofagos }\end{array}$ & $\begin{array}{l}\text { hemoglobina, } \\
\text { ferritina e } \\
\text { hemossiderina }\end{array}$ & $\begin{array}{l}\text { armazenamento } \\
\mathrm{Fe}^{+3}\end{array}$ & 153 & 3,7 \\
\hline Cérebro & $\begin{array}{l}\text { células } \\
\text { da glia e } \\
\text { neurônio }\end{array}$ & $\begin{array}{l}\text { ferritina,L-ferrit } \\
\text { ferro e e } \\
\text { transferrina }\end{array}$ & ina, & $60^{a}$ & 1,5 \\
\hline $\begin{array}{l}\text { Múltiplos } \\
\text { tecidos }\end{array}$ & $\begin{array}{l}\text { múltiplos } \\
\text { tecidos }\end{array}$ & $\begin{array}{lr}\text { grupos } & \text { de } \\
\text { FeSS } & \text { e } \\
\text { enzimas } & \end{array}$ & $\begin{array}{l}\text { transferência } \\
\text { de elétrons, } \\
\text { catalise e } \\
\text { peroxidase }\end{array}$ & 8 & 0,2 \\
\hline Plasma & plasma & transferrina & $\begin{array}{l}\text { transporte } \\
\mathrm{Fe}^{+3}\end{array}$ & 3 & 0,1 \\
\hline $\begin{array}{l}\text { Intestino } \\
\text { Delgado }\end{array}$ & enterócitos & DMT1 & absorção & $1-3$ & 0,1 \\
\hline $\begin{array}{l}\text { Pele, trato } \\
\text { gastrointestinal, } \\
\text { útero e outros }\end{array}$ & ........... & …...... & $\begin{array}{l}\text { descamação, } \\
\text { trauma menor, } \\
\text { menstruação, } \\
\text { gravidez e } \\
\text { lactação }\end{array}$ & $1-3$ & 0,1 \\
\hline Valor total & ........... & ........... & ........... & 4060 & 100 \\
\hline
\end{tabular}

Tabela 1.1: Distribuição de ferro em adultos saudáveis. As quantidades de ferro foram estimadas a partir dos dados de Andrews (1999), Kaushansky et al. (2010), Connor, Boeshore e Benkovic (1992). ${ }^{a}$ Valor obtido de dados de volumetria por nosso grupo e de dados de concentração de Hallgren e Sourander (1958). 
A homeostase do ferro é mantida pela absorção alimentar, distribuição no corpo e perda do ferro. A perda do metal ocorre diariamente devido à transpiração, descamação da pele e ferimentos leves, e do trato gastrointestinal. As mulheres possuem níveis de ferro inferiores aos homens, principalmente devido à perda do metal durante a menstruação, gravidez, parto e lactação. Geralmente, perdas de ferro em homens adultos e mulheres pós-menopausa são aproximadamente $1,0 \mathrm{mg}$ e em mulheres com ciclo menstrual regulado aproximadamente 1,5 mg (BOTHWELL et al., 1979). A Tabela 1.1 resume a distribuição de ferro no organismo humano de acordo com a região, sub unidade, forma molecular, função fundamental, quantidade e quantidade relativa.

Uma classificação usual é de ferro heme e ferro não heme. Ferro heme possui a presença do agrupamento heme como em hemoglobinas, mioglobinas e enzimas de peroxidase. Já o ferro não heme não possui o agrupamento heme e em geral serve para classificar todas as outras moléculas que possuem ferro: (i) complexos de baixo peso molecular, (ii) metaloproteínas como transferrina, melanotransferrina e lactoferrina, (iii) proteínas de armazenamento como ferritina e hemossiderina e (iv) ferro iônico.

Com intuito de resumir a revisão obtida de distribuição de ferro e da sua importância funcional no organismo classificamos-lo abaixo nos seguintes tópicos: ferro funcional, armazenamento de ferro e transporte de ferro.

\section{A)Ferro funcional}

O ferro desempenha duas funções básicas no organismo: transporte de oxigênio (hemoglobina e mioglobina) e elétrons (agrupamentos ferro-enxofre).

Dois terços da deposição normal de ferro no corpo humano estão incorporados na hemoglobina na forma $\mathrm{Fe}^{+2}$ em 4 grupos heme (Figura 1.1). A hemoglobina é uma metaloproteína presente nos eritrócitos com função de transporte de oxigênio no sangue. Nesta função o ferro desempenha o papel fundamental, pois o oxigênio liga-se a ele diretamente. O íon de $F e^{+2}$ quando 
isolado e exposto ao oxigênio é oxidado de maneira irreversível a $F e^{+3}$, que não liga a $O_{2}$. A porção protéica da hemoglobina impede essa oxidação e torna possível a ligação reversível do $O_{2}$ ao grupo heme (VOET; VOET; PRATT, 2000).

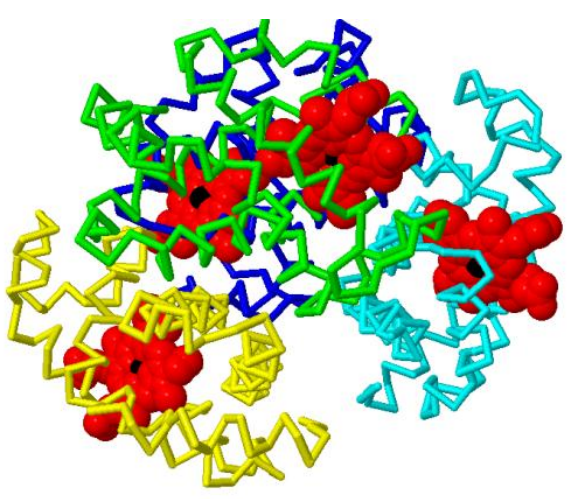

(a)

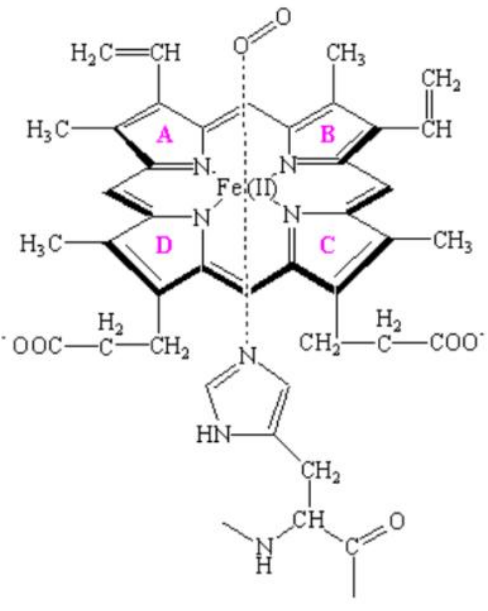

(b)

Figura 1.1: Metaloproteínas envolvendo ferro e grupo heme: (a) representação da molécula de hemoglobina, onde as cores verde, azul escuro, azul claro e amarelo representam as cadeias de aminoácidos ou subunidades, a cor vermelha indica um grupo heme e preto o átomo de $\mathrm{Fe}^{+2}$ (imagem modificada de Matz E, 2013); (b) Grupo heme, onde o átomo central de $\mathrm{Fe}^{+2}$ está ligado a quatro átomos de nitrogênio de cada anel porfirínico (marcados de $A$ a D) no plano, a histidina e ao oxigênio molecular num plano perpendicular (VOET; VOET; PRATT, 2000).

De acordo com (ANDREWS, 1999) aproximadamente $10 \%$ do ferro do organismo está distribuído na mioglobina(Mb) (Figura1.2). Esta pequena metaloproteína intracelular do músculo dos vertebrados, que contém somente um agrupamento heme, é capaz de se ligar reversivelmente ao oxigênio molecular e facilitar o transporte do mesmo dentro da célula muscular para as mitocôndrias durante períodos de aumento da atividade metabólica. Também pode atuar como reservatório de oxigênio em condições de anóxia (ORDWAY; GARRY, 2004).

Em menores quantidades no organismo, aproximadamente $8 \mathrm{mg}$, existem proteínas com agrupamentos de ferro-enxofre (Fe-S) (ROUAULT, 


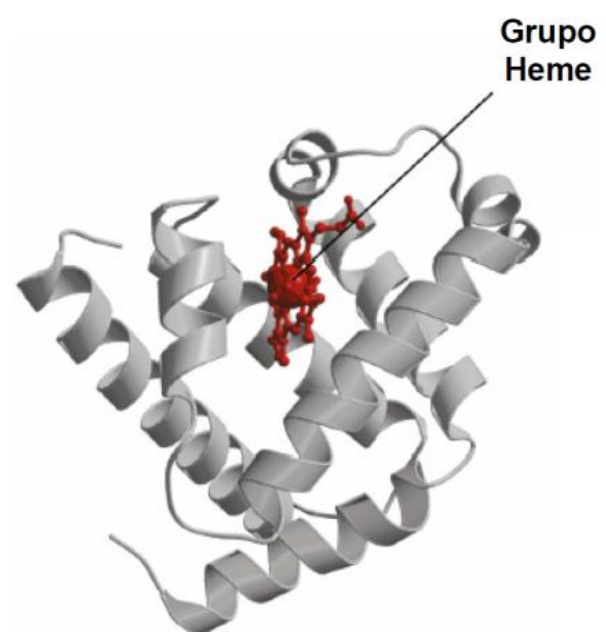

Figura 1.2: Representação da molécula de mioglobina. Figura adaptada de Nelson e Cox (2000).

2001; LILL; MUHLENHOFF, 2006), com funções de transporte de elétrons na mitocôndria, enzimáticas e regulatórias de proteínas.

\section{B) Armazenamento de ferro}

A segunda maior deposição deste íon metálico no organismo, após a hemoglobina, está nas proteínas de armazenamento de ferro. Elas são encontradas sob duas formas: ferritina e hemossiderina (BARTON et al., 2010). No nosso organismo, o fígado contém uma alta concentração destas proteínas nos hepatócitos e macrófagos (incluindo células Kupffer) com uma distribuição relativamente uniforme, já no cérebro predomina-se em oligondendrócitos e células da glia e na forma particular (H-ferrtina) em neurônios.

A ferritina é uma molécula protéica, principalmente intracelular, que captura $\mathrm{Fe}^{+2}$ e armazena como $\mathrm{Fe}^{+3}$. Ela reduz o risco de dano intracelular que pode ser causado pela formação de radicais oxigenados e está presente principalmente no fígado, medula óssea e gânglios da base. A ferritina livre sem estar combinada com o $\mathrm{Fe}^{+2}$ é chamada de apoferritina (Figura 1.3(a)), sendo um heteropolímero de 24 sub unidades que formam uma concha oca com diâmetro externo de 12-13 nm e diâmetro interno de 7-8 nm, peso 
molecular aproximadamente $500 \mathrm{kD}$, com capacidade de armazenar até 4500 átomos de $\mathrm{Fe}^{+3}$ por molécula (HARRISON, 1996). Esta molécula é composta de canais ou sub unidades L(do inglês light) e H(do inglês heavy). A sub unidade L tem atividade ferroxidase que é necessária para a entrada do ferro na apoferritina. A sub unidade $\mathrm{H}$ facilita a formação do núcleo de ferro da ferritina (HARRISON, 1996). A ferritina com dois átomos de ferro é denominada holoferritina (Figura 1.3(b)).

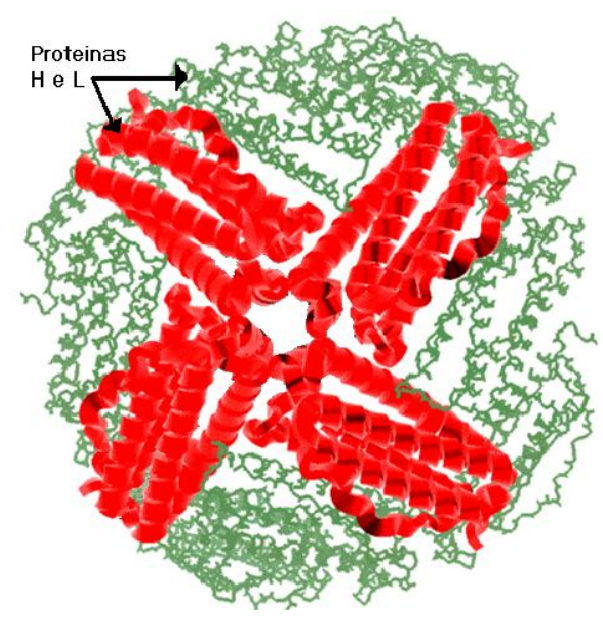

(a)

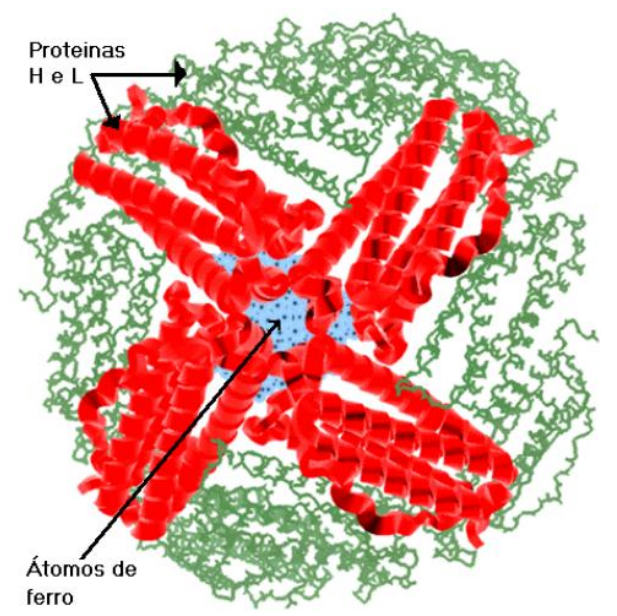

(b)

Figura 1.3: Representação ilustrativa de proteínas envolvidas no armazenamento de ferro: (a) Ferritina na forma de Apoferritina ilustrada com protéinas $H$ e L. (b) Ferritina na forma de holoferritina, indicado o núcleo que armazena o ferro como um complexo de hidróxido de óxido de ferro. Figuras adaptadas de Carneiro (2001).

Outra molécula que armazena ferro é a hemossiderina. Apesar de ter sido identificada por Perl no século XIX (PERL, 1867), ainda é pouco explorada em termos de composição, estrutura, biossíntese e metabolismo. Ela é uma molécula protéica insolúvel de massa molecular superior a 4000 kD (WARD et al., 2000). De acordo com Weir, Gibson e Peters (1984) a hemossiderina é formada principalmente por núcleos de FeOOH com uma incompleta superfície protéica e compostos bioquímicos de fosfato e magnésio, e alguns possíveis lipídios. O autor também sugere que os núcleos de ferro presente na hemossiderina são derivados da digestão lisossomal de 
agregados de moléculas de ferritina, assim a hemossiderina pode ser uma molécula derivada da ferritina.

Selden et al. (1980) reportaram que a concentração de hemossiderina aumenta cerca de 100 vezes em células do fígado em pacientes com hemocromatose. Também foi constatado aumento da concentração de hemossiderina em pacientes com siderose superficial do sistema nervoso central (DURIEUX et al., 1999), angioma cavernoso cerebral (VYMAZAL; URGOSÍK; BULTE, 2000) e em lisossomos (Figura 1.4) e siderossomos de células da glia de pacientes com doença neurodegenerativa (QUINTANA; COWLEY; MARHIC, 2004; QUINTANA et al., 2006).

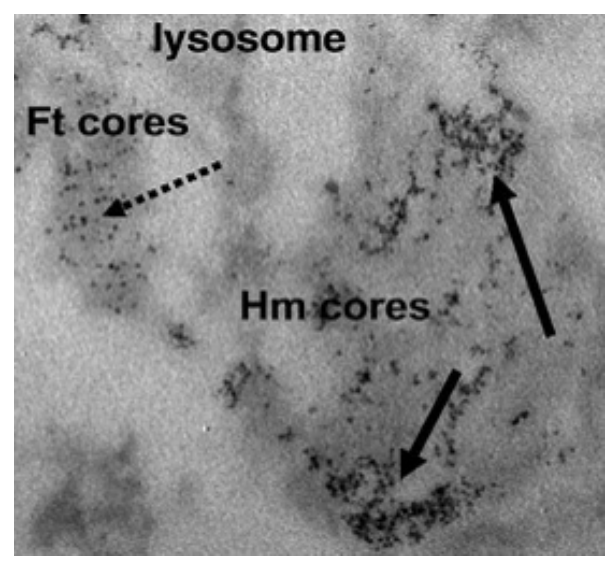

Figura 1.4: Imagem de microscopia eletrônica dos núcleos de Ferritina (Ft) e de Hemossiderina $(\mathrm{Hm})$ no interior de um lisossomo de uma célula da glia do hipocampo de um paciente com Alzheimer. Imagem reproduzida de Quintana et al. (2006).

\section{C) Transporte de ferro}

O ferro circula no corpo, principalmente, através de uma glicoproteína denominada transferrina que se liga ao $\mathrm{Fe}^{+3}$ e o transporta para todo o corpo através do sistema sanguíneo (TRINDER; MORGAN, 2001). Esta proteína possui meia vida de oito dias e é produzida por hepatócitos e em pequenas quantidades por outros tipos de células (FINCH; HUEBERS, 1982). Porém ela esta distribuída em todas as regiões do organismo onde exista necessidade de ferro. 
Em mamíferos, a transferrina sem ferro (apotransferrina) tem capacidade de se ligar a dois íons $\mathrm{Fe}^{+3}$ por moléculas de forma dependente do $\mathrm{pH}$, quando está saturada é chamada de holotransferrina. Maior parte do ferro que circula no plasma ou no fluído extracelular é ligado à transferrina (Tf), e isto previne danos que poderiam ser causados por produtos altamente reativos gerados pela presença de ferro livre (VOET; VOET; PRATT, 2000). Embora seja produzida mais transferrina em resposta à deficiência de ferro, o acúmulo de ferro tem pouco efeito na síntese. Um número de outros fatores afeta a produção de Tf, incluindo citocinas, hormônios e hipóxia (PONKA; BEAUMONT; RICHARDSON, 1998). Em geral o controle de Tf aparece ocorrer no nível de transcrição e possivelmente no nível translacional (LOK; LOH, 1998).

A figura 1.5 resume o processo de transporte de ferro para o interior da célula partindo da transferrina. A transferrina carregada de ferro $\left(\mathrm{Fe}_{2}\right.$-Tf) se liga aos receptores de transferrina (TfR) sobre a superfície da membrana. Formando complexos revestidos por clatrina pits, que invaginam para formar endossomas (AISEN; WESSLING-RESNICK; LEIBOLD, 1999). A bomba de prótons intracelular diminui o $\mathrm{pH}$ dentro dos endossomas, levando a mudanças conformacionais em proteínas que resultam na liberação de ferro da transferrina. O transportador de metal divalente 1 (DMT1) movimenta o ferro, através da membrana endossomal, para dentro do citoplasma. Enquanto isso, apotransferrina e receptores de transferrina (Apo-Tf) são reciclados para a superfície celular. No citoplasma de células eritróides o ferro movimenta-se mais para as mitocôndrias, onde é incorporado a protoporfirina para gerar o grupo heme. Já em células não eritróides, o ferro é armazenado como ferritina e hemossiderina (ANDREWS, 1999).

A quantidade de ferro levado para o interior das células é muito dependente da quantidade de receptores de transferrina na membrana, assim cada TfR se liga a 2 moléculas de transferrina. Estes receptores são regulados pela concentração de ferro celular e pelo ácido ribonucleico citoplasmático 


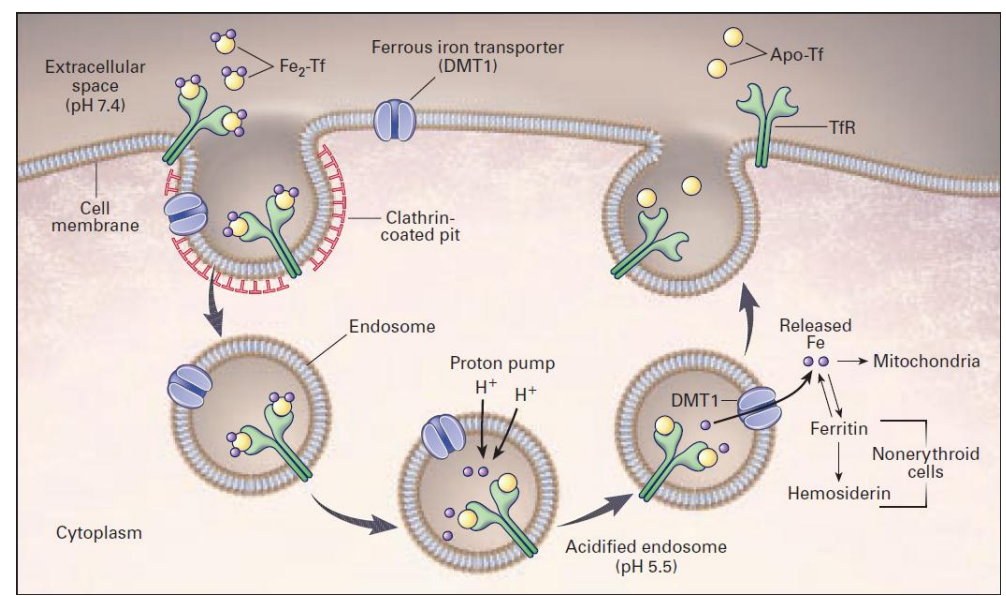

Figura 1.5: Processo de transporte de ferro para o interior da célula partindo da transferrina. Figura obtida de Andrews (1999).

(RNA) regulador de proteínas com ferro(IRPs) (ROUAULT, 2001).

A Tf também é sintetizada localmente em órgãos que apresentam barreira fisiológica ao movimento de proteínas plasmáticas, como a barreira hemato-encefálica (ZAKIN, 1992).

\subsection{Distribuição de ferro no cérebro}

O ferro possui uma distribuição característica e heterogênea no cérebro (Tabela 1.2), sendo o metal mais abundante neste órgão (BEARD; CONNOR; JONES, 1993). Ele é um essencial co-fator para algumas proteínas que estão envolvidas na função normal do tecido neuronal, como a síntese de dopamina. 


\begin{tabular}{|c|c|c|c|}
\hline $\begin{array}{l}\text { Região } \\
\text { Anatômica }\end{array}$ & $\begin{array}{l}\mu \mathrm{g} \text { de Fe total } / g \\
\text { de tecido úmido }\end{array}$ & $\begin{array}{l}\text { Método } \\
\text { Bioquímico* }\end{array}$ & Referência \\
\hline Globo pálido & 213 & Colorimetria & Hallgren e Sourander (1958) \\
\hline Globo pálido & 176 & AAS & Chen e Hardy (1993) \\
\hline Globo pálido & 182 & AAS & Chen e Hardy (1993) \\
\hline Globo pálido(lat.) & 207 & AS & Griffiths et al. (1999) \\
\hline Globo pálido & 205,0 & ICP & Langkammer et al. (2010) \\
\hline Globo pálido & $\underline{175-213}$ & & \\
\hline Substância negra & 185 & Colorimetria & Hallgren e Sourander (1958) \\
\hline Substância negra & 140 & AS & Griffiths et al. (1999) \\
\hline Substância negra & 84 & Colorimetria & Thomas et al. (1993) \\
\hline Substância negra & $\underline{85-185}$ & & \\
\hline $\begin{array}{l}\text { Substância negra } \\
\text { ZC+ZR }\end{array}$ & 157 & AS & Sofic et al. (1991) \\
\hline $\begin{array}{l}\text { Substância negra } \\
\text { ZC }\end{array}$ & 63 & AS & Sofic et al. (1991) \\
\hline $\begin{array}{l}\text { Substância negra } \\
\text { ZR }\end{array}$ & 94 & AS & Sofic et al. (1991) \\
\hline Putâmen & 130 & Colorimetria & Hallgren e Sourander (1958) \\
\hline Putâmen & 110 & AAS & Chen e Hardy (1993) \\
\hline Putâmen & 120 & AS & Griffiths et al. (1999) \\
\hline Putâmen & 78 & Colorimetria & Thomas et al. (1993) \\
\hline Putâmen & 153 & ICP & Langkammer et al. (2010) \\
\hline Putâmen & $\underline{78-130}$ & & \\
\hline Núcleo caudado & 93 & Colorimetria & Hallgren e Sourander (1958) \\
\hline Núcleo caudado & 116 & NAA & Brooks et al. (1989) \\
\hline Núcleo caudado & 92 & AAS & Chen et al. (1989) \\
\hline Núcleo caudado & 117 & ICP & Dexter et al. (1991) \\
\hline Núcleo caudado & 100 & AS & Griffiths et al. (1999) \\
\hline Núcleo caudado & 56 & Colorimetria & Thomas et al. (1993) \\
\hline Núcleo caudado & 92 & ICP & Langkammer et al. (2010) \\
\hline Núcleo caudado & $\underline{56-117}$ & & \\
\hline Núcleo Rubro & 195 & Colorimetria & Hallgren e Sourander (1958) \\
\hline
\end{tabular}

Tabela 1.2: Conteúdo de ferro total por unidade de peso de tecido úmido em regiões cerebrais de sujeitos saudáveis. Tabela modificada de Haacke et al. (2005). * Os métodos bioquímicos estão descritos no tópico 2.1. 
O ferro no cérebro está concentrado principalmente nos gânglios da base (Figura 1.6) e está nas forma de ferro iônico, ferritina e transferritina, e sua quantificação absoluta envolve uso de técnicas in vitro.

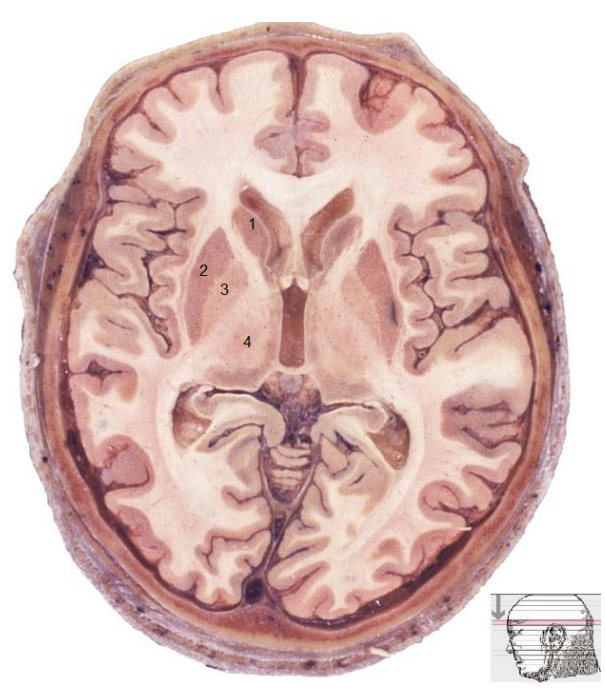

(a)

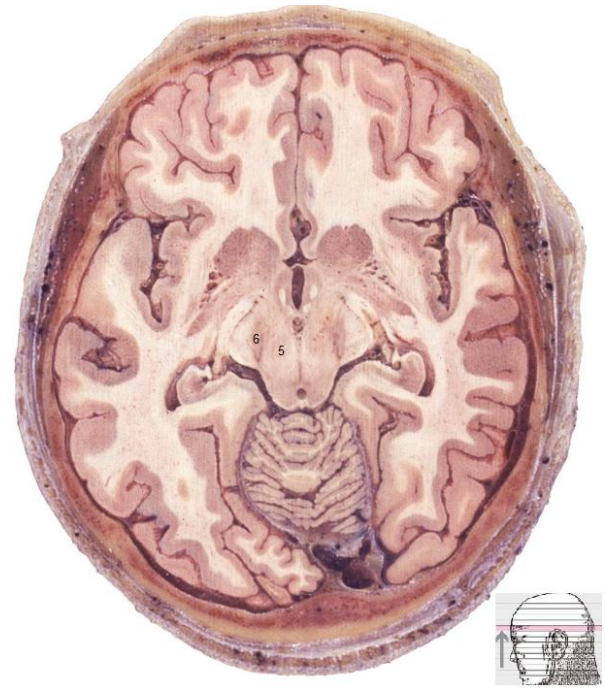

(b)

Figura 1.6: Cortes transversais contendo os gânglios da base: (1) Núcleo Caudado, (2) Putâmen, (3) Globo Pálido, (4) Tálamo, (5) Núcleo Rubro e (6) Substância Negra. Imagem adaptada de Mai, Paxinos e Voss (2008)

A distribuição regional de ferro foi primeiramente demonstrada pela técnica histoquímica Perl's Stain. Um trabalho pioneiro com este marcador em amostras in vitro mostrou uma intensa mancha de ferro férrico $\left(\mathrm{Fe}^{+3}\right)$ em partes do sistema extrapiramidal, menos intensa no córtex cerebral e nenhuma reação na substância branca (SPATZ, 1922). Posteriormente, muitos outros trabalhos utilizando diversas técnicas têm demonstrado concentrações relevantes do metal, principalmente no Globo Pálido, Núcleo Rubro, Substância Negra e Putâmen (HALLGREN; SOURANDER, 1958; BROOKS et al., 1989; SOFIC et al., 1991; GRIFFITHS et al., 1999; LANGKAMMER et al., 2010).

Alguns pesquisadores têm quantificado seletivamente a ferritina no cérebro, porém com variações consideráveis (Tabela 1.3). Os resultados de 
Riederer et al. (1989) e Dexter et al. (1987) foram similares, porém entre 5 e 10 vezes menores que as concentrações obtidas posteriormente por Connor et al. (1992), Connor et al. (1995). Algumas destas possíveis discrepâncias podem ter sido resultado do uso de um anticorpo policlonal não específico de isoferritina nos trabalhos de Riederer et al. (1989) e Dexter et al. (1987), que não possibilitou estimar a concentração de ferritina correta (HAACKE et al., 2005). O estudo individual de Connor, Boeshore e Benkovic (1992) indica que a distribuição de ferritina no cérebro se assemelha à do ferro total, com concentrações nos gânglios da base de aproximadamente duas ou três vezes maiores do que no córtex motor (Tabela 1.3). Connor et al. (1995) em um estudo mais específico de quantificação das isoformas H-ferritina e L-ferritina observaram que H-ferritina é a mais dominante no cérebro e a concentração aumenta com a idade.

\begin{tabular}{|c|c|c|c|}
\hline Região Anatômica & $\begin{array}{l}\mu \text { g de ferretina } \\
\text { total/g de tecido } \\
\text { úmido }\end{array}$ & $\begin{array}{l}\text { Método } \\
\text { Bioquímico* }\end{array}$ & Referência \\
\hline Globo pálido & 1440 & Sobrenadante & Connor et al. (1995) \\
\hline Globo pálido medial & 262 & Sobrenadante & Dexter et al. (1991) \\
\hline Globo pálido lateral & 250 & Sobrenadante & Dexter et al. (1991) \\
\hline Substância negra & 1535 & Sobrenadante & Connor et al. (1995) \\
\hline Substância negra & 292 & Sobrenadante & Dexter et al. (1991) \\
\hline Substância negra ZC & 218 & Sobrenadante & Dexter et al. (1991) \\
\hline Substância negra & 223 & Incerto & Riederer et al. (1989) \\
\hline Putâmen & 1125 & Sobrenadante & Connor et al. (1995) \\
\hline Putâmen & 237 & Sobrenadante & Dexter et al. (1991) \\
\hline Putâmen & 240 & Incerto & Riederer et al. (1989) \\
\hline Núcleo caudado & 1080 & Sobrenadante & Connor et al. (1995) \\
\hline Núcleo caudado & 116 & Sobrenadante & Dexter et al. (1991) \\
\hline
\end{tabular}

Tabela 1.3: Conteúdo de ferritina por unidade de peso de tecido úmido em regiões cerebrais. $O$ peso da ferritina refere-se à molécula toda. Tabela modificada de Haacke et al. (2005). 
A análise quantitativa da distribuição regional de transferrina no cérebro foi avaliada por apenas alguns trabalhos (CONNOR et al., 1992; CONNOR et al., 1995). No trabalho de Connor et al. (1992) constataram que os níveis de transferrina são tipicamente entre 10 e 50 vezes menores que a concentração de ferritina por unidade de proteína. A substância branca apresenta cerca de 2,5 a 3,5 vezes mais transferrina do que a corresponde substância cinzenta (CONNOR et al., 1992). No geral, a distribuição de ferro é oposta à Tf, em áreas que a concentração de ferro é alta (Globo Pálido, Substância Negra, Núcleo Rubro, Giros Dentados, Tálamo e Putâmen) tem relativamente baixas concentrações de Tf. Já altas concentrações de Tf são encontradas no hipocampo e na região cortical, onde existem baixos níveis relativos de ferro (ZATTA, 2003).

Para o estudo de distribuição de ferro no cérebro usando técnicas macroscópicas, como neuroimagens, a avaliação deve ser feita por regiões anatômicas como descrito anteriormente. Porém, para entender um pouco melhor a gênese e evolução de algumas doenças neurodegenerativas, devemos olhar a um nível microscópico, celular, como é exposto na Tabela 1.1.

O trabalho pioneiro de Spatz (1922) também estudou a deposição intracelular do ferro nas regiões citadas acima, onde constatou que a deposição ocorre principalmente em células oligodendrócitas, células endoteliais de capilares e neurônios gigantes piramidais do córtex motor (células Betz). De acordo com Connor et al. (2001) células oligodendrócitas ricas em ferro são comuns na substância branca, células responsáveis pela produção de mielina, mas também são encontradas em gânglios da base.

A presença de ferritina, indicada por métodos imuno-histoquímicos foi observada principalmente em células oligodendrócitas, microglia no córtex cerebral e astrócitos, particularmente nos gânglios da base (CONNOR et al., 1990). Utilizando anticorpo monoclonal para cada isoforma da ferritina, Connor, Boeshore e Benkovic (1992) encontraram H-ferritina em neurônios, 
enquanto que L-ferritina foi predominante em células gliais.

Transferrina é predominantemente associada com oligodendrócitos, mas com a idade acumula-se em astrócitos, principalmente na substância branca (CONNOR et al., 1990). Embora a Tf é sintetizada em oligodendrócitos, ela não parece se secretada por oligodendrócitos já que ela foi localizada no citosol e não no compartimento de secreção (De Arriba Zerpa et al., 2000). Dessa forma os achados sugerem que Tf sintetizado no cérebro é funcionalmente diferente da Tf de outros lugares do corpo e possui outra função do que transporte de Fe nos oligodendrócitos. 


\subsection{Acúmulo de ferro no cérebro e doenças neurodegenerativas (Doença de Parkinson)}

O acúmulo de ferro no cérebro tem sido relacionado a diferentes doenças neurodegenerativas: doença de Parkinson (SOFIC et al., 1988; CONNOR et al., 1995; GöTZ et al., 2004; MITTAL et al., 2009), Esclerose Múltipla (HAACKE et al., 2009a), Alzheimer(CONNOR et al., 1995; QUINTANA et al., 2006; STANKIEWICZ et al., 2007) e Pantothenate Kinase (BARTON et al., 2010). Os pacientes que sofrem destas patologias apresentam geralmente idades acima de 45 anos. Nesta faixa etária, mesmo em indivíduos saudáveis, já existe uma deposição considerável de ferro no cérebro (HALLGREN; SOURANDER, 1958). Na maioria dos casos graves da doença de Parkinson, alguns autores têm reportado um aumento na concentração de ferro no cérebro em medidas in vitro (Tabela 1.4) e in vivo (Tabela 1.5), mas nenhuma mudança nos casos intermediários da doença (RIEDERER et al., 1989; DEXTER et al., 1987; HIRSCH et al., 1991; GöTZ et al., 2004).

\begin{tabular}{|c|c|c|c|c|}
\hline Região Anatômica & $\begin{array}{l}\text { Técnica } \\
\text { utilizada }\end{array}$ & $\begin{array}{l}\mu \mathrm{g} \text { de Fe total } / g \\
\text { de tecido úmido } \\
\text { em controles }\end{array}$ & $\begin{array}{l}\mu \mathrm{g} \text { de Fe total/g } \\
\text { de tecido úmido } \\
\text { em pacientes } \\
\text { com doença de } \\
\text { Parkinson } \\
\end{array}$ & Referência \\
\hline Substância negra* & AS & $48(8)$ & $85(11)$ & Sofic et al. (1991) \\
\hline Substância negra* & ICP & $122(14)$ & $165(14)$ & Dexter et al. (1987) \\
\hline Substância negra* & ICP & $122(13)$ & $164(13)$ & Dexter et al. (1989) \\
\hline Substância negra** & AS & $140(13)$ & $281(22)$ & Griffiths et al. (1999) \\
\hline Substância negra ZC ${ }^{* *}$ & AS & $64(16)$ & $86(18)$ & Sofic et al. (1991) \\
\hline Substância negra ZC* & ICP & $155(13)$ & $202(13)$ & Dexter et al. (1989) \\
\hline Globo pálido medial & AS & $207(10)$ & $295(12)$ & Griffiths et al. (1999)) \\
\hline Globo pálido lateral & AS & 164(19) & $114(10)$ & Griffiths et al. (1999) \\
\hline
\end{tabular}

Tabela 1.4: Regiões cerebrais que apresentaram aumento significativo de ferro em pacientes com doença de Parkinson, através de técnicas in vitro. $*(p<0,05), * *(p<0,01)$. 
A divergência entre os valores absolutos de concentração de ferro na Tabela 1.4 é explicada pelo uso de tecido cerebral em diferentes estágios de neurodegeneração, tão bem quanto diferentes dissecções dos tecidos manipulados (GöTZ et al., 2004).

\begin{tabular}{|c|c|c|c|c|c|}
\hline Região Anatômica & $\begin{array}{l}\text { Campo } \\
\text { magnético } \\
\mathrm{B}_{0}(\mathrm{~T})\end{array}$ & $\begin{array}{l}\text { R2 médio } \\
\text { (desvio) }\end{array}$ & $\begin{array}{l}\text { R2* médio } \\
\text { (desvio) }\end{array}$ & Sujeitos (idade) & Referência \\
\hline \multirow[t]{2}{*}{ Substância negra } & 1,5 & $14,3(1,1)$ & $21,2(2,6)$ & Controle(64) & $\begin{array}{l}\text { Graham, Paley } \\
\text { Grünewald (2000) }\end{array}$ \\
\hline & & $14,5(1,3)$ & $23,7(3,5)^{*}$ & Parkinson(61) & $\begin{array}{l}\text { Graham, Paley } \\
\text { Grünewald (2000) }\end{array}$ \\
\hline \multirow[t]{2}{*}{ Substância negra } & 3,0 & & $34,5(5,5)$ & Controle(57) & Peran et al. (2010) \\
\hline & & & $38,0(9,0)^{*}$ & Parkinson(62) & Peran et al. (2010) \\
\hline \multirow[t]{2}{*}{ Substância negra } & 3,0 & & $25,3(5,6)$ & Controle(62) & Baudrexel et al. (2010) \\
\hline & & & $28,0(4,9)^{*}$ & Parkinson(62) & Baudrexel et al. (2010) \\
\hline \multirow[t]{2}{*}{ Substância negra ZC } & 1,5 & & $12,7(0,6)$ & Controle(64) & Kosta et al. (2006) \\
\hline & & & $13,6(1,6)^{*}$ & Parkinson(64) & Kosta et al. (2006) \\
\hline \multirow[t]{2}{*}{ Substância negra ZC } & 3,0 & & $22,8(2,8)$ & Controle(56) & $\begin{array}{l}\text { Martin, Wieler e Gee } \\
(2008)\end{array}$ \\
\hline & & & $26,9(2,8)^{*}$ & Parkinson(62) & $\begin{array}{l}\text { Martin, Wieler e Gee } \\
(2008)\end{array}$ \\
\hline \multirow[t]{2}{*}{ Globo pálido } & 1,5 & $16,2(1,8)$ & $24,9(5,6)$ & Controle(64) & $\begin{array}{l}\text { Graham, Paley } \\
\text { Grünewald (2000) }\end{array}$ \\
\hline & & $14,9(1,5)^{*}$ & $22,6(3,7)$ & Parkinson(61) & $\begin{array}{l}\text { Graham, Paley } \\
\text { Grünewald (2000) }\end{array}$ \\
\hline \multirow[t]{2}{*}{ Globo pálido externo } & 1,5 & $14,9(1,2)$ & & Controle(64) & Kosta et al. (2006) \\
\hline & & $14,3(1,3)^{*}$ & & Parkinson(64) & Kosta et al. (2006) \\
\hline \multirow[t]{2}{*}{ Putâmen } & 1,5 & $12,8(0,5)$ & & Controle(19/90) & Chen e Hardy (1993) \\
\hline & & $13,7(0,7)^{*}$ & & Parkinson(19/90) & Chen e Hardy (1993) \\
\hline \multirow[t]{2}{*}{ Putâmen } & 1,5 & $12,6(0,8)$ & & Controle(64) & Kosta et al. (2006) \\
\hline & & $14,7(0,3)^{*}$ & & Parkinson(64) & Kosta et al. (2006) \\
\hline
\end{tabular}

Tabela 1.5: Regiões cerebrais que apresentaram aumento significativo das taxas de relaxação $R 2\left(s^{-1}\right)$ e $R 2 *\left(s^{-1}\right)$ em pacientes com doença de Parkinson. * $(p<0,05)$.

A causa do acúmulo de ferro na Substância Negra em pacientes com doença de Parkinson é ainda desconhecida. A alteração da barreira 
hemato-encefálica por circunstâncias inflamatórias e o aumento das proteínas transportadoras de ferro, como transferrina, são sugeridos como causa do acúmulo de ferro (ZATTA, 2003). Os estudos também demonstram que as proteínas transportadoras de ferro como transferrina, lactoferrina e melanotransferrina com seus respectivos receptores de membrana são relatados estarem desregulados em neurônios sobreviventes na substância negra (MORRIS et al., 1994; FAUCHEUX et al., 1995; LEVEUGLE et al., 1996).

Embora a causa fisiológica do acúmulo de ferro no cérebro seja desconhecida em doenças neurodegenerativas, Moussa et al. (2010) sugerem que o ferro no cérebro pode induzir a progressiva degeneração dos neurônios da substância negra e do striatum (núcleo caudado, putâmen e globo pálido). Este processo acontece por meio da formação de reativos intermediários biológicos, incluindo espécies reativas de oxigênio e a formação de agregados de proteínas citotóxicos, causadores do estresse oxidativo (MOUSSA et al., 2010).

O estresse oxidativo pode ser definido como o desequilíbrio no balanço entre agentes antioxidantes e pró-oxidantes. $\mathrm{O}$ íon de $\mathrm{Fe}^{+2}$ é um dos agentes pró-oxidantes que geram radicais hidroxilas por meio da reação de Fenton. Durante esta reação, íons ferrosos $\left(\mathrm{Fe}^{+2}\right)$ reagem com $\mathrm{H}_{2} \mathrm{O}_{2}$, em presença de ácido ascórbico, produzindo $\mathrm{Fe}^{+3}$ e os radicais hidroxilas $\left(\mathrm{OH}^{*}\right.$ e $\mathrm{OH}^{-}$). A formação em excesso destes radicais sobrecarrega a capacidade de desintoxicação das células, que pela sua alta reatividade promovem a destruição das proteínas, das membranas e do material genético com posterior morte celular (Figura 1.7). 


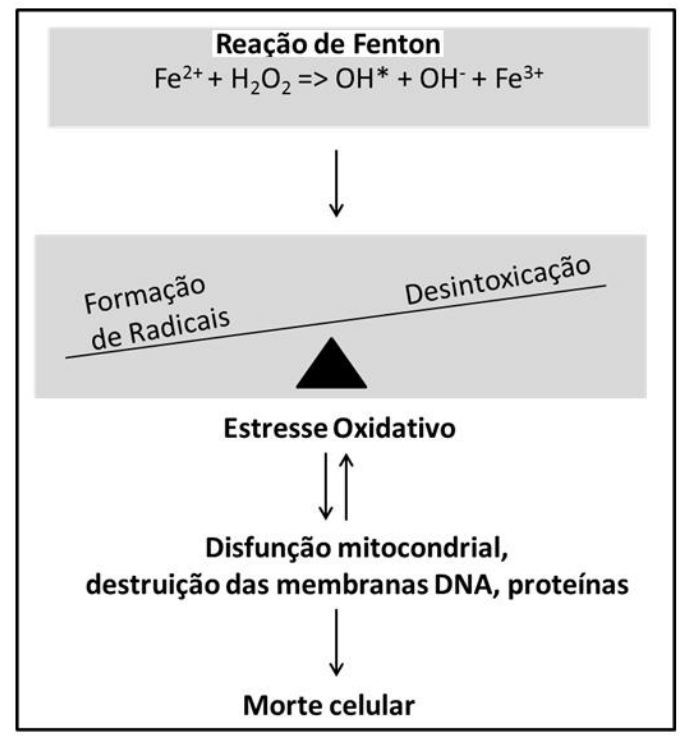

Figura 1.7: Esquema simplificado do estresse oxidativo: Adaptado de Berg e Hochstrasser (2006).

Por outro lado, outros estudos sugerem que o aumento de ferro pode ser um evento tardio ou secundário no processo da doença de Parkinson. De acordo com Riederer et al. (1989) a concentração de ferro na Substância Negra não variou em casos intermediários da doença de Parkinson. Dexter et al. (1991) não reportaram mudança na concentração de ferro em casos incidentes de corpo de Lewy (possível estágio pré-clínico da doença de Parkinson). Desta forma, os dois trabalhos concluíram que o aumento de ferro somente ocorreu no estágio avançado da neurodegeneração.

De acordo com Hirsch (1988) e colaboradores e Jellinger (1991) a degeneração dos neurônios localizados nos gânglios da base é de fato mais provável devido a um processo secundário relacionado a algum insulto tóxico inicial envolvendo grupos heterogêneos de células catecolaminérgicas no cérebro (HIRSCH; GRAYBIEL; AGID, 1988; JELLINGER, 1991). No entanto, acredita-se que um excesso de ferro dentro da Substância Negra também contribui na progressão da doença através da sua participação na formação continuada de radicais livres citotóxicos (SENGSTOCK et al., 1992).

Na literatura consultada, não existe um consenso em quanto à relação causa e efeito e não está definido se uma vez estabelecida à doença mudam os 
1.3 - Acúmulo de ferro no cérebro e doenças neurodegenerativas (Doença de Parkinson)19 padrões de deposição devido a ela (FERNANDEZ; BARBOSA; Schroder, M. V., 2007; CRICHTON; DEXTER; WARD, 2011). A quantificação da concentração de ferro in vivo permite acompanhar a relação de acúmulo e causa de sintomas clínicos. 


\section{Capítulo}

\section{2}

\section{Metodologia de quantificação de ferro no cérebro}

A distribuição de ferro iônico, ferritina e transferrina no organismo, descrito no capítulo 1 , vêm sendo estimada in vitro a partir de medidas físicas, histoquímicas e bioquímicas desde a década de 20 do século passado. As medidas in vitro permitem uma quantificação absoluta do ferro, porém possuem suas limitações quando comparadas com as técnicas in vivo. Neste capítulo, faremos uma revisão das principais metodologias de quantificação deste metal e das proteínas associadas ao mesmo no cérebro humano considerando ambas as abordagens: in vitro e in vivo.

\subsection{Medidas in vitro}

O acúmulo de ferro no cérebro foi inicialmente demonstrado por técnicas histoquímicas no começo da década de 1920-1930 usando Perl's Stain (SPATZ, 1922). Posteriormente quantificou-se o conteúdo de ferro de tecidos cerebrais post mortem através de técnicas como a colorimetria melhorada com outros corantes (HALLGREN; SOURANDER, 1958; DRAYER et al., 1986; RIEDERER et al., 1989; SOFIC et al., 1991; THOMAS et al., 1993), espectroscopia por absorção atômica (RIEDERER et al., 1989), espectrofotometria de absorção (GRIFFITHS et al., 1999), análise por ativação com nêutrons (BROOKS et al., 1989), plasma indutivamente acoplado (DEXTER et al., 1989; LANGKAMMER et al., 2010). 
A colorimetria melhorada é uma técnica de espectrofotometria de absorção. Constitui-se na leitura de absorbância de uma mistura de um quelante ou outra substância marcadora com a amostra de interesse. Para a quantificação de $\mathrm{Fe}^{+2}$ e $\mathrm{Fe}^{+3}$ Riederer et al. (1989) homogeneizaram as amostras de cérebro de cadáver em ácido hidro clorídrico, misturaram no quelante ferrozina e realizaram-se medidas de absorbância.

A espectroscopia por absorção atômica (AAS, do inglês) é fundamentada na observação das transições entre níveis eletrônicos para caracterizar as amostras. O experimento é basicamente constituído por uma fonte de radiação que irá incidir radiação eletromagnética sobre a amostra atomizada. Os átomos da amostra irão absorver e posteriormente emitir energia, a qual será detectada por um sistema de detecção, obtendo-se um espectro característico.

Espectrofotometria por absorção ( $A S$, do inglês) tem um principio físico semelhante à espectroscopia por absorção atômica, diferindo somente na fonte de energia eletromagnética (desde o ultra-violeta até o infra vermelho) e na forma como a amostra é preparada.

A análise por ativação com nêutrons (NAA, do inglês) ocorre através do bombardeamento de nêutrons no material induzindo radioatividade. Neste material são gerados radioisótopos emissores de raios gama, posteriormente, detectados na forma de um espectro. Como cada núcleo irá produzir um radioisótopo com características próprias (energia, intensidade e meia vida) é possível quantificar a concentração de alguns dos núcleos contidos no material de interesse.

Espectrometria de massa com plasma indutivamente acoplado (ICP, do inglês) utiliza como fonte de ionização um plasma de argônio criado por uma fonte de alta potência (até $1.5 \mathrm{~kW}$ ). A amostra sofre nebulização e por um sistema de aerossol é inserida no plasma, resultando numa mistura de átomos, íons, fragmentos moleculares não dissociados e partículas não volatilizadas. Esta mistura é direcionada ao espectrômetro de massa, o qual submete os íons 
gerados a um campo magnético de onde emergem em trajetórias diferentes em função das diferenças na razão massa/carga.

Os resultados das medidas in vitro, reportados na literatura, permitem concluir a existência de uma distribuição heterogênea deste metal no cérebro (Figura 2.1). Globo pálido, núcleo rubro, substância negra e putâmen foram indentificadas como estruturas com os valores mais elevados, acima de $180 \mu \mathrm{g}$ de ferro total por g de tecido úmido (HALLGREN; SOURANDER, 1958; DRAYER et al., 1986).

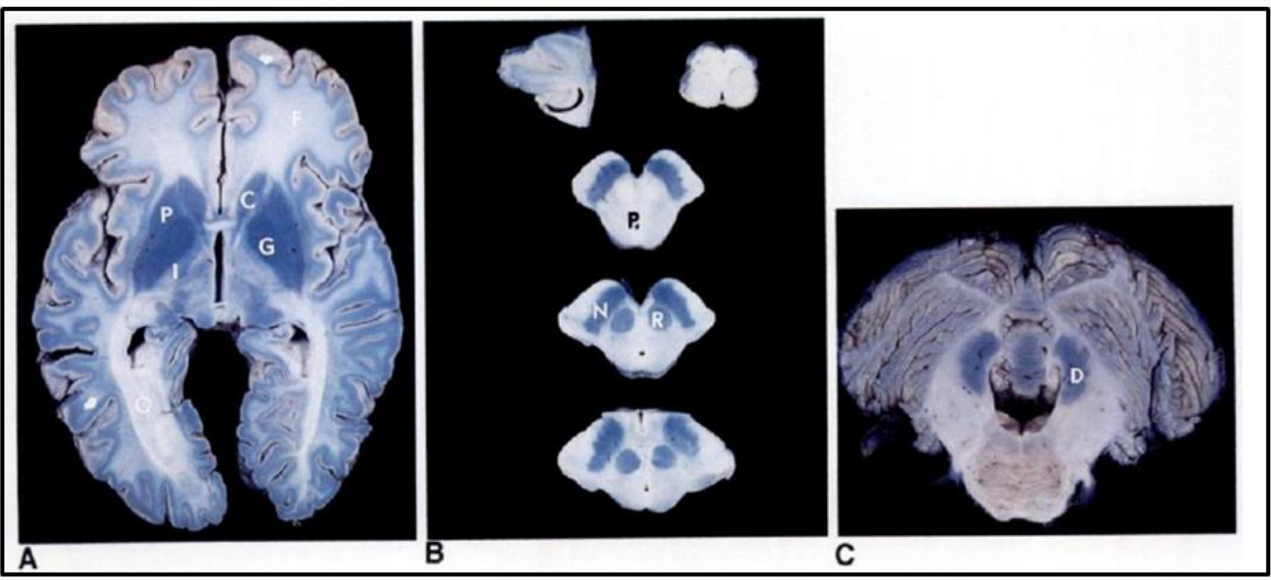

Figura 2.1: Método histoquímico de Pers'l stain aplicado nos núcleos da base de um cadáver (homem saudável de 44 anos). Maior intensidade de azul representa maior concentração de ferro. A: Globo Pálido(G), Putâmen(P), Núcleo Caudado(C), Capsula Interna(I), Substância Branca Frontal(F), Radiações óticas(O), Fibra U Subcortical(seta). B: Núcleo Rubro (R), Substância Negra(N), Substância Cinzenta, Periaqueductal(P). C: Núcleo Dentado do Cerebelo(D). Imagem obtida de Drayer et al. (1986).

Existem variações nos resultados in vitro de quantificação de ferro reportados por alguns autores, mesmo utilizando a mesma técnica, fato que pode ser justificado pelo uso de diferentes métodos de preparação do tecido cerebral. Por exemplo, a imersão prolongada em formalina leva ferro para fora do tecido e isso pode explicar os baixos resultados encontrados por Thomas et al. (1993). Já as técnicas in vivo não são dependentes de métodos de preparação de amostras e permitem o acompanhamento longitudinal do conteúdo de ferro no cérebro. 


\subsection{Medidas in vivo}

As medidas in vivo de quantificação de ferro no cérebro são principalmente realizadas através de métodos não invasivos por imagem, como ultrassom transcranial e ressonância magnética nuclear (RMN).

Estudos com ultrassom transcranial tem encontrado uma correlação positiva entre a área de ecogenicidade da substância negra e a concentração de ferro na mesma. Apesar desta técnica não gerar imagem de alta resolução espacial como a imagem de RMN, vem mostrando que pode ser uma ferramenta valiosa no diagnóstico de distúrbios extrapiramidais relacionados com o acúmulo de ferro (BERG, 2006). Porém, estes achados ainda são incipientes e não têm sido reportados de forma reprodutível. Já as técnicas de RMN possuem alta resolução espacial e têm sido abordadas por mais pesquisadores em todo o mundo há mais de 25 anos.

As imagens de ressonância magnética nuclear possuem resolução espacial suficiente para gerar imagens semelhantes aos atlas anatômicos e capacidade de medir indiretamente níveis de ferro no tecido, através das taxas de relaxação transversal $(\mathrm{R} 2=1 / \mathrm{T} 2$ e $\mathrm{R} 2 *=1 / \mathrm{T} 2 *)$ e da susceptibilidade magnética $(\Delta \chi)$ (DRAYER et al., 1986; HAACKE et al., 2005).

O ferro como íon paramagnético se apresenta na forma de $\mathrm{Fe}^{+2} \mathrm{e} \mathrm{Fe}^{+3}$. Sendo o íon férrico $\left(\mathrm{Fe}^{+3}\right)$ o mais forte íon paramagnético com três possíveis estados de spin eletrônico: $1 / 2,3 / 2$ e 5/2, que são facilmente identificados por ressonância paramagnética eletrônica (BAFFA, 1984). Os elétrons desemparelhados do átomo de ferro constituem centros paramagnéticos que geram campos magnéticos locais intensos. Desta forma, a presença de íons de ferro, livres ou ligados às moléculas nos tecidos cerebrais distorce o campo magnético a nível molecular (Figura 2.2).

A interferência do íon de ferro produz inomogeneidade no campo magnético local, que diminui a magnetização resultante dos spins nucleares e consequentemente reduz a intensidade do sinal e os tempos de relaxação transversal (T2 e T2*). A intensidade do efeito de redução é dependente da 


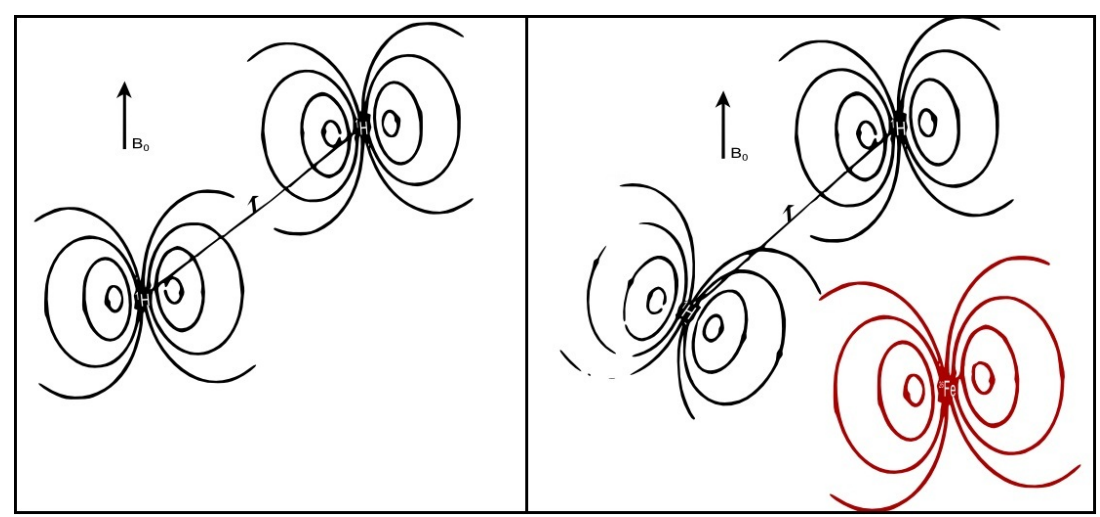

Figura 2.2: Representação do efeito do íon de ferro paramagnético na distorção do campo magnético local. Imagem adaptada de Tofts (2003).

concentração e distribuição do ferro no tecido, o que possibilita estimar a concentração de ferro e o estado de ligação. Na figura 2.3 é observado uma hipointensidade do sinal na imagem ponderada de ressonância ponderada em T2 nas regiões que apresentam acúmulo de ferro.
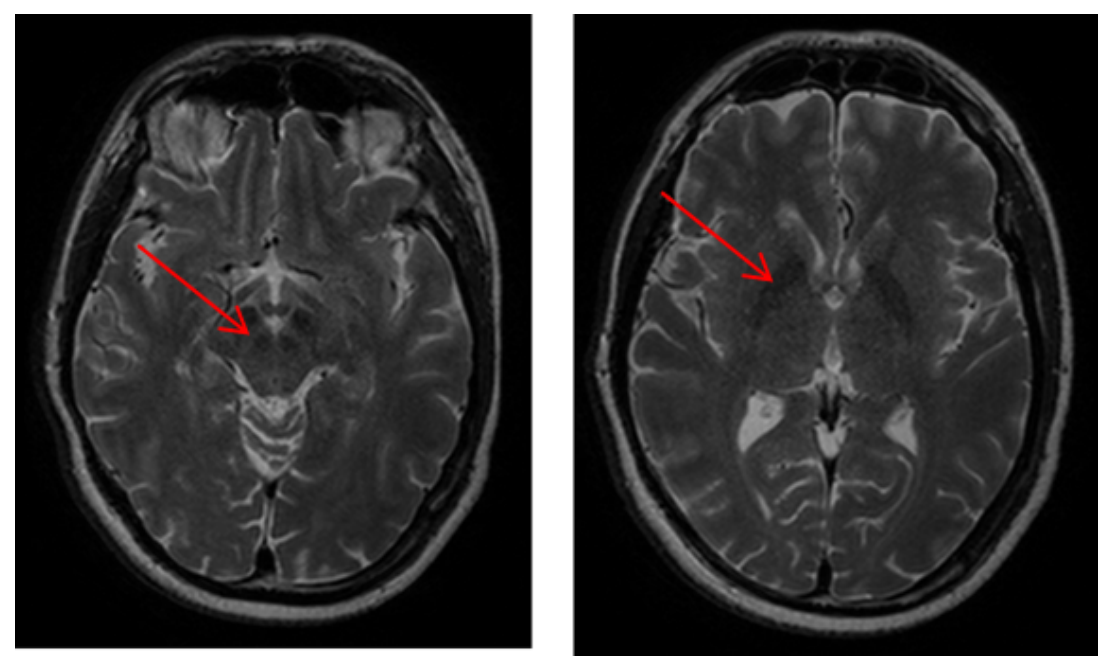

Figura 2.3: Imagens axiais do cérebro ponderadas em T2. Região de sinal hipointenso (setas indicadas) podem representar acúmulo de ferro .

Uma regra mais ou menos geral sobre o efeito do ferro no contraste da imagem é sugerida por Schenck (2003) indicando que somente em regiões com concentrações de íons de ferro maiores que $0,1 \mathrm{mM}(0,1 \mathrm{mM}=5,58 \mu \mathrm{g}$ de ferro/g de tecido úmido) são capazes de afetarem o contraste. Os depósitos de concentrações de ferro no tecido cerebral capazes de alterar o 
contraste da imagem estão principalmente na forma mineralizada (ferridrita: 5Fe2O3-9H2O) associada à ferritina ou à hemossiderina. A concentração nas restantes proteínas que contém ferro (cadeia respiratória mitocôndrial, tirosina hidroxilase, ribonucleotídeo redutase e outras) e nas reservas de ferro instáveis possuem um valor muito baixo $(1,5 \mu \mathrm{M})$ e podem ser desconsideradas (SCHENCK, 2003).

A intensidade de sinal em imagens convencionais de RMN (Spin Eco e Gradiente Eco) ponderadas em T2 e em T2* não é um dado quantitativo. Visto que as variações na intensidade de sinal podem acontecer em equipamentos diferentes. Portanto a intensidade de sinal não pode ser usada como parâmetro reprodutível e representa uma medida qualitativa.

\subsubsection{Relaxometria R2 e R2*}

As taxas de relaxometria (R2 e R2*) fornecem dados quantitativos, já que representam grandezas físicas associadas às propriedades intrínsecas de relaxação do tecido e são relacionados com a concentração de ferro no cérebro (Figura 2.4). No entanto, essas taxas podem ser influenciadas por fatores extrínsecos, como a inomogeneidade do campo magnético estático $\left(B_{0}\right)$.

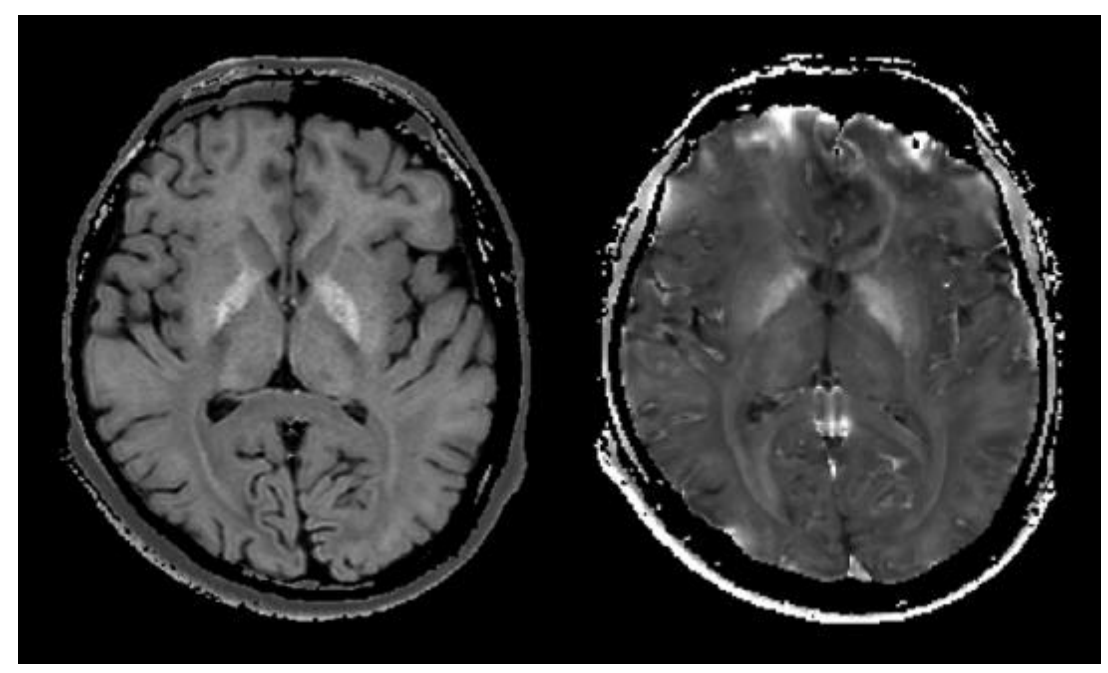

Figura 2.4: Mapas de relaxometria do cérebro por ressonância magnética nuclear: (a) Mapa de R2 e (b) mapa de R2*. Região de hiperintensidade representa acúmulo de ferro. 
As taxas de relaxometria R2 e R2* são obtidas através da aquisição de imagens por meio de sequências Spin Eco ou Eco de Spin e Gradiente Eco ou Eco de Gradiente respectivamente. O processamento dos mapas de R2 e R2* será discutido na seção de Métodos 4.3.1.

A sequência Spin Eco possui a vantagem de ser menos sensível a inomogeneidade de $\mathrm{B}_{0}$, que é o principal problema da sequência Gradiente Eco (JENSEN, 2011). Na sequência Spin Eco, é aplicado um pulso de radiofrequência de $90^{\circ}$ e após certo tempo, chamado de tempo de eco, é aplicado outro pulso de $180^{\circ}$ para refocalizar a fase dos spins nucleares e obter a coerência de fase novamente, obtendo apenas a taxa de relaxação intrínseca do tecido. No entanto, a sequência Spin Eco necessita de um maior tempo de aquisição de imagem do que a sequência Gradiente Eco e deixa de ser sensível às pequenas variações de inomogeneidades de campo magnético local. A taxa de relaxação R2 medida pode ser influenciada pela escolha do tempo de eco e pelo coeficiente de difusão da água do tecido (GHUGRE et al., 2005).

A sequência Gradiente Eco é construída com um pulso de radiofrequência com certo ângulo, não necessariamente $90^{\circ}$, e com aplicação de um gradiente de campo bipolar na direção da leitura que permite fazer a codificação espacial e, então, gerar a imagem. Diferentemente da sequência Spin Eco, o sinal obtido em sequência Gradiente Eco é muito dependente da homogeneidade de $\mathrm{B}_{0}$ e de gradientes macroscópicos de campo magnético gerado por interface de tecido e ar (WOOD; GHUGRE, 2008). Esses gradientes podem gerar um decaimento de sinal não mono exponencial e resultar em vários valores de R2*. O efeito pode ser reduzido com a diminuição do tamanho do voxel. No entanto esta redução pode causar diminuição da relação sinal/ruído, e gerar menor acurácia no ajuste mono exponencial do decaimento do sinal (JENSEN, 2011).

A aquisição em ambas as sequências pode ser realizada em eco único ou múltiplos ecos. Na sequência Spin $E c o$, a aquisição de eco único é mais robusta com respeito a imperfeições do pulso de rádio frequência, no entanto 
a aquisição múltiplos ecos necessita de menos tempo. Caso seja usada esta última, deve-se buscar minimizar o erro do ângulo de flip, através do aumento da espessura do corte de refocalização para três vezes mais que a espessura do corte de seleção (PELL et al., 2006).

A utilização das taxas de relaxometria R2 e R2* para diagnosticar o acúmulo de ferro cerebral em pacientes com doenças neurodegenerativas tem apresentado resultados controversos. Kosta et al. (2006) constataram aumento significativo $(\mathrm{p}<0,05)$ para valores de R2 da substância negra de pacientes com doença de Parkinson. Graham, Paley e Grünewald (2000) e Martin, Wieler e Gee (2008) também constataram aumento significativo $(\mathrm{p}<0,05)$ para valores de R2* da substância negra de paciente com doença de Parkinson. No entanto outros estudos similares (VYMAZAL et al., 1999; GRAHAM; PALEY; GRüNEWALD, 2000), não encontraram variação significativa de valores de R2 na substância negra de controles e de pacientes. Devido ao possível aumento de água, gerado pela morte neuronal, que consequentemente diminui a taxa de relaxação e, então, tornou a quantificação do conteúdo de ferro incorreta.

A taxa de relaxação é diretamente proporcional ao acúmulo de ferro e inversamente ao acúmulo de água. (KAMMAN et al., 1988; GELMAN et al., 1999; BARTZOKIS et al., 1999; HAACKE et al., 2005). Uma alternativa para quantificar o conteúdo de ferro em tecidos que apresentam variação do conteúdo de água é a quantificação da susceptibilidade magnética destes depósitos de ferro, através da informação resultante da defasagem dos spins nuclear (HAACKE et al., 2005; MCCREA et al., 2008).

Durante a aquisição da imagem de RMN são obtidos dados de magnitude e de fase do vetor magnetização em cada pixel. As imagens convencionalmente usadas na clínica e os mapas de relaxação citados acima utilizam apenas os dados de magnitude. Os dados de fase de sequências de Gradiente Eco são capazes de gerar imagens ponderadas em susceptibilidade magnética (SWI) que exploram as propriedades magnéticas dos tecidos 
(HAACKE et al., 2005; HAACKE et al., 2009a).

\subsubsection{Imagem por susceptibilidade magnética}

As imagens convencionais ponderadas em T1 e T2 realçam o contraste para os tecidos que possuem diferenças significantes de tempo de relaxação longitudinal (T1) e transversal (T2), respectivamente. Da mesma forma, a imagem ponderada em susceptibilidade magnética realça o contraste da imagem para tecidos com diferentes valores de susceptibilidade magnética. Em geral, a imagem ponderada em SWI (Figura 2.5) tem contrastado regiões venosas e com acúmulo de ferro (DUYN et al., 2007; MCCREA et al., 2008; GUPTA et al., 2010; ROSSI et al., 2010).
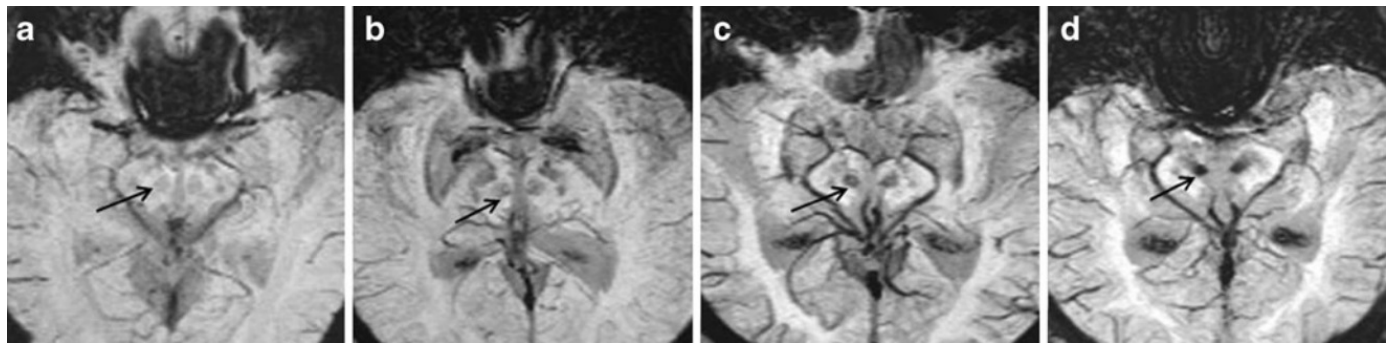

Figura 2.5: Imagens ponderadas em SWI: Ilustra de (a) a (d) como o a intensidade do sinal diminui na região do núcleo rubro (seta). Imagem obtida de Gupta et al. (2010).

Além disso, SWI tem adicionado informações clinicas complementares às sequências convencionais imagens de RMN. Incluindo vários distúrbios neurológicos: traumatismo crânio-encefálico, coágulos danosos; e distúrbios hemorrágicos: mal formação vascular, infarto cerebral, neoplasias; e distúrbios neurodegenerativos associadas com calcificação intracraniana ou depósito de ferro.

A SWI utiliza tanto a informação de magnitude quanto a de fase. A imagem de fase geralmente era descartada pela clinica devido ao aparecimento de artefatos, causados pela inomogeneidade do campo estático. No entanto, alguns processamentos na imagem foram aplicados para reduzir ou eliminar este artefato. O grupo de Reichenbach J.R. liderado por 
Haacke E.M. foi quem desenvolveu o processamento da imagem ponderada em susceptibilidade magnética (patenteada nos Estados Unidos por Haacke (2002)).

A imagem de SWI é resultante da ponderação da imagem de fase na imagem de magnitude adquirida em uma sequência Gradiente Eco. No entanto, a imagem SWI é apenas qualitativa e, portanto, não é muito sugerida para quantificar deposição de ferro. Assim, nesta dissertação não utilizamos a imagem SWI para estudar controles e pacientes. Mas foi realizado um estudo detalhado e a descrição do processo de obtenção da imagem SWI está no Apêndice A, visto que na literatura brasileira ainda não tem sido descrito.

Como dado quantitativo de susceptibilidade magnética, tem sido calculado pela literatura mapas quantitativos de susceptibilidade magnética (QSM, sigla em inglês de Quantitative Susceptibility Mapping) (ROCHEFORT et al., 2008). O mapa QSM é obtido da imagem de fase de sequência Gradiente Eco por métodos baseados em Transformada de Fourier (TF). O leitor interessado neste método pode ler em mais detalhes no capítulo 3.

De acordo com Lotfipour et al. (2012) a susceptibilidade magnética é menos influenciada pelo ambiente microscópico em volta da deposição de ferro no cérebro quando comparada às taxas de relaxação R2 e R2* (Lotfipour et al., 2012). Desta forma, o mapa de susceptibilidade torna-se uma técnica mais sensível ao conteúdo de ferro em si, porem requer um processamento mais elaborado e demorado. Um exemplo da aplicação desta técnica na distinção de pacientes com doença de Parkinson e controles pode ser visto na Figura 2.6.

Portanto, de acordo com literatura revisada todas as técnicas de RMN citadas não são medidas específicas do conteúdo de ferro. Como consequência a maioria das técnicas possuem uma limitação na validação do conteúdo de ferro, dependendo de detalhes da sequência utilizada e da calibração de parâmetros específicos para o tecido. Assim a aplicação simultânea de dois ou mais métodos de quantificação de ferro por RMN visam aumentar a 


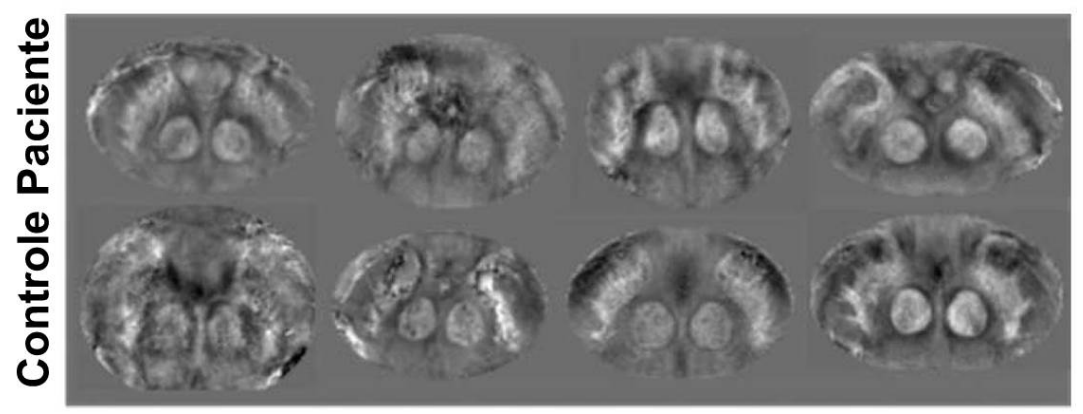

Figura 2.6: Mapas de susceptibilidade magnética. Imagem extraída de Lotfipour et al. (2012).

sensibilidade e especificidade na detecção de alterações do conteúdo de ferro tecidual (JENSEN, 2011).

Como têm sido mostrado, nos últimos 20 anos diferentes medidas in vivo de controles saudáveis e pacientes com acúmulo de ferro têm sido realizadas com diferentes técnicas de aquisição de imagens de RMN, porém poucos trabalhos abordam a comparação destas técnicas. Neste trabalho serão abordadas várias técnicas de imagens de RMN a fim de expor numa mesma amostra de indivíduos as vantagens e desvantagens das mesmas na quantificação de ferro cerebral. 
2.3 - Variáveis associadas à distribuição de ferro no cérebro de indivíduos normais31

\subsection{Variáveis associadas à distribuição de ferro no cérebro de indivíduos normais}

Usando as técnicas comentadas no tópico anterior, têm sido reportados valores de R2 e R2* em diversas regiões do cérebro de indivíduos saudáveis sob diferentes condições experimentais (Tabela 2.1). 
2.3 - Variáveis associadas à distribuição de ferro no cérebro de indivíduos normais32

\begin{tabular}{|c|c|c|c|c|c|}
\hline Região Anatômica & $\begin{array}{l}\text { Campo } \\
\text { magnético } \\
\mathbf{B}_{0}(\mathrm{~T})\end{array}$ & R2(desvio) & R2*(desvio) & Idade(anos) & Referência \\
\hline Substância negra & 1,5 & & $30,8(1,7)$ & 40 & Aquino et al. (2009) \\
\hline Substância negra & 1,5 & $14,3(1,1)$ & $21,2(2,6)$ & 66 & $\begin{array}{l}\text { Graham, Paley e } \\
\text { Grünewald (2000) }\end{array}$ \\
\hline Substância negra & 3,0 & $24,1(2,1)$ & & $19-42$ & Gelman et al. (1999) \\
\hline Substância negra & 3,0 & & $34,5(5,5)$ & 57 & Peran et al. (2010) \\
\hline Substância negra & 3,0 & & $25,3(5,6)$ & 62 & Baudrexel et al. (2010) \\
\hline Substância negra ZC & 1,5 & $11,7(0,6)$ & & $47-74$ & Vymazal et al. (1999) \\
\hline Substância negra ZC & 1,5 & & $12,7(0,6)$ & 64 & Kosta et al. (2006) \\
\hline Substância negra ZC & 3,0 & & $22,8(2,8)$ & 56 & $\begin{array}{l}\text { Martin, Wieler e Gee } \\
(2008)\end{array}$ \\
\hline Globo pálido & 1,5 & $13,1(2,0)$ & & $19-90$ & Chen e Hardy (1993) \\
\hline Globo pálido & 1,5 & $16,2(1,8)$ & $24,9(5,6)$ & 64 & $\begin{array}{l}\text { Graham, Paley e } \\
\text { Grünewald (2000) }\end{array}$ \\
\hline Globo pálido & 1,5 & & $22,8(1,3)$ & 31 & Yao et al. (2009) \\
\hline Globo pálido externo & 1,5 & $14,9(1,2)$ & & 64 & Kosta et al. (2006) \\
\hline Globo pálido & 3,0 & $25,8(1,1)$ & & $19-42$ & Gelman et al. (1999) \\
\hline Globo pálido & 3,0 & & $39,5(1,4)$ & 31 & Yao et al. (2009) \\
\hline Globo pálido & 3,0 & $13,0(7,0)$ & $72,0(10,0)$ & $38-81$ & $\begin{array}{l}\text { Langkammer et al. } \\
(2010)\end{array}$ \\
\hline Globo pálido ant. & 3,0 & & $41,7(5,3)$ & 56 & $\begin{array}{l}\text { Martin, Wieler e Gee } \\
\text { (2008) }\end{array}$ \\
\hline Globo pálido & 7,0 & & $86,2(3,2)$ & 31 & Yao et al. (2009) \\
\hline Putâmen & 0,5 & $12,6(0,3)$ & & $21-30$ & Bartzokis et al. (1993) \\
\hline Putâmen & 1,5 & $14,5(0,5)$ & & $21-30$ & Bartzokis et al. (1993) \\
\hline Putâmen & 1,5 & $12,9(0,8)$ & & $47-74$ & Vymazal et al. (1999) \\
\hline Putâmen & 1,5 & $23.6(0.7)$ & & 40 & Aquino et al. (2009) \\
\hline Putâmen & 1,5 & $13,4(0,7)$ & $18,7(3,6)$ & 64 & $\begin{array}{l}\text { Graham, Paley } \\
\text { Grünewald (2000) }\end{array}$ \\
\hline Putâmen & 3,0 & $19.4(0,8)$ & & $19-42$ & Gelman et al. (1999) \\
\hline Putâmen & 3,0 & & $25,2(0,9)$ & 31 & Yao et al. (2009) \\
\hline Putâmen & 3,0 & $15,0(1,0)$ & $56,0(11,0)$ & $38-81$ & $\begin{array}{l}\text { Langkammer et al. } \\
(2010)\end{array}$ \\
\hline Putâmen & 7,0 & & $50,7(2,0)$ & 31 & Yao et al. (2009) \\
\hline
\end{tabular}

Tabela 2.1: Resumos dos valores de $R 2\left(s^{-1}\right)$ e $R 2^{*}\left(s^{-1}\right)$ encontrados na literatura por região cerebral para indivíduos saudáveis. Tabela modificada de Haacke et al. (2005). 
Pode ser notada uma alta dispersão nos valores de R2 e R2* que define a variabilidade do controle normal. Esta variabilidade deve ser considerada em qualquer estudo comparativo e é possivelmente influenciada por outros fatores não associados com doença como: envelhecimento, dominância hemisférica, gênero e função cognitiva.

O envelhecimento é a principal variável associada com a distribuição de ferro no cérebro. O trabalho mais citado sobre o assunto observou por análise de colorimetria que o ferro não heme aumenta gradualmente nas duas primeiras décadas de vida e assume um patamar durante a vida adulta (Figura 2.7) (HALLGREN; SOURANDER, 1958).

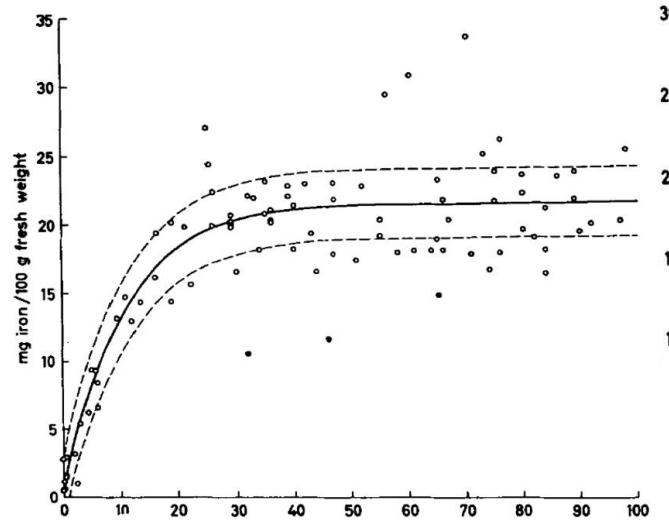

(a)

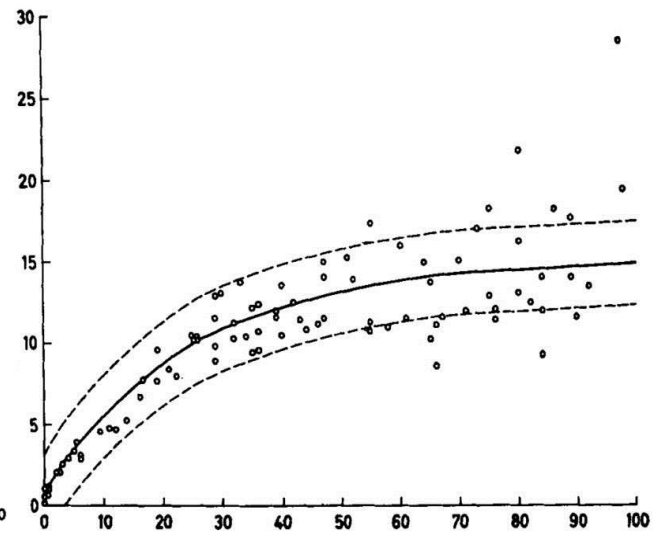

(b)

Figura 2.7: Acúmulo de ferro com o avanço da idade em regiões anatômicas. a, Globo Pálido. b, Putâmen. O eixo das abscissas representa mg de ferro por $100 \mathrm{~g}$ de tecido fresco e o eixo das ordernadas representa a idade em anos. Gráficos reproduzidos de Hallgren e Sourander (1958).

Medidas recentes de relaxometria, in vivo, também têm relatado acúmulo de ferro com o avanço da idade em sujeitos normais (HEBBRECHT; MAENHAUT; REUCK, 1999; XU; WANG; ZHANG, 2008; AQUINO et al., 2009; HAACKE et al., 2010). Aquino et al. (2009) observaram um aumento exponencial de R2* em função da idade (Figura 2.8) em algumas regiões dos gânglios da base. Este aumento foi mais significativo no globo pálido e na 


\section{3 - Variáveis associadas à distribuição de ferro no cérebro de indivíduos normais34}

substância negra, atingindo um valor aproximadamente constante na idade adulta, entre a terceira e quarta década de vida, semelhante aos resultados de Hallgren e Sourander (1958) e Drayer et al. (1986).

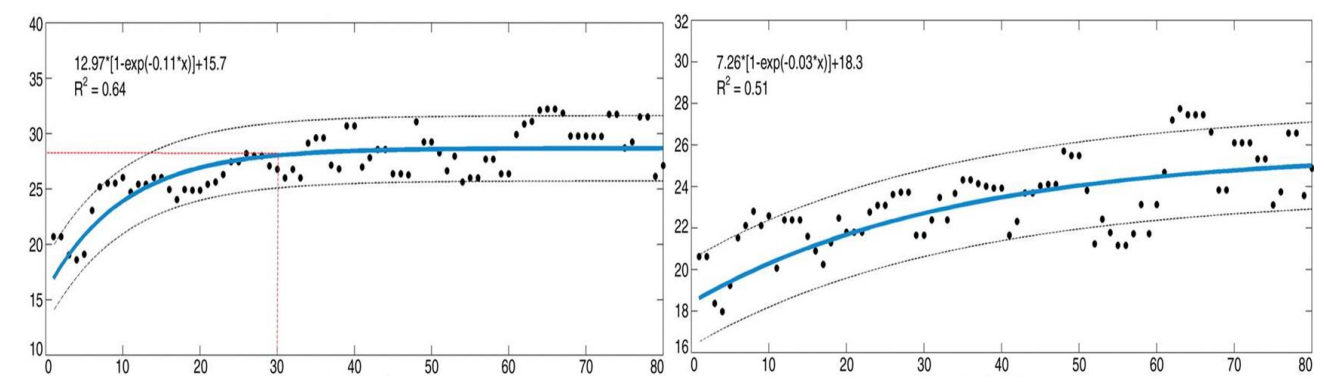

(a)

(b)

Figura 2.8: Dependência do valor de R2* com o avanço da idade. a, Globo Pálido. b, Putâmen. Gráficos reproduzidos de Aquino et al. (2009).

Outra variável que possivelmente interfere na distribuição de ferro no cérebro é a dominância hemisférica que leva a uma assimetria nesta distribuição. Supprian et al. (1997) reportaram um menor valor de T2 na substância branca do lobo frontal. Mais recentemente, Xu, Wang e Zhang (2008) detectaram maiores valores de mudança de fase no hemisfério esquerdo das seguintes regiões: putâmen, globo pálido, substância negra, tálamos e substância branca. A possível explicação destes autores está relacionada com o nível de dopamina. Este nível apresenta assimetria à esquerda nos gânglios da base (GLICK; ROSS; HOUGH, 1982; Jr. Wagner et al., 1983; De la Fuente-Femeez et al., 2000) e pelo ferro ser um essencial cofator para a síntese de dopamina (YOUDIM; M.B.H., 1988) é sugestivo a existência de um maior conteúdo de ferro no hemisfério esquerdo (XU; WANG; ZHANG, 2008).

Mais uma variável associada à distribuição de ferro no cérebro é o gênero, assunto abordado por Bartzokis et al. (2007) utilizando a dependência da taxa de relaxação com o campo magnético. Estes pesquisadores detectaram menores concentrações de ferro na ferritina para mulheres em algumas regiões: núcleo caudado, tálamo, lobo frontal, genu e splenium do 


\section{3 - Variáveis associadas à distribuição de ferro no cérebro de indivíduos normais35}

corpo caloso. Os achados foram justificados pelo fato das mulheres possuir menores quantidades de ferro no organismo em relação ao homem (FLEMING et al., 2001) e o fato do nível de ferro no cérebro ser sensível ao conteúdo de ferro no sangue (BORTEN et al., 2004). Porém, Xu, Wang e Zhang (2008) não encontraram diferenças para as mesmas regiões utilizando os valores da fase do sinal de RMN. A discrepância nestes achados poderia ser explicada pelo uso de técnicas diferentes de imagens de RMN, sendo necessários mais dados para elucidar o efeito do gênero na concentração de ferro no cérebro (XU; WANG; ZHANG, 2008).

Além disso, os resultados recentes de Penke et al. (2012) sugerem a relação da variável função cognitiva associada com o acúmulo de ferro no cérebro, o qual se associou inversamente com a capacidade cognitiva (PENKE et al., 2012), porem estes resultados são muito isolados e preliminares.

Adicionalmente às variáveis, anteriormente mencionadas, associadas à distribuição de ferro no cérebro sadio, diversos trabalhos sobre patologias cerebrais, principalmente de doenças neurodegenerativas, têm sugerido que o acúmulo de ferro esteja relacionado com processos oxidativos, como descrito no tópico 1.3.

Por conseguinte, muitos estudos tem proposto a quantificação in vivo da concentração de ferro no cérebro por ressonância magnética para entender a relação da deposição do metal e a progressão da doença. Mas todos os trabalhos não reportaram alta sensibilidade para quantificar ferro e não é conhecido entre as técnicas propostas a mais sensível. Propomos o estudo da identificação da melhor técnica quantitativa de ressonância magnética para estimar ferro em controles e pacientes com doença de Parkinson, levando em consideração os efeitos de idade e sexo. 


\section{Capítulo}

\section{Mapa de Susceptibilidade Magnética}

\subsection{Introdução}

Técnicas quantitativas de Imagem por Ressonância Magnética, como Imagem funcional por Ressonância Magnética e Relaxometria, relacionam de forma indireta a susceptibilidade magnética dos tecidos com a relaxação dos spins nucleares. Compostos abundantes no cérebro sejam eles paramagnéticos (metalo-proteínas com íons paramagnéticos, por exemplo: hemoglobina desoxigenada) ou diamagnéticos (água, sangue oxigenado) alteram o campo magnético local e consequentemente os tempos de relaxação.

Em 2005 foi proposta a técnica de mapeamento de susceptibilidade magnética (HAACKE et al., 2005). Nos últimos anos esta técnica tem-se aperfeiçoado visando, uma análise quantitativa mais precisa para avaliações clínicas (SHMUELI et al., 2009; LIU et al., 2009; WHARTON; SCHAFER; BOWTELL, 2010; ROCHEFORT et al., 2008; SCHWESER et al., 2011). Atualmente pode ser muito útil para o diagnóstico e o acompanhamento de patologias que acumulam compostos com diferente susceptibilidade magnética em relação ao tecido sadio (Doença de Parkinson: Lotfipour et al. (2012); Esclerose Multipla: Langkammer et al. (2013)). Nesta dissertação é de especial interesse a doença de Parkinson que como descrito no capitulo 1 apresenta um acúmulo significativo de ferro nos gânglios da base. 
Neste capitulo abordamos diferentes técnicas de quantificação da susceptibilidade magnética no cérebro humano a partir de Imagens por Ressonância Magnética Nuclear. Partindo da definição de susceptibilidade e a classificação de compostos comuns no corpo humano, descrevemos diferentes modalidades da técnica QSM seguindo uma ordem de complexidade.

\subsection{Susceptibilidade Magnética e classificações}

Susceptibilidade magnética é uma medida quantitativa da interação entre um material e um campo magnético externo aplicado $(\vec{H})$ (SCHENCK, 1996). O valor da susceptibilidade magnética pode ser obtido através da quantificação da magnetização resultante da amostra, considerando o meio linear:

$$
\vec{M}=\vec{M}_{0}+\overleftrightarrow{\chi} \cdot \vec{H}
$$

Onde $\vec{M}_{0}$ representa a magnetização inerente, que está presente em alguns materiais mesmo na ausência de um campo magnético aplicado. $\mathrm{O}$ termo $\overleftrightarrow{\chi} \cdot \vec{H}$ quantifica a magnetização induzida pelo campo externo aplicado. Sendo $\overleftrightarrow{\chi}$ o tensor de susceptibilidade magnética do material.

Os materiais em geral podem ser classificados levando em conta suas propriedades magnéticas como: Materiais magnéticos duros (termo em inglês hard magnetic), materiais magnéticos moles (termo em inglês soft magnetic) e materiais não magnéticos (termo em inglês nonmagnetic) ou fracamente magnéticos.

Materiais magnéticos duros apresentam um elevado valor de $\vec{M}_{0}$ quando comparada a magnetização induzida (Equação 3.1). Este valor pode chegar até $106 \mathrm{~A} / \mathrm{m}$. A expressão dureza magnética refere-se à habilidade de se resistir a mudanças induzidas pelo campo e de manter uma alta magnetização remanescente.

Materiais magnéticos moles possuem naturalmente valores muito baixos de $\vec{M}_{0}$. Geralmente, esses materiais têm susceptibilidade magnética 
muito alta. Resultando em forças e torques facilmente detectados na presença de um forte campo magnético.

Materiais não magnéticos ou fracamente magnéticos apresentam valores muito baixos de $\vec{M}_{0}$ e de $\overleftrightarrow{\chi}(<0,01)$. Forças e torques não são normalmente aparentes quando são colocados em um campo aplicado, porém a ressonância magnética é o suficientemente sensível ao efeito destes. A maioria dos materiais, incluindo os tecidos animais, podem ser considerados não magnéticos (SCHENCK, 1996). Os materiais não magnéticos são divididos em paramagnéticos e diamagnéticos (Figura 3.1).

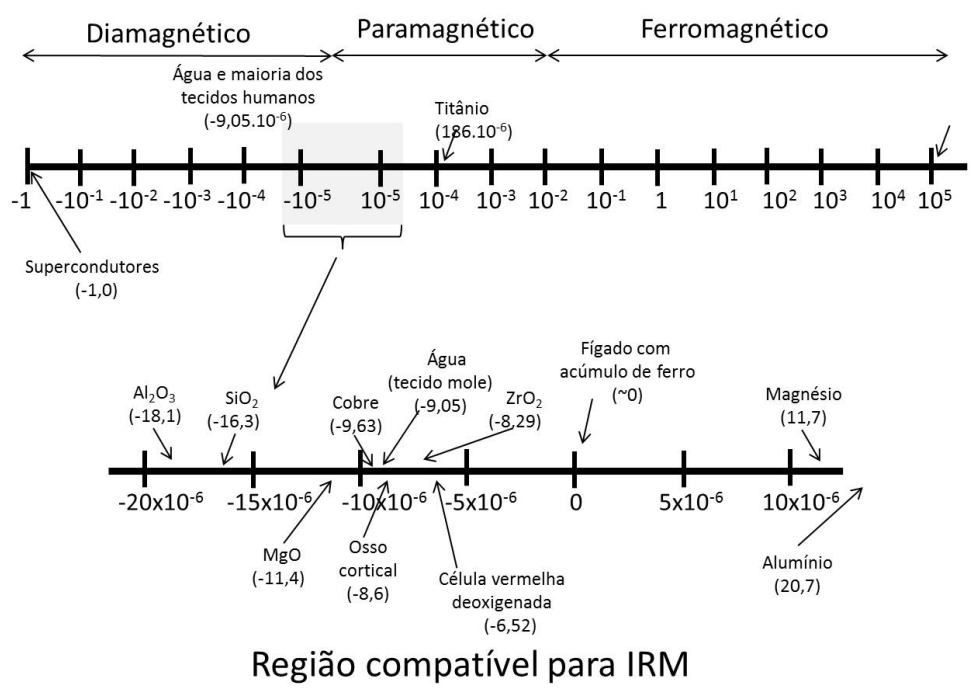

Figura 3.1: Espectro de susceptibilidade magnética. Adaptado de Schenck (1996).

De acordo com Saini et al. (1988) materiais paramagnéticos possuem elétrons desemparelhados e apresentam momento de dipolo magnético na presença de um campo magnético externo. O momento magnético resultante de certa amostra paramagnética é dependente da temperatura. O efeito da agitação térmica não permite o alinhamento correto dos átomos individuais, que podem se anularem. Fato que ocorre na ausência de um campo magnético externo. Exemplos de materiais paramagnéticos são ilustrados na Tabela 3.1. Já os materiais diamagnéticos possuem elétrons emparelhados em todos os subníveis energéticos, logo apresentam momentos de dipolo 


\begin{tabular}{llll}
\hline Diamagnéticos & $\chi\left(.10^{-6}\right)$ & Paramagnéticos & $\chi\left(.10^{-6}\right)$ \\
\hline \hline $\begin{array}{l}\text { Células vermelhas } \\
\text { totalmente } \\
\text { desoxigenadas }\end{array}$ & $-6,56^{c}$ & $\begin{array}{l}\text { Fígado (hemocromatose 6,6mg } \\
\text { de Fe por g) }\end{array}$ & $0,01^{a}$ \\
$\begin{array}{l}\text { Sangue totalmente } \\
\text { desoxigenado } \\
\text { (assumindo Hct=0,45) }\end{array}$ & $-7,9^{c}$ & Tálamo & $0,04^{b}$ \\
$\begin{array}{l}\text { Fígado (normal 0,21mg } \\
\text { de Fe por g) }\end{array}$ & $-8,74^{a}$ & Núcleo Caudado & \\
$\begin{array}{l}\text { Hemoglobina } \\
\text { (oxigenada) }\end{array}$ & -9.91 & Putâmen & $0,09^{b}$ \\
$\begin{array}{l}\text { Água(37 }) \\
\text { Cobre }\end{array}$ & $-9,05$ & Núcleo Rubro & $0,10^{b}$ \\
Lipídeos & $-9,6$ & Substância negra & $0,14^{b}$ \\
Osso cortical & $-10,0$ & Globo pálido & $0,17^{b}$ \\
& $-12,82^{c}$ & Hemoglobina (desoxigenada) & 0,20 \\
& & Ar (CNTP) & $0,19^{b}$ \\
\hline \hline
\end{tabular}

Tabela 3.1: Susceptibilidade magnética ( $\chi$, adimensional no SI) de alguns materiais fracamente magnéticos e tecidos biológicos. Valores estimados a partir de Schenck (1996). ${ }^{a}$ Os valores foram calculados baseado na equação de Schenck (1993). ${ }^{b}$ Valores relativos a substância branca de Wharton e Bowtell (2010). ${ }^{c}$ Valores obtidos de Haacke e Reichenbach (2011).

magnético líquido zero. Contudo se estes átomos são colocados em um campo magnético externo, existe uma ligeira alteração assimétrica no movimento do orbital dos elétrons e uma pequena magnetização líquida pode ser detectada em sentido contrário ao campo aplicado (SAINI et al., 1988). Exemplos de materiais diamagnéticos são ilustrados na Tabela 3.1.

A molécula de hemoglobina apresenta comportamento paramagnético e diamagnético quando é desoxigenada e oxigenada, respectivamente. A deoxi-hemoglobina contem 4 átomos de ferro com 2 elétrons desemparelhados $\left(F e^{+2}\right)$, densidade de $4,98 \times 1019$ partículas $/ \mathrm{cm}^{3}$ e possui, a $37^{\circ} \mathrm{C}$, susceptibilidade paramagnética de $10,1 \times 10^{-6}$. Além disso, a susceptibilidade da matriz protéica desta molécula é de $-9.91 \times 10^{-6}$, indicando que a molécula desoxigenada é ainda ligeiramente paramagnética $\chi=0,2 \times 10^{-6}($ SCHENCK, 
1993).

O sangue é considerado ser formado por dois compartimentos: plasma e células vermelhas (eritrócitos). Os glóbulos brancos são desconsiderados por serem menos que $1 \%$ dos eritrócitos. A susceptibilidade do plasma é próxima do tecido vizinho. A susceptibilidade das células vermelhas é dependente do seu nível de oxigenação: Y (fração de oxigenação das células vermelhas). Nesta abordagem a susceptibilidade do sangue pode ser escrita como (HAACKE et al., 1999):

$$
\chi_{\text {sangue }}=H c t\left(Y \chi_{\text {oxi }}+(1-Y) \chi_{\text {deoxi }}\right)+(1-H c t) \chi_{\text {plasma }}
$$

Onde Hct corresponde à fração de eritrócitos presente no sangue (0,45 para homens), $\chi_{o x i}$ a susceptibilidade da hemoglobina oxigenada, $\chi_{\text {deoxi }}$ a susceptibilidade da hemoglobina desoxigenada e $\chi_{\text {plasma }}$ a susceptibilidade do plasma.

Dado uma variação do nível de oxigenação do sangue $\Delta Y$ e a variação de susceptibilidade resulta em:

$$
\Delta \chi_{\text {sangue }}=\Delta H c t\left(\chi_{o x i}-\chi_{\text {deoxi }}\right)
$$

Além disso, podemos assumir que $\chi_{\text {oxi }}=\chi_{\text {plasma }}$, logo:

$$
\chi_{\text {sangue }}=\chi_{\text {oxi }}+(1-Y) H c t+\left(\chi_{\text {deoxi }}-\chi_{\text {oxi }}\right)
$$

Portanto pode ser estimado o valor absoluto de susceptibilidade magnética do sangue a partir dos seus componentes. Pode ser observado que para os valores fisiológicos de nível de oxigenação $(\mathrm{Y})$ e a concentração de eritrócitos (Hct) a susceptibilidade do sangue será menor que zero, isto é, diamagnética como apresentado na Tabela 3.1.

O Fígado também apresenta susceptibilidade diamagnética e paramagnética. Embora seja um órgão rico em ferro, em condições normais o valor de susceptibilidade magnética é próximo da água 
(diamagnético). Contudo o fígado com alta concentração de ferro, pacientes com Hemocromatose, torna-se paramagnético (Figura 3.2).

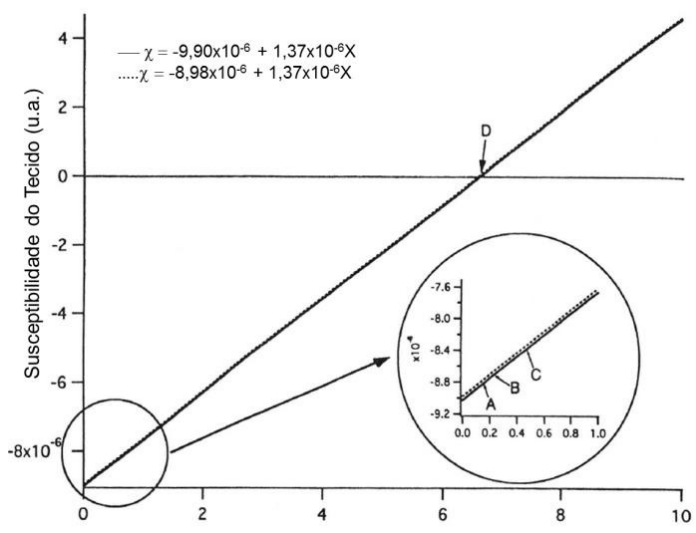

Figura 3.2: Susceptibilidade magnética do fígado de acordo com o acúmulo de ferro. Os pontos na curva representam diferentes tecidos com acúmulo de ferro: A, 0,14mg/g (mulher saudável); B, 0,21 $\mathrm{mg} / \mathrm{g}$ (homem saudável); $C$, $0,48 \mathrm{mg} / \mathrm{g}$ (acima do limite normal para homens); $D, 6,6 \mathrm{mg} / \mathrm{g}$ (alto acúmulo de ferro, hemocromatose hereditária). Adaptado de Schenck (1993).

O cérebro apresenta regiões diamagnéticas: substância branca; e paramagnéticas: gânglios da base e substância cinzenta. Os gânglios da base possuem acúmulo de ferro como descrito no tópico 1.2 e são muito estudados in vitro na doença de Parkinson (tópico 1.3). Portanto há necessidade de técnicas que estime in vivo a concentração de ferro por meio da medida de susceptibilidade magnética.

\subsection{Mapa}

\section{quantitativo de susceptibilidade magnética (QSM)}

A imagem ponderada em susceptibilidade magnética (tópico 2.2.2) apenas contrasta ou realça regiões com diferente susceptibilidade magnética, contudo não permite uma medida quantitativa. Para quantificação é necessário a construção do mapa quantitativo de susceptibilidade magnética. Em geral, os algoritmos para elaboração deste mapa têm sido principalmente propostos por grupos localizados em três países: Estados Unidos em Detroit 
por E.M. Haacke (HAACKE et al., 2005) e em Nova York por Y. Wang (ROCHEFORT et al., 2008); Inglaterra em Nottingham por R. Bowtell (MARQUES; BOWTELL, 2005); Alemanhã em Jena por J.R. Reichenbach (SCHWESER et al., 2011). Abaixo será descrito a relação teórica de susceptibilidade e imagem de fase, o pré-processamento da imagem de fase e o calculo do mapa de susceptibilidade.

\subsubsection{Relação teórica}

Quando um campo magnético uniforme $(\vec{H})$ é aplicado a uma substância, em geral o campo dentro do material $\vec{B}$ resulta em:

$$
\vec{B}=\mu_{0}(\vec{H}+\vec{M})
$$

Onde $\vec{B}$ é medido em Tesla (T), $\vec{H}$ em Ampére por metro (A/m). $\vec{M}$ é a magnetização permanente ou induzida e $\mu_{0}$ é a permissividade absoluta do vácuo $\left(4 \pi \times 10^{-7}\right)$ com unidade de $\mathrm{Tm} / \mathrm{A}$. O campo fora do material é assumido ser $\vec{B}=\mu_{0} \vec{H}$.

Para a maioria dos materiais biológicos a magnetização é definida pela equação 3.1 e re-escrita na forma: $\vec{M}=\overleftrightarrow{\chi} \vec{H}$. Logo, o campo $\vec{B}$ dentro destes materiais resulta em:

$$
\vec{B}=\mu_{0}(1+\overleftrightarrow{\chi}) \vec{H}
$$

Alguns métodos têm sido propostos para calcular a susceptibilidade magnética através da medida de campo em um experimento de Ressonância Magnética (LIU et al., 2009; SHMUELI et al., 2009; WHARTON; SCHAFER; BOWTELL, 2010; ROCHEFORT et al., 2010). Todos levam em conta a contribuição de todos os dipolos magnéticos na amostra (volume $\mathrm{V}^{\prime}$ ) para estimar o vetor indução magnética em uma posição arbitraria $\vec{r}$ (Figura $3.3 \mathrm{e}$ equação 3.7). 


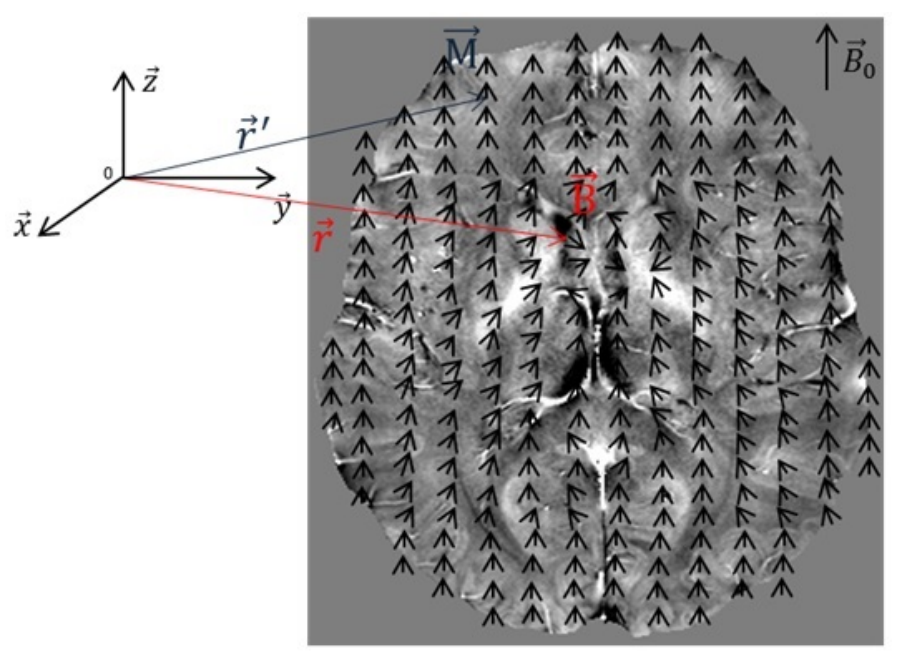

Figura 3.3: Representação do problema para o cálculo do campo magnético numa posição $\vec{r}$ arbitraria a partir de uma amostra com distribuição de magnetização $\vec{M}(\vec{r})$ no interior de um campo de intensidade $\vec{B}_{0}$.

$$
\vec{B}(\vec{r})=\overrightarrow{B_{0}}+\frac{\mu_{0}}{4 \pi} \int_{V^{\prime}} d^{3} r^{\prime}\left[\frac{3 \vec{M}\left(\overrightarrow{r^{\prime}}\right)\left(\vec{r}-\overrightarrow{r^{\prime}}\right)}{\left|\vec{r}-\overrightarrow{r^{\prime}}\right|^{5}}\left(\vec{r}-\overrightarrow{r^{\prime}}\right)-\frac{\vec{M}\left(\overrightarrow{r^{\prime}}\right)}{\left|\vec{r}-\overrightarrow{r^{\prime}}\right|^{3}}\right]
$$

Logo a seguir descrevemos de forma mais detalhada a teoria sobre a construção de mapas de susceptibilidade magnética a partir de uma revisão recente de Haacke e Reichenbach (2011).

No caso da Ressonância Magnética Nuclear, podemos considerar que o campo magnético $\overrightarrow{B_{0}}$ possui apenas uma componente principal, assumida como $\vec{z}$, pois ela é várias ordens de magnitude maior do que as outras duas componentes. Também é considerado apenas a componente $\vec{z}$ da magnetização induzida $\vec{M}(\vec{r})$ e a susceptibilidade magnética é considerada isotrópica, logo podemos escrever como:

$$
\vec{M}_{z}(\vec{r})=\frac{\chi(\vec{r})}{\mu_{0}} B_{0}
$$

Assim a equação 3.7 pode ser rescrita como:

$$
\vec{B}_{z}(\vec{r})=B_{0}+\frac{\mu_{0}}{4 \pi} \int_{V^{\prime}} d^{3} r^{\prime}\left[\frac{3 \vec{M}_{z}\left(\overrightarrow{r^{\prime}}\right)\left(\vec{r}-\overrightarrow{r^{\prime}}\right)}{\left|\vec{r}-\overrightarrow{r^{\prime}}\right|^{5}}\left(\vec{r}-\overrightarrow{r^{\prime}}\right)-\frac{\vec{M}_{z}\left(\overrightarrow{r^{\prime}}\right)}{\left|\vec{r}-\overrightarrow{r^{\prime}}\right|^{3}}\right]
$$


Considerando a equação 3.8 e que $B_{0}$ é uma constante, a equação 3.9 pode ser escrita em termos da variação do campo magnético causada pela magnetização induzida no volume $B_{d z}(\vec{r})=B_{z}(\vec{r})-B_{0}$ :

$\vec{B}_{d z}(\vec{r})=\frac{B_{0}}{4 \pi}+\int_{V^{\prime}} d^{3} r^{\prime}\left[\frac{3 \chi\left(\overrightarrow{r^{\prime}}\right)\left(z-z^{\prime}\right)^{2}}{\left|\vec{r}-\overrightarrow{r^{\prime}}\right|^{5}}\left(\vec{r}-\overrightarrow{r^{\prime}}\right)-\frac{\chi\left(\overrightarrow{r^{\prime}}\right)}{\left|\vec{r}-\overrightarrow{r^{\prime}}\right|^{3}}\right]$

Tomando a susceptibilidade em evidência:

$$
\vec{B}_{d z}(\vec{r})=\frac{B_{0}}{4 \pi}+\int_{V^{\prime}} d^{3} r^{\prime}\left[\chi\left(\overrightarrow{r^{\prime}}\right) \cdot \frac{3\left(z-z^{\prime}\right)^{2}-\left|\vec{r}-\overrightarrow{r^{\prime}}\right|^{2}}{\left|\vec{r}-\vec{r}^{\prime}\right|^{5}}\right]
$$

Definindo uma função $G\left(\vec{r}-\overrightarrow{r^{\prime}}\right)$ :

$$
G\left(\vec{r}-\overrightarrow{r^{\prime}}\right)=\frac{3\left(z-z^{\prime}\right)^{2}-\left|\vec{r}-\overrightarrow{r^{\prime}}\right|^{2}}{\left|\vec{r}-\overrightarrow{r^{\prime}}\right|^{5}}
$$

A equação 3.11 passa a ser escrita como:

$$
\vec{B}_{d z}(\vec{r})=B_{0} \int_{V^{\prime}} d^{3} r^{\prime} \chi\left(\overrightarrow{r^{\prime}}\right) \cdot G\left(\vec{r}-\overrightarrow{r^{\prime}}\right)
$$

A partir da definição de convolução (Apêndice B):

$$
h(z)=f(z) * g(z)=\int_{-\infty}^{+\infty} f(x) \cdot g(z-x) d x
$$

A equação 3.13 pode ser expressa como a convolução entre $\chi\left(\overrightarrow{r^{\prime}}\right)$ e a função $G\left(\vec{r}-\overrightarrow{r^{\prime}}\right)$ :

$$
\vec{B}_{d z}(\vec{r})=B_{0}[\chi(\vec{r}) * G(\vec{r})]
$$

Aplica-se a TF na equação 3.15:

$$
T F \vec{B}_{d z}(\vec{r})=B_{0} T F[\chi(\vec{r}) * G(\vec{r})]
$$

Onde os símbolos matemáticos descritos acima são legendados para evitar dúvidas: "*"representa convolução e "."representa multiplicação. 
A partir do teorema da convolução (Apêndice B), a transformada de Fourier da convolução de $\mathrm{f}(\mathrm{x})$ e $\mathrm{g}(\mathrm{x})$ pode ser escrita como o produto das funções transformadas em Fourier e multiplicado por $\sqrt{ } 2 \pi$ :

$$
T F[f(x) * g(x)]=\sqrt{ } T F[f(x)] . T F[g(x)]
$$

Logo, a equação 3.15 resulta em:

$$
T F[f(x) * g(x)]=B_{0} \sqrt{ } 2 \pi T F[\chi(\vec{r})] \cdot T F[G(\vec{r})]
$$

Aplicando a transformada inversa de Fourier $\mathrm{TF}^{-1}$ em ambos os lados da equação temos:

$$
\vec{B}_{d z}(\vec{r})=B_{0} T F^{-1}[\chi(\vec{r})] \cdot T F[G(\vec{r})]
$$

A função $G(\vec{r})$ é conhecida como a função de Green $3 D G_{c, 3 D}(\vec{r})$ e sua transformada de Fourier é a seguinte (HAACKE; REICHENBACH, 2011):

$$
T F G_{c, 3 D}(\vec{r})=G_{c, 3 D}(\vec{k})=\frac{1}{3}-\frac{k_{z}^{2}}{k^{2}}
$$

Portanto, substituindo-se a equação 3.20 em 3.19 resulta na perturbação de campo na componente $\vec{r}$ :

$$
\vec{B}_{d z}(\vec{r})=B_{0} \cdot T F^{-1}\left[T F(\chi(\vec{r})) \cdot\left(\frac{1}{3}-\frac{k_{z}^{2}}{k^{2}}\right)\right]
$$

Na equação 3.21 temos como incógnita $B_{d z}(\vec{r})$, como obter ela experimentalmente? A imagem de fase numa sequência gradiente echo fornece uma relação direta entre a evolução da fase e a inomogeneidade do campo magnético:

$$
\varphi(\vec{r})=-\gamma \vec{B}_{d z}(\vec{r}) T E
$$

Onde $\gamma$ é a razão giromagnética e TE é o tempo ao eco da imagem. 
Substituindo a equação 3.21 em 3.22 temos:

$$
\varphi(\vec{r})=-\gamma B_{0} T E \cdot T F^{-1}\left[T F(\chi(\vec{r}))\left(\frac{1}{3}-\frac{k_{z}^{2}}{k^{2}}\right)\right]
$$

O mapa de susceptibilidade magnética poderia assim ser gerado a partir dos valores de fase $(\varphi)$. Rearranjando os membros da equação 3.23, temos:

$$
\frac{\varphi(\vec{r})}{-\gamma B_{0} T E}=T F^{-1}\left[T F(\chi(\vec{r}))\left(\frac{1}{3}-\frac{k_{z}^{2}}{k^{2}}\right)\right]
$$

Finalmente, aplicando a TF em ambos os lados, obtemos o mapa de susceptibilidade magnética:

$$
\chi(\vec{r})=T F^{-1}\left[T F\left(\frac{\varphi(\vec{r})}{-\gamma B_{0} T E}\right) \cdot F(k)^{-1}\right]
$$

Onde $\mathrm{F}(\mathrm{k})$ é conhecida como função kernel e sua inversa é descrita como:

$$
F(k)^{-1}=1 /\left(\frac{1}{3}-\frac{k_{z}^{2}}{k^{2}}\right)
$$

É importante ressaltar que o denominador da equação 3.26 tende a zero quando o ângulo entre o vetor do espaço $\mathrm{k}$ e a direção do campo é igual a $54,7^{\circ}$ ou $125,3^{\circ}$. Logo $\chi(\vec{r})$ tende a infinito nas duas superfícies cônicas do espaço k (Figura 3.4) e causa uma amplificação do ruído na região adjacente a estas superfícies (HAACKE et al., 2005).

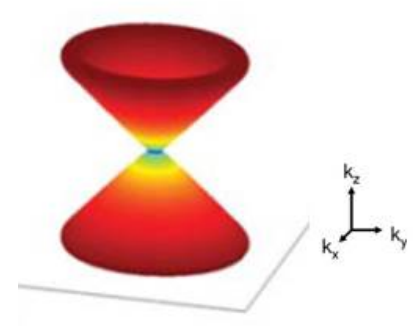

Figura 3.4: Regiões de descontinuidade da função kernel inversa $\left(F(k)^{-1}\right)$. Imagem adaptada de Wharton, Schafer e Bowtell (2010)

Apresentamos no tópico 3.3.3 algumas estratégias para contornar este problema, mas primeiramente abordaremos o pré-processamento da imagem 
de fase.

\subsubsection{Pré processamento da imagem de fase}

O pré-processamento da imagem de fase consiste, primeiramente, em aplicar o unwrapping (em inglês, desenrolar) na imagem de fase original. Já que a imagem de fase adquirida é limitada ao intervalo de $2 \pi$, enquanto que o sinal de fase original assume valores superiores a $2 \pi$. Para recuperar o sinal original é aplicado um algoritmo computacional. Por exemplo, a função prelude que faz parte do programa FSL (SMITH; JENKINSON; WOOLRICH, 2004).

Após desenrolar a imagem de fase, é obtido o mapa de campo por meio da divisão da imagem de fase pela razão giromagnética e o tempo de eco. Este mapa de campo contem campos gerados por fontes tanto externas $\left(\Delta \vec{B}_{\text {externo }}\right)$ : inomogeneidades do campo estático do equipamento; quanto internas $\left(\Delta \vec{B}_{\text {interno }}\right.$ ): regiões com elevada susceptibilidade (Ar e osso) ou baixa susceptibilidade (tecido cerebral).

$$
\Delta \vec{B}=\Delta \vec{B}_{\text {externo }}+\Delta \vec{B}_{\text {interno }}
$$

Onde $\Delta \vec{B}_{\text {interno }}$ pode ser escrito em termos de duas componentes:

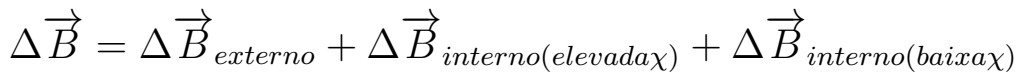

A etapa seguinte no pré-processamento consiste em eliminar os campos $\Delta \vec{B}_{\text {externo }}$ e $\Delta \vec{B}_{\text {interno(elevadax) }}$ do mapa de campo. Estes campos na literatura são chamados de campo de fundo (do inglês background field).

Inicialmente foi proposto o filtro passa alta para eliminar as componentes de fundo como descrito no Apêndice A (HAACKE et al., 2004). Contudo, atualmente não é o mais indicado para o mapa $Q S M$, sugere-se o uso de filtros mais robustos com menos perda da informação da evolução da fase. A seguir serão comentadas estas principais abordagens propostas na literatura. Em mais detalhes descrevemos o filtro SHARP (SCHWESER et 
al., 2011) por possuir maior acurácia, menos perda do sinal de fase e sem a necessidade de um algoritmo iterativo ou com conhecimento a priori.

\section{A) Filtro SHARP}

O filtro SHARP (sigla em inglês de Sophisticated Harmonic Artifact Reduction) é baseado no fato que o campo magnético criado por fontes externas ou campo de fundo $\left(\Delta \vec{B}_{\text {externo }}\right)$ possui um comportamento harmônico no volume de interesse da amostra (VOI), mas não o campo gerado por fontes internas ao VOI ( $\Delta \vec{B}_{\text {interno }}$ ). A figura 3.5 ilustra claramente este fato mostrando que a fonte geradora interna não possui linhas entrando e saindo do VOI.

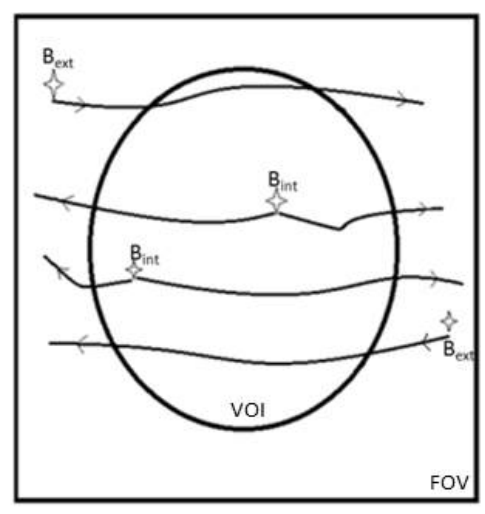

Figura 3.5: Representação das componentes de campo para uma imagem $2 D$. $B_{\text {int }}$ são fontes de campo interna ao VOI, $B_{\text {ext }}$ são fontes de campo externa ao VOI, FOV é o campo de visão (imagem total).

Desta forma, as linhas de campo satisfazem a equação de Laplace $\nabla^{2} \vec{B}_{\text {externo }}=0$ (LI; LEIGH, 2001). Logo, o uso do operador Laplaciano $\left(\nabla^{2}\right)$ sobre os dados de fase, considerando a relação linear entre a fase e o campo magnético, com ambos os comportamentos: harmônico e não harmônico 
resulta na equação abaixo.

$$
\nabla^{2} \vec{B}_{t o t a l}=\nabla^{2} \vec{B}_{i n t}
$$

Para solucionar a equação acima Schweser et al. (2011) utilizou a propriedade do valor médio de funções harmônicas (ROY, 2008) e o teorema do valor dos estados harmônicos médio. O teorema afirma que uma função harmônica é preservada sob uma transformada de convolução de uma função não negativa, com simetria radial e normalizada para $1(\rho(\vec{r}))$. Assim, é proposto o uso da função $\rho(\vec{r})$ para convoluir sobre $\vec{B}_{\text {total }}$ :

$$
\vec{B}_{\text {conv }}=\rho(\vec{r}) * \vec{B}_{\text {total }}
$$

O $\vec{B}_{\text {total }}$ pode ser dividido em $\vec{B}_{i n t}$ e $\vec{B}_{\text {ext }}$ :

$$
\vec{B}_{\text {total }}=\vec{B}_{i n t}+\vec{B}_{e x t}
$$

Assim:

$$
\vec{B}_{c o n v}=\rho(\vec{r}) * \vec{B}_{i n t}+\rho(\vec{r}) * \vec{B}_{e x t}
$$

Para eliminar a informação de $\vec{B}_{\text {ext }}$ é feito a seguinte manipulação matemática:

$$
\vec{B}^{\prime}=\vec{B}_{\text {total }}-\vec{B}_{\text {conv }}=\vec{B}_{i n t}+\vec{B}_{\text {ext }}-\rho(\vec{r}) * \vec{B}_{i n t}-\rho(\vec{r}) * \vec{B}_{\text {ext }}
$$

Pela propriedade do valor médio de funções harmônicas $\vec{B}_{\text {ext }}=\rho(\vec{r}) *$ $\vec{B}_{e x t}$ :

$$
\vec{B}^{\prime}=\vec{B}_{i n t}-\rho(\vec{r}) * \vec{B}_{i n t}
$$

Reescrevendo:

$$
\overrightarrow{B^{\prime}}=(\delta-\rho(\vec{r})) * \vec{B}_{i n t}
$$


Onde $\delta$ é impulso unitário no centro da função radial.

Finalmente é possível obtermos $\vec{B}_{i n t}$ através da deconvolução do kernel $(\delta-\rho(\vec{r}))$ :

$$
\vec{B}_{i n t}=(\delta-\rho(\vec{r}))^{-1} * \vec{B}^{\prime}
$$

A figura 3.6 apresenta uma comparação das imagens de fase filtrada com filtro passa alta e o filtro SHARP:
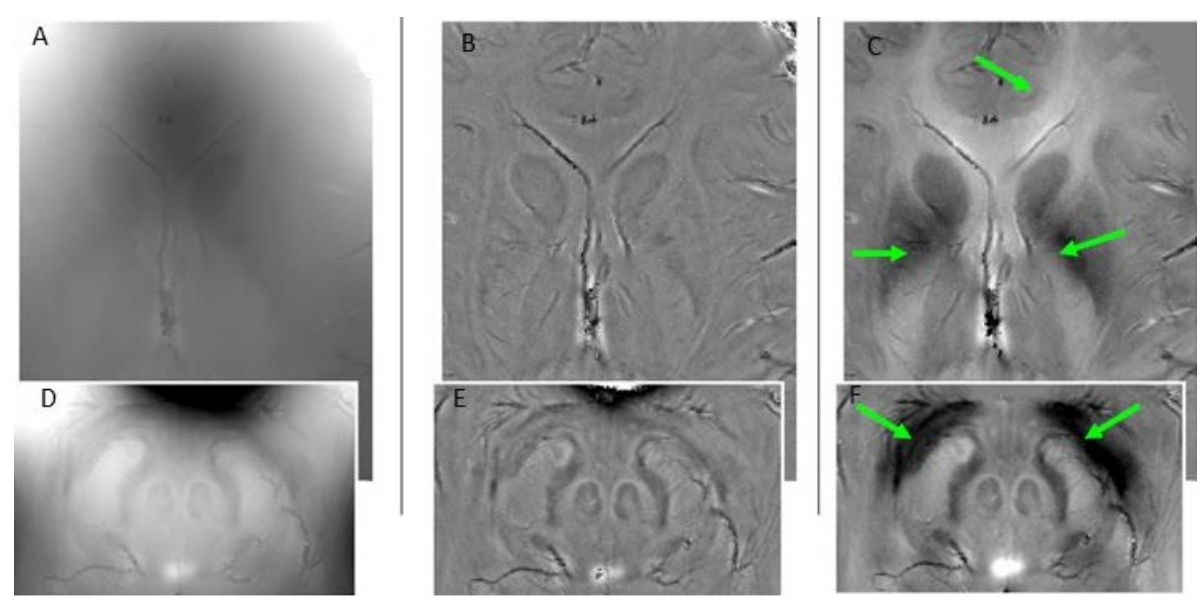

Figura 3.6: Comparação do filtro $\operatorname{SHARP}(C, F)$ com o filtro passa alta $(B, E)$ a partir das imagens desenroladas $(A, D)$. Imagem retirada da apresentação de Schweser (2010)

\section{B) Filtro de dipolo}

Wharton, Schafer e Bowtell (2010) propuseram o filtro de dipolo (do inglês Dipole Filter). O método proposto envolve a modelagem da variação de campos não desejados usando uma ou mais fontes pontuais de dipolo orientados paralelamente a $\vec{B}_{0}$ e posicionado fora da região de interesse ( $R O I$, sigla em inglês de Region of Interest).

$$
\Delta B_{z}^{d i p}(\vec{r})=\frac{P}{\left|\vec{r}-\vec{r}_{d}\right|^{3}}\left(3\left(\frac{\left(\vec{r}-\vec{r}_{d}\right) \hat{z}}{\left|\vec{r}-\vec{r}_{d}\right|}\right)-1\right)
$$

Onde $\vec{r}_{d}=x d \hat{x}+y d \hat{y}+z d \hat{z}$ e P: é o modulo do momento do dipolo.

Nesta expressão a variação de campo na condição $\vec{r}=\vec{r}_{d}$ é mal definida, mas isso não é um problema devido aos dipolos serem considerados 
somente para $\vec{r}>\vec{r}_{d}$.

Primeiramente é realizado o ajuste de mínimos quadrados para a posição e momento de um único dipolo, localizado fora da ROI. Este ajuste é implementado pela variação iterativa de quatro parâmetros $\mathrm{P}, \mathrm{xd}$, yd e zd até atingir um erro mínimo entre o campo do dipolo estimado e o mapa de campo gerado dos dados da fase.

Somente em alguns casos o primeiro estágio pode ser suficiente. Para outros casos aparece uma variação de campo nos seios nasais que pode não ser modelada suficientemente por um único dipolo. Mais dipolos devem ser aplicados dentro do ajuste. De forma prática, os novos dipolos são arranjados em posições fixas ao redor do dipolo original, novamente restringe a localização para fora da ROI. Fato que reduz o número de parâmetros que devem ser ajustados, sendo necessário alterar apenas a força do dipolo. Posteriormente é calculado o $\Delta B_{z}^{d i p}(\vec{r})$ e subtraído da medida de $\Delta B_{z}(\vec{r})$, produzindo o mapa de campo filtrado $\Delta B_{z}^{f i l t}(\vec{r})$, o qual contem somente variações de campo devido à distribuição de susceptibilidade magnética dentro da ROI. Em casos onde as fontes externas de campo magnético não são restritas em um específico lugar, o ajuste pode ser estendido para uma distribuição de dipolos mais uniformes ao redor da ROI.

\section{C) Filtro polinomial}

O filtro polinomial consiste no uso de funções polinomiais de até oitava ordem para determinar a magnitude e a distribuição dos efeitos mais globais da susceptibilidade magnética (DUYN et al., 2007). A distribuição de fase "ajustada", que representa regiões com variações suaves de susceptibilidade, é subtraída da imagem de fase original. No entanto, o efeito nas regiões com alta diferença de susceptibilidade não é totalmente removido, por exemplo, na região dos seios nasais onde existe uma grande diferença de susceptibilidade entre o ar, o osso e o tecido. Fato que torna não muito recomendado para o uso em processamento de mapas quantitativos de susceptibilidade magnética na região basal do cérebro. 


\section{D) Filtro baseado em geometria}

O filtro baseado em geometria foi proposto por Neelavalli et al. (2009), o qual desejava reduzir os artefatos de aliasing (em inglês, dobramento) nas imagens de fase de sequência gradiente eco sem alterar os valores de fase original. Os autores propuseram a subtração da imagem de fase por uma imagem simulada contendo apenas evolução de fase para regiões com alta diferença de susceptibilidade magnética (exemplo seios nasais e maxilar).

Esta imagem simulada é obtida a partir dos valores de susceptibilidade magnética de diferentes estruturas com uma geometria especifica. A geometria destas estruturas é obtida a partir de um limiar complexo aplicado numa imagem 3D ponderada em T1. Já os valores de susceptibilidade são obtidos iterativamente usando a equação abaixo, a partir destas geometrias e uma imagem formada pela diferença de duas imagens de fase com tempos ao eco muito próximos.

$$
\varphi(\vec{r})=-\gamma T E B_{0} T F^{-1}\left[T F(x 1 . g 1+x 2 . g 2+\ldots+x n . g n)\left(\frac{1}{3}-\frac{k_{z}^{2}}{k^{2}}\right)\right]
$$

Onde cada estrutura tem uma susceptibilidade espacial constante xi, e gi é a transformada de Fourier da geometria da i-ésima estrutura. Aqui TE e $\varphi(\vec{r})$ representam a diferença dos tempos ao eco e a imagem de fase, respectivamente. Esta mesma equação é utilizada para simular o efeito na fase de regiões com altas diferenças de susceptibilidade na nossa imagem de interesse. A figura abaixo mostra o efeito deste filtro em uma imagem de fase. 

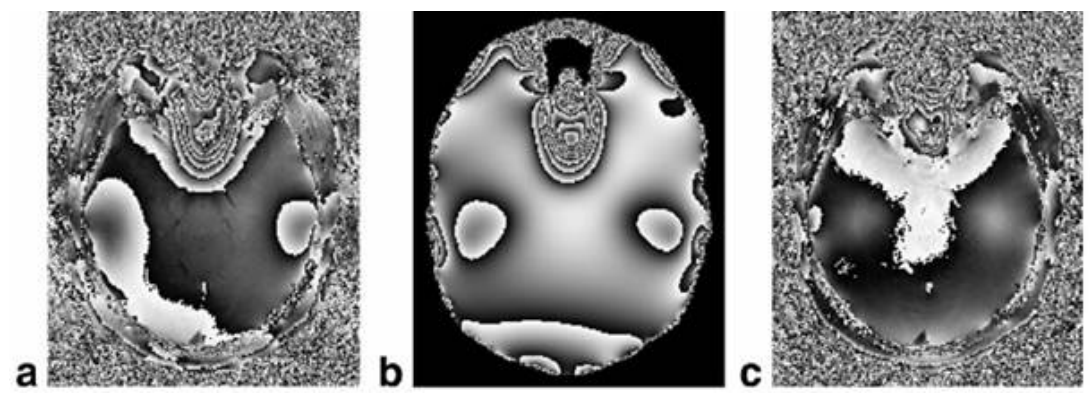

Figura 3.7: Resultados do processamento do filtro baseado em geometria. a: imagem de fase de sequência gradiente eco. b: imagem de fase simulada com o uso de geometria e susceptibilidade encontrada por algoritmo de iteração. c: resultado da subtração de (a-b). Imagem obtida de Neelavalli et al. (2009).

\subsubsection{Cálculo do mapa de susceptibilidade magnética}

Uma vez pré-processada a imagem de fase, é aplicado um algoritmo para determinar o mapa de susceptibilidade magnética. Como descrito na equação 3.26 o valor de susceptibilidade magnética não pode ser determinado de forma direta. A literatura recente tem proposto três abordagens diferentes para este cálculo: (A) Limiarização, (B) Regularização por conhecimento prévio e (C) Múltiplas orientações (COSMOS).

\section{A) Limiarização}

Haacke et al. (2010) e colaboradores propuseram a seguinte abordagem para eliminar as descontinuidades na função $F(k)^{-1}$ (Figura 3.8b). Primeiramente o modulo de $\mathrm{F}(\mathrm{k})$ é restringido para ter um valor mínimo $\alpha$ (Figura 3.8c). Isto é, para algum valor de $\mathrm{k}$, onde $|F(k)|<\alpha, \mathrm{F}(\mathrm{k})$ é substituído para $-\alpha$ ou $\alpha$ dependendo do sinal de $\mathrm{F}(\mathrm{k})$. Este primeiro passo evita que os valores de $F(k)^{-1}$ se tornem muito grandes e amplifiquem o ruído da fase nos pontos no espaço inverso perto das singularidades. 


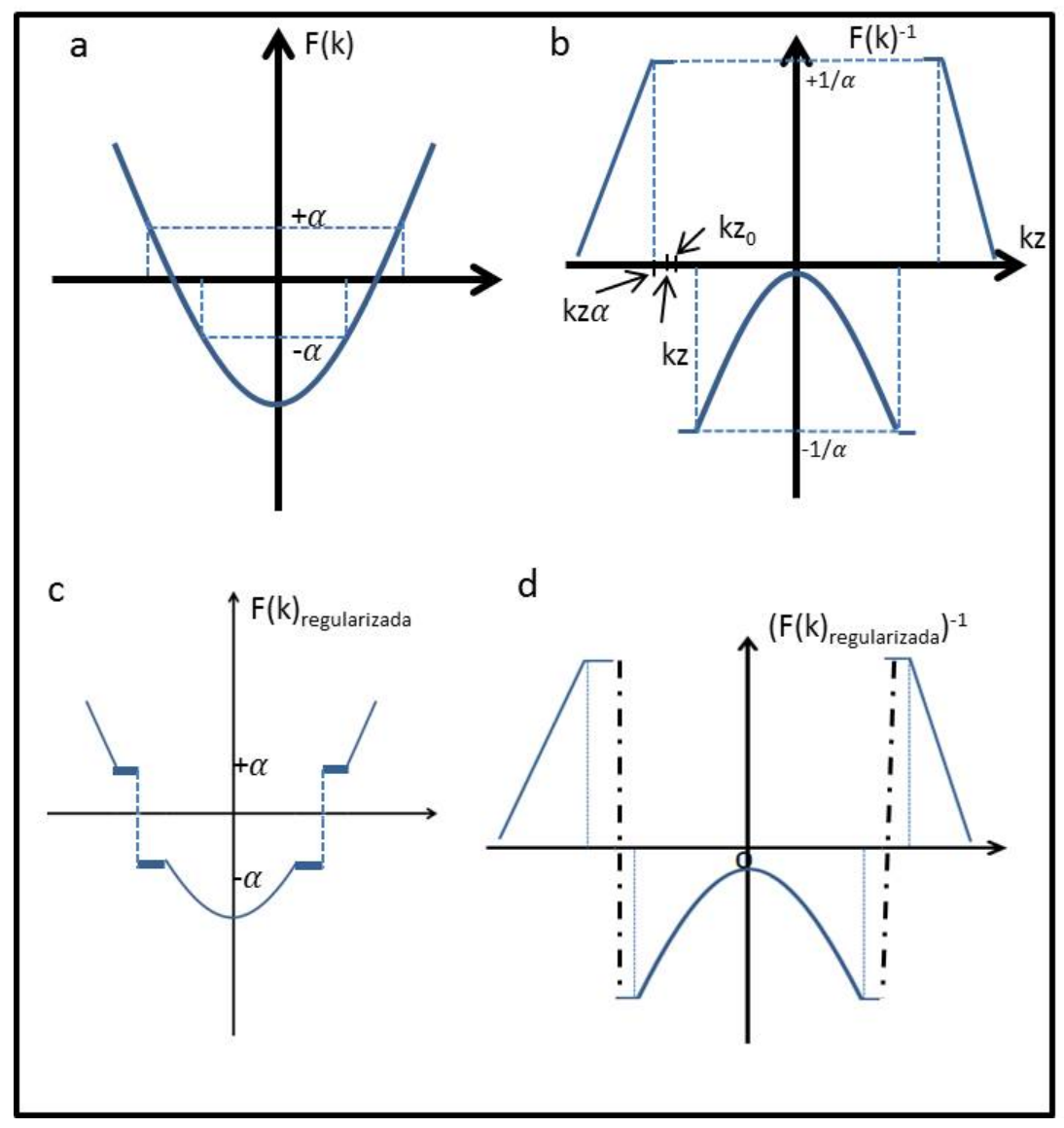

Figura 3.8: Representação da função $F(k)$.

Posteriormente a $F(k)^{-1}$ na região da regularização é suavizada para zero, tal que a descontinuidade seja totalmente removida. Esta suavização é gerada pela multiplicação de $F(k)_{\text {regularizada }}^{-1}$ por $c(k z)^{2}$ (Figura 3.8d, linha tracejada) onde $\mathrm{c}(\mathrm{kz})$ é definido como:

$$
c(k z)= \begin{cases}\frac{\left(k_{z}-k_{z 0}\right)}{\left|k_{z \alpha}-k_{z 0}\right|} & \text { para }\left|k_{z}-k_{z 0}\right|<\left|k_{z \alpha}-k_{z 0}\right| \\ l & \text { para }\left|k_{z}-k_{z 0}\right| \geq\left|k_{z \alpha}-k_{z 0}\right|\end{cases}
$$

Onde $k_{z}$ é a componente $\mathrm{z}$ de cada ponto no espaço $\mathrm{k}, k_{z 0}$ é o ponto em que a função $F(k)^{-1}$ torna-se indefinida e $k_{z a}$ é o ponto máximo ou minimo de $k \mathrm{em}$ 
que a função $F(k)^{-1}$ será regularizada (Figura 3.8).

Esta abordagem está implementada no programa SMART (tópico 4.3.2)

\section{B) Regularização por conhecimento prévio}

Outro método para determinar o valor de susceptibilidade magnética é o uso do conhecimento prévio para regularizar a solução do mapa de susceptibilidade por mínimos quadrados. De acordo com Rochefort et al. (2010), o ruído do sinal de RM é considerado de natureza gaussiana, logo a melhor solução probabilística para o mapa de susceptibilidade pode ser derivado da seguinte ponderação de minimização quadrática entre o mapa de campo simulado $(F \chi)$ e o mapa de campo obtido experimentalmente $(\delta)$ :

$$
\min _{\chi}\|W(F \chi-\delta)\|_{2}^{2}
$$

Onde $\delta$ representa o vetor coluna com variação de campo normalizada $B_{d z}$ no espaço real e a expressão $F \chi$ representa a convolução da matriz de susceptibilidade $\chi$ com a função kernell $F$ no espaço real. $W$ é uma matriz que pondera o efeito do ruído e será diagonal se consideramos um sinal de RM com ruído gaussiano não correlacionado. $W$ contém o inverso do desvio padrão do sinal para cada ponto.

Além disso, os autores sugerem a adição de termos de regularização na equação acima na forma de uma regularização de Tikhonov. Estes termos utilizam um conhecimento espacial prévio impondo condições similares a condições de contorno. A expressão de minimização para determinar $\chi$ fica descrita como:

$$
\min _{\chi}\|W(F \chi-\delta)\|_{2}^{2}+\alpha^{2}\left\|W_{0} \chi\right\|_{2}^{2}+\beta^{2}\left\|W_{1} G \chi\right\|_{2}^{2}
$$

O primeiro termo é o geral que garante a fidelidade aos dados adquiridos, no sentido de mínimos quadrados.

No segundo termo a matriz $W_{0}$ denota uma ponderação aplicada na solução, semelhante à matriz de ponderação aplicada no primeiro termo. 
Onde $W_{0}$ é uma máscara que assume a priori valores iguais a 1 em regiões de susceptibilidade homogênea. Este termo representa a imposição de uma condição de contorno na forma de condição de Dirichlet. A influência relativa deste termo é controlada pelo parâmetro $\alpha$. O resultado obtido pela imposição deste termo é uma suavização das regiões de susceptibilidade homogênea.

O ultimo termo similarmente impõe condição de contorno na forma de uma condição de Neumann, isto é, sobre o gradiente da solução. A matriz $G=$ $\left[G_{x} ; G_{y} ; G_{z}\right]$ denota o operador gradiente nas três direções e $\beta$ é o parâmetro de regularização. $W_{1}$ é similar a matriz de ponderação no primeiro termo, $W_{1}=\left[W_{1 x} W_{1 y} W_{1 z}\right]$ em que cada submatriz é a matriz diagonal ponderada. Onde cada matriz de ponderação é derivada da imagem de magnitude.

\section{C) Múltiplas Orientações (COSMOS)}

Para determinar o valor de susceptibilidade sem aplicar correções na equação 3.26, Liu et al. (2009) propuseram a aquisição da imagem com diferentes ângulos de orientação da cabeça em relação ao campo estático. A combinação de mais de duas orientações elimina as singularidades na função kernel $F(k)^{-1}$ (Figura 3.9). A técnica é denominada COSMOS (sigla em inglês Calculation of Susceptibility Through Multiple-Orientation Sampling).

De forma semelhante ao método anterior é utilizado o método de mínimos quadrados para determinar o valor de susceptibilidade (equação 35).

$$
\min _{\chi}\left(\sum_{i}\left\|W_{i}\left(T F^{-1}\left(F(k)_{i} \cdot \chi(k)^{i}\right)-I(r)_{i}\right)\right\|^{2}\right)
$$

Onde $I(r)_{i}$ representa as imagens de campo magnético obtidas em $i$ orientações diferentes, $F(k)_{i}$ são as funções kernel para cada orientação, $W_{i}$ é uma matriz de regularização para reduzir o efeito do ruído. Nesta aproximação $W_{i}$ é uma mascara obtida a partir da intensidade da imagem de magnitude da orientação $i$, sendo 0 para voxels com intensidade menor que $10 \%$ da intensidade máxima e 1 para o restante.

A função kernel rotacionada um ângulo $\theta_{i}$ em relação ao eixo x passa a 


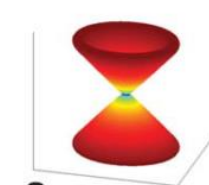

a

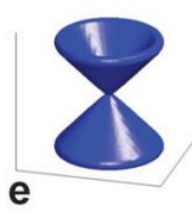

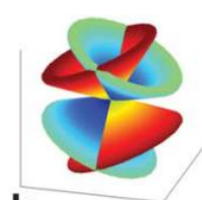

b

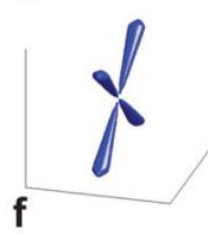

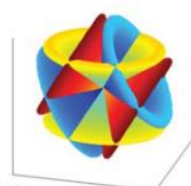

C

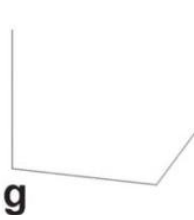

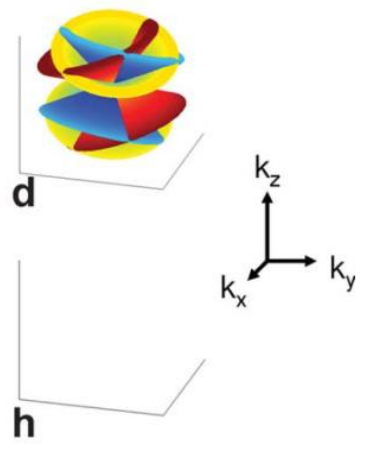

Figura 3.9: Representação $3 D$ das singularidades geradas pela aplicação de filtros $F(k)$. a, única orientação (igual à figura 3.4). b, combinação de duas orientações sobre o eixo x com $\Delta \theta=40^{\circ}$. combinação de três orientações sobre o eixo x com $\Delta \theta=60^{\circ}$. d, combinação de três orientações seguidas produzidas pela seguinte sequência de rotação sobre o eixo x e y tal que $(\theta, \phi)=\left(20^{\circ}, 0^{\circ}\right),\left(-10^{\circ}, 17^{\circ}\right) e\left(10^{\circ}, 17^{\circ}\right)$. e-h, singularidades que permaneceram após a combinação das medidas feitas em diferentes orientações de a-d respectivamente. Imagem retirada de Wharton, Schafer e Bowtell (2010).

ser descrita por:

$$
F(k)_{i}=\frac{1}{3}-\frac{\left(k_{z} \cos \theta_{i}-k_{y} \sin \theta_{i}\right)^{2}}{k^{2}}
$$

A acurácia do valor de susceptibilidade demanda um valor alto para o ângulo de rotação das orientações. Desta forma a técnica COSMOS não é muito prática. Contudo, Wharton, Schafer e Bowtell (2010) propuseram fazer a aquisição em múltiplos ângulos sobre mais de um eixo para diminuir o ângulo de rotação tornando viável este tipo de aquisição. Neste caso a função kernel passa ser descrita como:

$$
F(k)_{i}=\frac{1}{3}-\frac{\left(k_{z} \cos \theta_{i} \cos \phi_{i}-k_{y} \sin \theta_{i} \cos \phi_{i}+k_{x} \sin \phi_{i}\right)^{2}}{k^{2}}
$$

Sendo que $\phi_{i}$ é um ângulo de rotação em torno do eixo y.

De forma geral, o mapa de susceptibilidade magnética é muito recente e ainda não tem sido descrito na comunidade científica brasileira. Propomos a implementação do mapa de susceptibilidade magnética e avaliação da sensibilidade na estimativa de ferro em sujeitos controles e pacientes com 
doença de Parkinson. 


\section{Capítulo}

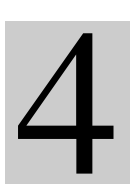

\section{Materiais e Métodos}

Durante o desenvolvimento deste trabalho foi realizado o recrutamento de indivíduos (sujeitos controles e pacientes com doença de Parkinson); a aquisição de imagens de RMN; a segmentação das regiões de interesses; estimativa da concentração de ferro; o processamento dos valores de R2, R2* e susceptibilidade magnética; mapa de susceptibilidade magnética com diferentes resoluções de imagem; múltiplos tempos de relaxação T2; análise estatística.

\subsection{Casuística}

A pesquisa foi aceita no comitê de ética da faculdade de Filosofia Ciências e Letras de Ribeirão Preto da Universidade de São Paulo e em concordância com comitê de ética do Hospital das Clínicas da Faculdade de Medicina de Ribeirão Preto pertencente à mesma universidade. Nos anexos A e B estão os termos de consentimento livre e esclarecido para sujeitos controles e pacientes. Nos anexos C e D estão as cópias dos termos de aceite de ambos os comitês de ética.

\section{Sujeitos Controles}

Os sujeitos controles foram recrutados por meio de pesquisa simples no Departamento de Física da Faculdade de Filosofia Ciências e Letras e indicação de amigos. Os critérios de inclusão e exclusão foram definidos de 
acordo com a literatura e discutidos junto com o neuroradiologista Prof. Dr. Antônio Carlos dos Santos. Buscamos sempre parear os sujeitos controles com os pacientes (sexo e idade) para que outras variáveis não interferissem nos resultados. Como descrito no tópico 2.3 o ser humano acumula ferro principalmente com o avanço da idade nos núcleos da base. Além disso, estudos apresentam resultados conflitantes em relação ao acúmulo de ferro em diferente gênero. Ressaltamos os pontos de inclusão e exclusão utilizados:

Inclusão

- Possuir idade acima de 50 anos.

- Resultado normal de exame estrutural de Ressonância Magnética realizado previamente.

\section{Exclusão}

- Histórico de trauma craniano, derrame e doença neurológica.

- Sinais extrapiramidais, déficit senso motor e cognitivo avaliado de forma simples na entrevista.

- Claustrofóbicos.

- Achado de anormalidade encefálica após laudo do exame de Ressonância Magnética.

\section{Pacientes}

Os sujeitos pacientes com doença de Parkinson foram recrutados por meio de entrevista no Ambulatório Extra Piramidal do Hospital das Clinicas de Ribeirão Preto durante o período de 01/09/2012 até 01/04/2013. Os pacientes foram diagnóstico com doença de Parkinson segundo os critérios do United Kingdom Brain Bank, sobre a coordenação do neurologista Prof. Dr. Vitor Tumas e seus residentes. Os critérios de inclusão e exclusão também foram selecionados da literatura e discutidos junto com os médicos do ambulatório: 
Inclusão

- Possuir idade acima de 50 anos.

- Diagnóstico da doença de Parkinson segundo os critérios do United Kingdom Brain Bank.

- Inclusão do estágio da doença na escala de incapacidade de Hohen e Yahr.

Exclusão

- Histórico de outra doença neurológica e psiquiátrica.

- Paciente com doença de Parkinson com evolução da doença atípica.

- Pacientes com secundária doença de Parkinson.

- Claustrofóbicos.

Foram recrutados 20 sujeitos controles, sendo dois sujeitos excluídos por movimento durante a realização do exame de RMN, um por artefatos na imagem de fase e um por apresentar anormalidade encefálica. Os sujeitos pacientes foram 18, sendo um paciente excluído por interrupção do exame, dois por artefatos na imagem de fase e um por não ter diagnóstico conclusivo da doença de Parkinson. Em resumo, foram selecionados 16 controles saudáveis e 14 pacientes com doença de Parkinson (Tabela 4.1).

\begin{tabular}{|c|c|c|c|c|c|}
\hline Grupo & & $\begin{array}{l}\text { Número de } \\
\text { Indivíduos }\end{array}$ & $\begin{array}{l}\text { Idade em anos } \pm \\
\text { desvio padrão }\end{array}$ & Homens (\%) & Mulheres (\%) \\
\hline $\begin{array}{l}\text { Doença } \\
\text { Parkinson }\end{array}$ & de & 14 & $64,1 \pm 8,1$ & 7 & 7 \\
\hline Controles & & 16 & $66,4 \pm 6,8$ & 6 & 10 \\
\hline
\end{tabular}

Tabela 4.1: Principais informações sobre os pacientes com doença de Parkinson e os controles avaliados. 
Os sujeitos controles e pacientes não apresentaram diferença significativa para os valores de idade $(p=0,16)$. A Tabela 4.2 apresenta maiores informações obtidas do prontuário clínico dos pacientes com doença de Parkinson. Gostaríamos ressaltar que pela pequena quantidade de pacientes não foi possível fazer uma análise de correlação entre os parâmetros quantitativos aqui estudados e o grau de gravidade da doença (por exemplo usando a escala de $\mathrm{H} \& \mathrm{Y})$.

\begin{tabular}{lllll}
\hline \hline Paciente & Sexo & $\begin{array}{l}\text { Idade } \\
\text { (anos) }\end{array}$ & $\begin{array}{l}\text { Duração } \\
\text { da } \\
\text { doença } \\
\text { (anos) }\end{array}$ & $\begin{array}{l}\text { Escala } \\
\text { da } \\
\text { doença } \\
\text { H\&Y }\end{array}$ \\
\hline 1 & $\mathrm{~m}$ & 72 & 5 & 2 \\
2 & $\mathrm{f}$ & 64 & 5 & 3 \\
3 & $\mathrm{f}$ & 72 & 5 & 2 \\
4 & $\mathrm{~m}$ & 66 & 5 & 3 \\
5 & $\mathrm{~m}$ & 73 & 11 & 2 \\
6 & $\mathrm{f}$ & 77 & 10 & 1 \\
7 & $\mathrm{f}$ & 65 & 7 & 2 \\
8 & $\mathrm{f}$ & 63 & 5 & 1 \\
9 & $\mathrm{f}$ & 59 & 4 & 2 \\
10 & $\mathrm{~m}$ & 50 & 8 & 3 \\
11 & $\mathrm{~m}$ & 69 & 6 & 2 \\
12 & $\mathrm{~m}$ & 63 & 7 & 2 \\
13 & $\mathrm{f}$ & 66 & 5 & 2 \\
14 & $\mathrm{~m}$ & 71 & 15 & 2 \\
\hline \hline
\end{tabular}

Tabela 4.2: Principais informações sobre os pacientes com doença de Parkinson avaliados.

\subsection{Aquisição das imagens}

A aquisição das imagens de ressonância magnética foi realizada no equipamento 3.0 Tesla (Philips, Achieva) do Hospital das Clínicas da Faculdade de Medicina de Ribeirão Preto. Foi utilizada uma bobina padrão 
de cabeça com 8 canais com capacidade para aplicar a técnica SENSE. Os cortes foram orientados paralelamente â linha que vai da comissura anterior à posterior. Os seguintes parâmetros foram usados:

- Sequência Turbo Spin Eco combinada com aquisição multiplanar GraSE (definida pela Philips para reduzir o tempo de exame) foi adquirida para a construção do mapa de R2. Com 12 ecos e 12ms de intervalo entre os ecos, TE/TR igual a 12/3000ms, fator EPI igual a três e resolução espacial de 0,5x0,5x2,0mm com FOV de 172x230x40mm.

- Sequência Gradiente Eco foi adquirida para a construção do mapa de R2*. Com 4 ecos de intervalo de 12ms, TE/TR igual a 7,7/100ms e o ângulo de flip $15^{\circ}$, otimizado para a melhor relação sinal ruído. Fator EPI igual a um, resolução espacial de 0,5x0,5x2,0mm com FOV de 172x230x40mm. Para o mapa de susceptibilidade magnética usou-se a imagem de magnitude e de fase do segundo eco $(19,7 \mathrm{~ms})$ da sequência Gradiente Eco.

\subsection{Processamento dos Mapas}

Todas as imagens adquiridas foram exportadas no formato do fabricante PAR/REC e também convertidas para o formato Nifti através de rotina no Matlab r2agui obtido do site http : //r2agui.sourceforge.net/. As imagens obtidas por sequência Turbo Spin Eco e Gradiente Eco não foram corregistradas, porque consideramos que o paciente não se movimentou no período de aquisição destas imagens. Além disso, a aquisição foi realizado para o mesmo protocolo de posicionamento.

\subsubsection{Mapa de Relaxometria}

Uma rotina escrita em Matlab foi gerada para desenhar a região de interesse sobre uma imagem adquirida em determinado tempo ao eco e obter o valor de intensidade do sinal para todos os tempos ao eco (Figura 4.1 e 4.2). 


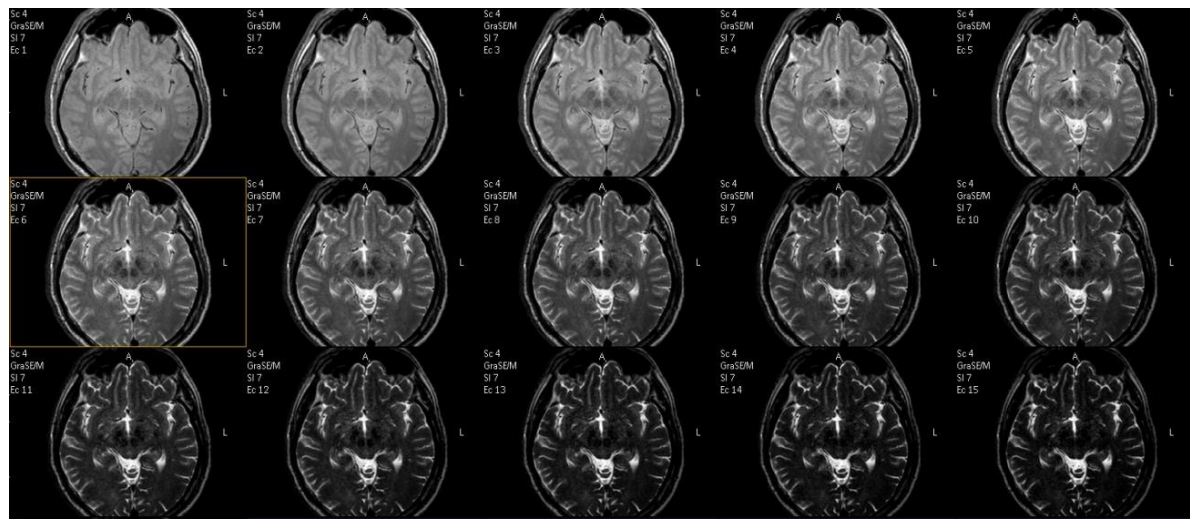

Figura 4.1: Exemplo de imagens de uma fatia da região dos núcleos da base adquiridas com uma sequencia Spin Eco mudando o tempo ao eco de $12 \mathrm{em}$ 12ms. Imagem de voluntário saudável com idade de 65 anos.

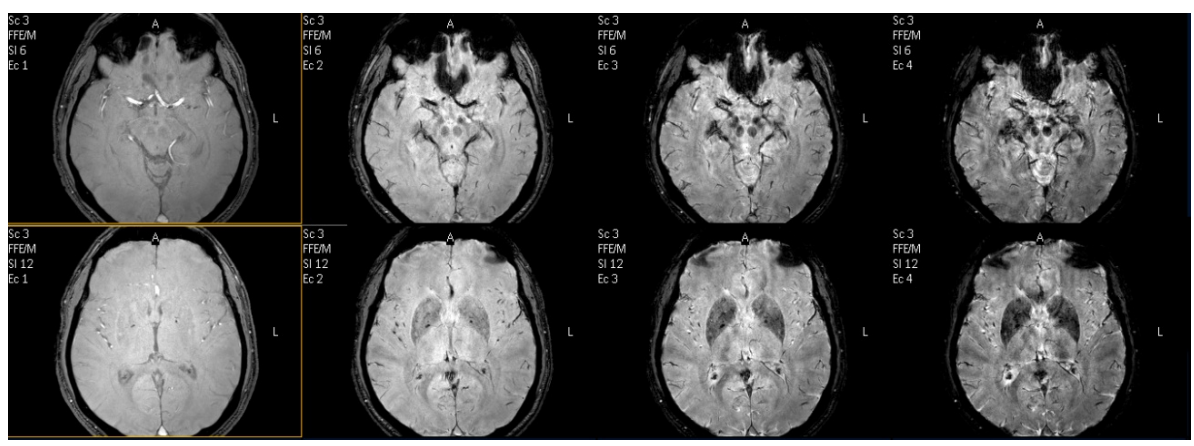

Figura 4.2: Exemplo de imagens de uma fatia da região dos núcleos da base adquiridas com uma sequencia Gradiente Eco com múltiplos ecos (4 ecos, $T E=12,24,36,48 \mathrm{~ms})$.

Como o sinal em cada pixel da região de interesse decai exponencialmente com o tempo ao eco, seguindo a equação 4.1, é possivel obter o parâmetro de decaimento T2 ou T2* por ajuste mono exponencialmente.

$$
y=A 1 * \exp (-T E / t)+y_{0}
$$

Onde A1 é uma constante relacionada com a densidade protônica, $y_{0}$ é um parâmetro constante, TE é o tempo ao eco da imagem correspondente, t é a constante de decaimento exponencial e y a intensidade do sinal.

Para imagens de sequência Turbo Spin Eco é estimado a constante de decaimento exponencial T2 e para a sequência Gradiente Eco é obtido 
T2*. Os inversos de T2 e T2* resultam nas taxas de relaxação R2 e R2*, respectivamente. Posteriormente, é obtido o valor médio e o desvio padrão de R2 ou de R2* da respectiva região de interesse.

Os valores de T2 para as regiões dos núcleos da base também foram estudado em análise multi exponencial. De acordo com Whittall e MacKay (1989) o valor do sinal $\left(y_{i}\right)$ é considerado uma soma das contribuições de diferentes valores de taxa de relaxação T2 presente na mesma amostra:

$$
y\left(t_{i}\right)=S\left(T_{1}\right) e^{-t_{i} / T_{1}}+S\left(T_{2}\right) e^{-t_{i} / T_{2}}+\ldots+S\left(T_{m}\right) e^{-t_{i} / T_{m}}=\int_{a}^{b} S(T) e^{-t_{i} / T} d T
$$

Onde S(T) indica a amplitude da componente espectral do tempo de relaxação T. Caso a amostra tenha mais de um decaimento exponencial irá resultar em diferentes valores de $T: T_{m}$. Os limites na integral são restritos a valores de a e b que são pré-definidos para conter os valores de T esperado.

A equação 4.2 dever ser discretizada para proceder a implementação computacional. Um método simples e rápido assume que $\mathrm{S}(\mathrm{T})$ é a soma de $\mathrm{M}$ funções $\delta$ com área desconhecida $s_{j}$ do tempo de relaxação conhecido $T_{j}$ :

$$
s(T)=\sum_{j=1}^{M} s_{j} \delta\left(T-T_{j}\right)
$$

Substituindo a equação 4.3 em 4.2, temos:

$$
y_{i}=\sum_{j=1}^{M} s_{j} e^{-t_{i} / T_{j}}
$$

Outra discretização é aplicada:

$$
y_{i}=\sum_{j=1}^{M} s_{j} g_{i j}
$$

Onde $g_{i j}$ são dados analíticos em termos de integral exponencial:

$$
g_{i j}=\sum_{T_{j}}^{T_{j+1}} e^{-t_{i} / T_{j}} d T
$$


As equações 4.4 e 4.5 são sistemas lineares de equações cuja a forma geral pode ser escrita como:

$$
y_{i}=\sum_{j=1}^{M} \text { Aijs }_{j}, \quad i=1,2, \ldots, N .
$$

Por meio de algoritmo de solução de mínimos quadrados não negativos (NNLS, sigla em inglês de Nonnegative Least Square) e a transformação estável de Householder o método computacional soluciona a equação 4.7 e garante encontrar uma solução em um finito número de operações. De forma resumida o NNLS encontra numericamente o valor de $s_{j}$ que minimiza o ajuste de mínimos quadrados:

$$
\sum_{i=1}^{N}\left|\sum_{j=1}^{M} A_{i j} s_{j}-y_{i}\right|^{2}
$$

Como resultado é gerado o espectro com valores de amplitude $s_{j}$ para cada valor de $\mathrm{T} 2$.

\subsubsection{Mapa de Susceptibilidade Magnética}

A Figura 4.3 contem as principais etapas do processamento do mapa de susceptibilidade, elas são: unwrapping da imagem de fase, geração de uma máscara do cérebro, uso do filtro $S H A R P$ e a técnica de limiarização para solucionar a inversão do kernel unitário de dipolo (equação 3.26). A seguir são descritas estas etapas.

\section{A)Desenrolar a imagem de fase (unwrapping)}

Primeiramente, para gerar o mapa QSM é necessário aplicar na imagem de fase o procedimento unwrapping (em inglês, desenrolar). Pode ser utilizada a função prelude que faz parte do programa FSL (SMITH; JENKINSON; WOOLRICH, 2004) para desenrolar as imagens. O programa FSL é de livre acesso e funciona em sistema Linux ou em Windows por meio de máquina virtual. 


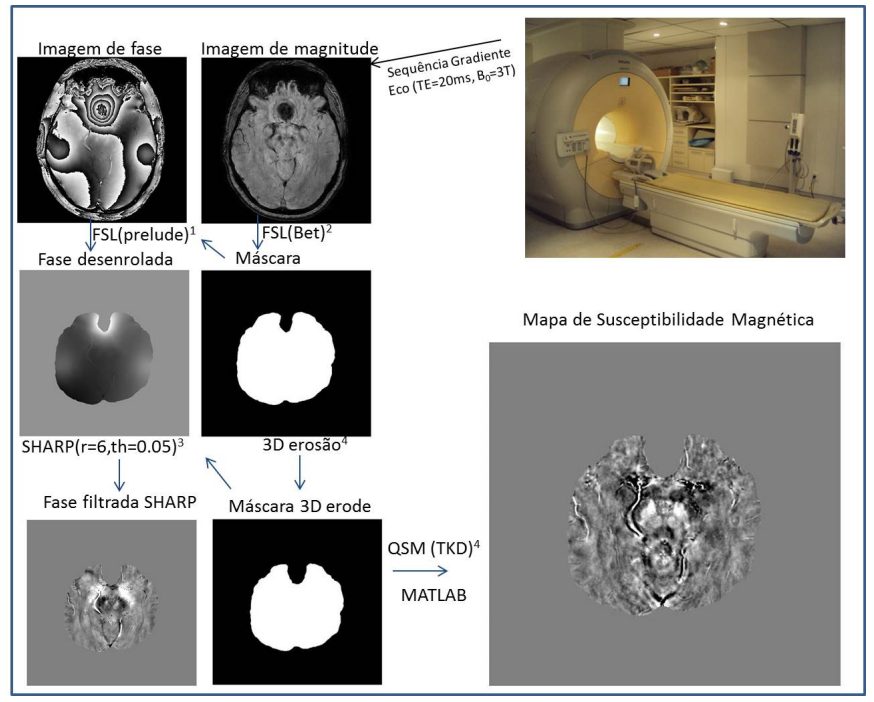

Figura 4.3: Etapas para o processamento do mapa de susceptibilidade magnética ( ${ }^{1}$ Jenkinson, Wilson e Jezzard (2004), ${ }^{2}$ Smith, Jenkinson e Woolrich (2004), ${ }^{3}$ Schweser et al. (2011), ${ }^{4}$ Haacke et al. (2010)).

\section{B)Filtragem das componentes de fundo (Filtro SHARP)}

O filtro SHARP foi utilizado para remover as componentes de fundo da imagem de fase. Este filtro foi apresentado teoricamente no tópico 3.3.2, aqui descreveremos como pode ser implementado, por exemplo no programa Matlab. Abaixo apresentamos as etapas para o processamento do filtro:

- Primeiramente é construída a função $\rho(\vec{r})$, filtro (kernel) com núcleo esférico não negativo, simetria radial e normalizado (a soma de todos os pixels da esfera deve ser igual a 1).

o Este filtro é gerado através do cálculo do valor de "r"para cada pixel, utilizando as coordenadas da imagem a ser filtrada (com uso da função MESHGRID em Matlab para todas as dimensões (X, Y, Z)).

○ A função r é convertida em uma função binária, onde apresenta dependência:

$$
r(x, y, z)=\left\{\begin{array}{cc}
1, & \text { para } \mathrm{r} \leqslant \text { Raio do filtro esférico } \\
0, & \text { para } \mathrm{r}>\text { Raio do filtro esférico }
\end{array}\right.
$$


- Finalmente é encontrado a função $\rho(\vec{r})$ por meio da normalização da função $r(x, y, z)$, onde se divide cada pixel binário de $r(x, y, z)$ pela soma do número total de pixels binários.

- Convolui-se $\rho(\vec{r})$ sobre a imagem de fase $\varphi_{\text {total }}(\vec{r})$. Para realizar esta convolução é utilizado o teorema da transformada da convolução (Apêndice B):

$$
\begin{gathered}
\varphi_{\text {conv }}(\vec{r})=\rho(\vec{r}) * \varphi_{\text {total }}(\vec{r})=T F^{-1}\left(T F\left(\rho(r) \cdot T F\left(\varphi_{\text {total }}(\vec{r})\right)\right)\right) \\
\varphi_{\text {conv }}^{\prime}(\vec{r})=\varphi_{\text {conv }}(\vec{r}) * \text { mask }_{\text {erode }}(\vec{r})
\end{gathered}
$$

- O kernel $\rho(\vec{r})^{\prime}=\delta-\rho(\vec{r})$ é gerado pela subtração do valor 1 do voxel central da função $\rho(\vec{r})$ e multiplicado posteriormente todos os valores por -1 .

- Recuperando a fase interna $\varphi_{i n t}(\vec{r})$ através do teorema da transformada da convolução temos:

$$
\varphi_{\text {int }}(\vec{r})=\rho(\vec{r})^{\prime-1} * \varphi_{\text {conv }}^{\prime}(\vec{r})=T F^{-1}\left(T F\left(\rho(\vec{r})^{\prime-1}\right) \cdot T F\left(\varphi_{\text {conv }}^{\prime}(\vec{r})\right)\right)
$$

- Por ultimo, para reduzir os artefatos da deconvolução na fase $\varphi_{\text {int }}(\vec{r})$ esta ultima imagem é multiplicado a máscara erodida:

$$
\varphi_{\text {intsharp }}(\vec{r})=\varphi_{\text {int }}(\vec{r}) \cdot \text { mask }_{\text {erode }}(\vec{r})
$$

\section{C)Processamento dos mapas de susceptibilidade magnética}

Nesta dissertação os mapas de susceptibilidade magnética foram calculados no progama SMART (versão v1.1a), por ser um programa já usado pela comunidade científica (TANG et al., 2013). O programa SMART foi obtido do Laboratório MRI Institute for Biomedical Research da universidade 
Wayne State University (Detroit, MI, EUA) através da visita de colaboração do aluno Jeam Haroldo Oliveira Barbosa durante o mestrado (24/09/2012 até 01/12/2012) em contato com o professor Eward Mark Haacke em 2012.

A Figura 4.4 ilustra a janela principal do programa SMART. O programa SMART permite escolher diferentes filtros para remover campo de fundo (filtro passa alta e $S H A R P$ ), gera como resultados a imagem filtrada, a máscara de magnitude e o mapa de susceptibilidade. 


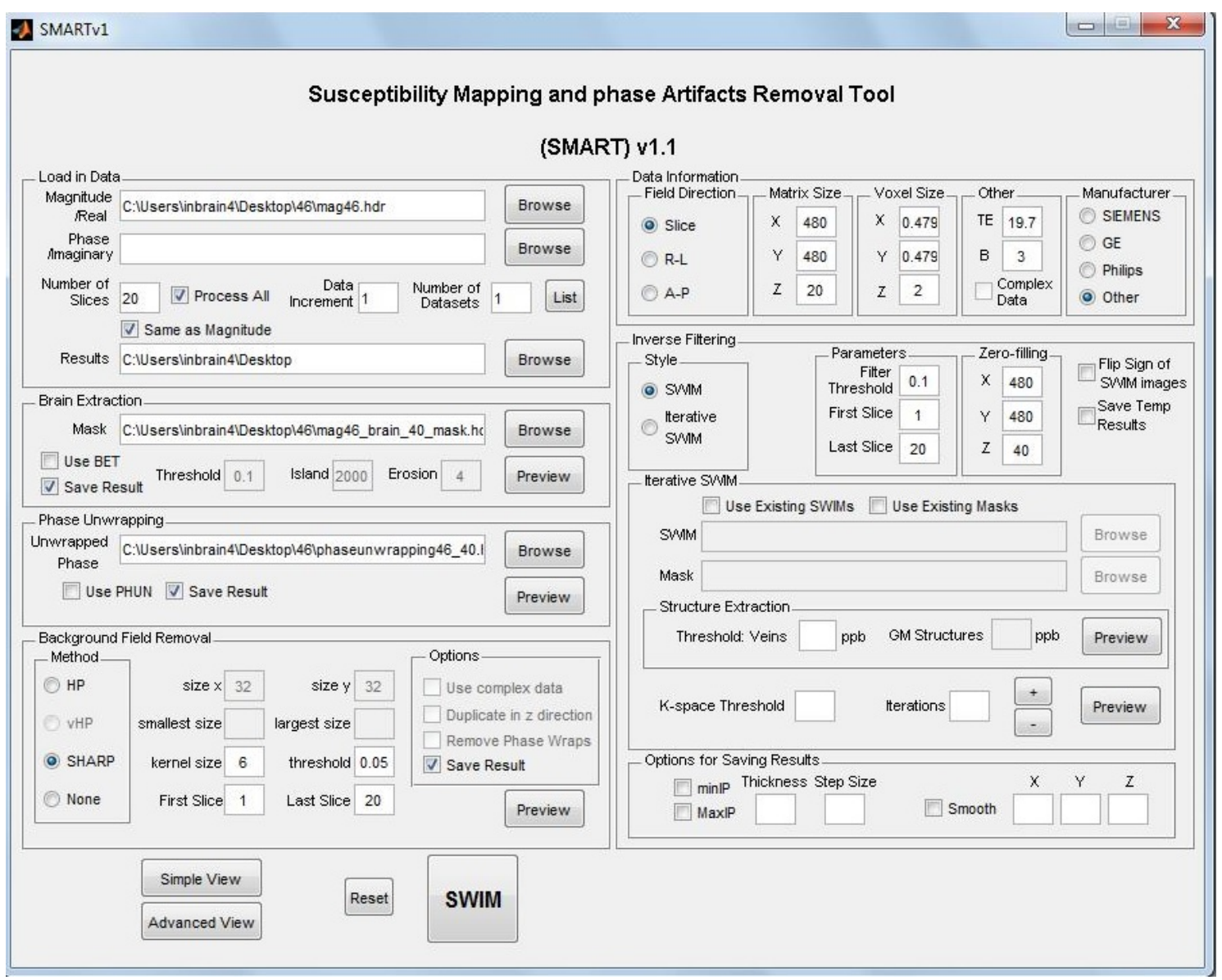

Figura 4.4: Tela principal do programa SMART (v1.1 2012)

Para processar o mapa QSM via somente programa SMART. É necessário selecionar no programa as funções BET para criação de uma máscara de magnitude e Unwrapped Phase/PHUN para desenrolar a imagem de fase. Caso contrário e mais indicado pela qualidade dos resultados, utiliza-se o programa FSL com a ferramenta BET para gerar a máscara de magnitude e com a ferramenta PRELUDE para desenrolar a imagem de fase. Como o programa FSL resulta imagens em formato Nifti é necessário converter para o formato Dicom ou Analyze para inserir no programa SMART.

Portanto neste trabalho foi adotado o seguinte processamento para o mapa de susceptibilidade:

- Remoção do crânio das imagens de magnitude e criação da máscara no programa FSL/BET/flirt. 
- Desenrolar das imagens de fase com ponderação da máscara de magnitude no programa FSL/PRELUDE.

- Conversão do formato Nifit das imagens de magnitude, mascara de magnitude e fase desenrolada para o formato Analyze.

- Inserção das imagens anteriores no programa SMART (Figura 4.4), e dos seus respectivos dados de tamanho da matriz, tamanho do voxel, TE e B.

- Seleção do filtro de campo de fundo para SHARP, com tamanho do núcleo (kernel size) igual a 6 e limiar (threshold) igual a 0,05.

Destacamos que embora o valor de susceptibilidade magnética seja absoluto o seu cálculo ainda possui alguns erros. Portanto, seguimos o conceito da literatura de usar o valor relativo de susceptibilidade magnética $\Delta \chi$ em relação a substância branca (que possui $\chi$ próxima de zero) (LOTFIPOUR et al., 2012; DEISTUNG et al., 2013).

\section{Mapa de susceptibilidade em diferentes resoluções de imagem}

A maioria dos artigos publicados sobre mapa de susceptibilidade magnética dos núcleos da base tem utilizado imagens de alta resolução (0,5x0,5x2,0mm) (SHMUELI et al., 2009; WHARTON; SCHAFER; BOWTELL, 2010; LOTFIPOUR et al., 2012; LANGKAMMER et al., 2012). A aquisição de imagens com alta resolução necessita de maior tempo de exame: consequentemente maior desconforto para o paciente e possível geração de artefato devido a movimento. Já a aquisição de imagens com baixa resolução $(1,0 \times 1,0 \times 2,0 \mathrm{~mm})$ necessitam de menos tempo de exame (YAO et al., 2009) mas apresenta uma perda de detalhes da imagem.

Neste trabalho, as imagens de alta resolução foram transformadas em baixa resolução por meio da remoção das bordas do espaço k da imagem complexa de alta resolução. Posteriormente foram processados os mapas de QSM e comparado os valores médios obtidos para a região dos núcleos 
da base. Os mapas de QSM com baixa resolução foram ampliados por interpolação no programa SPIN (http://www.mrc.wayne.edu/download.htm) para o mesmo tamanho de matriz que os mapas com alta resolução para facilitar a comparação entre os mapas.

\subsection{Segmentação das regiões de interesse}

A segmentação das regiões foi realizada manualmente no corte mais representativo da região de interesse e no mapa de susceptibilidade por um pesquisador treinado (Físico Médico e pós graduando Jeam Haroldo Oliveira Barbosa). Foi utilizado o programa Matlab com a função "roipoly"para realizar a segmentação e obtenção dos valores médios e desvio padrão de cada região. Além disso, para avaliar o viés de erro causado pela segmentação manual outros dois pesquisadores treinados (Físico Médico e pós graduando Antônio Carlos Senra Filho e Biológo e pós doutorando em Neurosciência Carlo Rondinoni) realizaram a segmentação e os resultados foram analisados apenas para os valores dos mapas de susceptibilidade de todos os sujeitos. Para análise de intra observador foi realizado mais uma vez a segmentação pelo pesquisador principal.

As regiões segmentadas do cérebro foram escolhidas de acordo com a revisão da literatura sobre regiões com acúmulo de ferro significativo (Tópico 1.2): Substância Negra (SN), Globo Pálido (GP), Núcleo Rubro (RN), Putâmen (PUT), Tálamo (THA), Substância Branca (WM), Substância Cinzenta (GM) e Núcleo Caudado (CN) (Figura 4.5) para ambos os lados. Foi utilizado como base o atlas anatômico Atlas of the Human Brain dos autores MAI J.K. e PAXINOS G. 


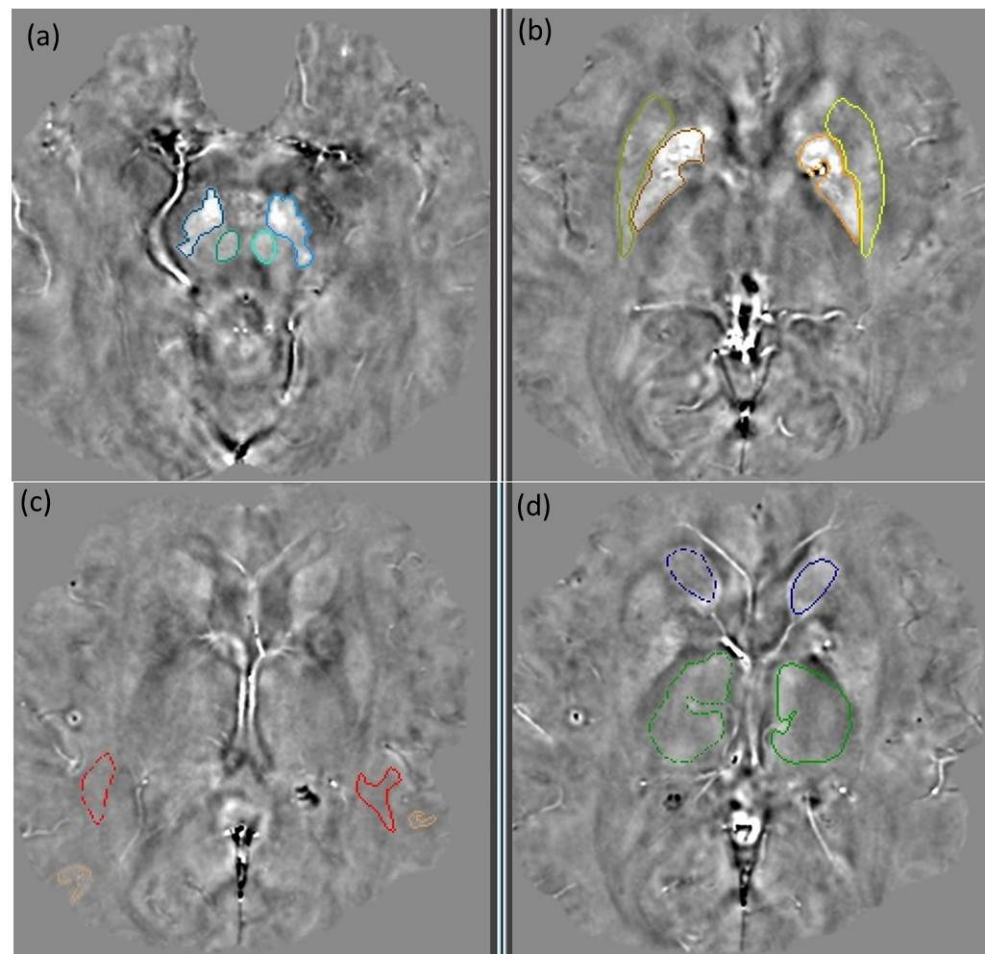

Figura 4.5: Exemplo de regiões segmentadas sobre diferentes fatias do mapa de susceptibilidade magnética (ppb). (a) Em azul escuro representada a Substancia Negra direita, azul claro a Substancia Negra esquerda, verde escuro e claro são o Núcleo Rubro direito e esquerdo, respectivamente. (b) Em marrom escuro indica Globo Pálido direito, laranja Globo Pálido esquerdo, em amarelo e bege indica Putâmen esquerdo e direito, respectivamente. (c) Em laranja indica Substância Cinzenta e vermelho representa Substância Branca de ambos os lados. (d) Em azul escuro representa a Núcleo Caudado e verde indica Tálamo

\subsection{Análises estatísticas}

Através de rotina escrita em Matlab foi possível utilizar a mesma ROI para obter o valor de R2, R2* e $\Delta \chi$. Desta forma geramos os três resultados para a mesma região. Fato que possibilitou a comparação da sensibilidade das técnicas para diferenciação de sujeitos saudáveis e pacientes com doença de Parkinson.

A confiabilidade da segmentação inter observador e intra observador foi avaliada por meio do coeficiente de correlação intra classe (CCI) no programa IBM-SPSS. O coeficiente CCI é muito usado para mensurar a homogeneidade 
das medias e é interpretado como uma descrição da variabilidade da medida realizada. O valor de CCI varia de 0 até 1 . Quanto mais próximo de 1 é o valor de CCI maior é a confiabilidade da segmentação analisado inter observador e intra observador.

Para avaliar o poder de diferenciação entre os pacientes e controles, foram analisados os valores de cada variável associada à técnica em ambos os grupos em diferentes regiões. Com estas populações foi utilizado o teste estatístico de Kolmogorov-Smirnov para analisar a normalidade das amostras e, para comparar os grupos com resultado de distribuição normal utilizamos o teste estatístico t de Student não pareado para amostras independentes. Um valor de $\mathrm{p}<0,05$ foi considerado estatisticamente significativo e os cálculos foram realizados no programa Origin.

Além disso, comparamos valores de susceptibilidade magnética obtidos com imagens de alta e baixa resolução por meio da avaliação dos coeficientes da regressão linear no programa Origin. Aplicamos também o teste estatístico t de Student para os valores de $\Delta \chi$ de controles e pacientes com doença de Parkinson obtidos com imagens de alta e baixa resolução para avaliar se a diferenciação entre os grupos se manteve.

De forma particular, foram comparados os valores de R2 com R2*, os valores de R2 com susceptibilidade mangética e os valores de R2* com susceptibilidade mangética através correlação linear no programa Origin. Esta avaliação foi abordada para estabelecer a equivalência entre os métodos de medida visando simplificar o procedimento a ser adotado na rotina clinica caso seja necessária à troca de um método pelo outro.

O resultado dos mapas $\mathrm{R} 2$, R2* e QSM para as regiões que apresentaram diferença significativa entre os controles e pacientes com doença de Parkinson ( $\mathrm{SN}, \mathrm{RN}, \mathrm{GP}$ ) foram analisados por meio das curvas ROC (do inglês receiver operating characteristic). A curva ROC é uma representação direta da habilidade da variável em classificar sujeitos em grupos (controles e pacientes) e oferece ao seu usuário um conjunto de 
diferentes regras de classificação, segundo os pontos de corte empírico que compõem a curva. Esta curva é capaz de indicar a probabilidade de um teste diagnóstico produzir um resultado positivo, caso o indivíduo seja portador da doença, que é chamada de sensibilidade do teste (eixo das ordenadas); e um resultado negativo, caso o indivíduo não porte a doença, que é chamada de especificidade (eixo das abscissas). A partir da área estimada sob a curva $R O C$, com o respectivo erro padrão ou intervalo de confiança, é possível comparar os mapas de R2, R2* e QSM e determinar a técnica mais sensível. A área sob a curva $R O C$ pode ser interpretada como a probabilidade do paciente ser diagnosticado como doente em relação a uma pessoa saudável. Onde o teste é classificado como incapaz de diagnosticar a doença quando assumi área igual a 0,5 e perfeito quando é igual a 1,0. 


\section{Capítulo}

\section{Resultados e Discussões}

Os resultados foram classificados em estudos específicos: análise estatística da segmentação; correlação linear entre R2, R2* e QSM com o acúmulo de ferro; correlação linear entre: R2 e QSM, R2* e QSM, R2 e R2*; mapas de R2, R2* e QSM para controles e pacientes com doença de Parkinson; diferença estatística entre controles saudáveis e pacientes com doença de Parkinson; comparação entre baixa e alta resolução para QSM; análise de múltiplos valores de T2.

\subsection{Análise estatística da segmentação}

Os resultados da análise de correlação linear para inter-observador (3 sujeitos) e intra-observador (1 sujeito repetido) da segmentação 2D das regiões de interesse estão nas Figuras 5.1 e 5.2 respectivamente. 


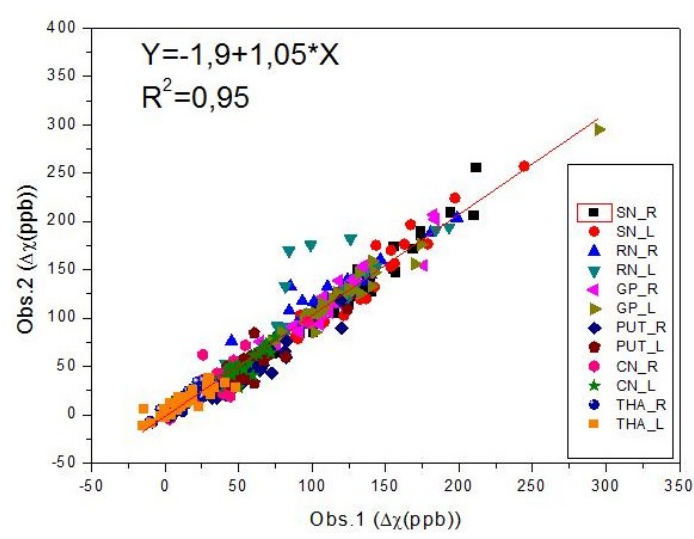

(a)

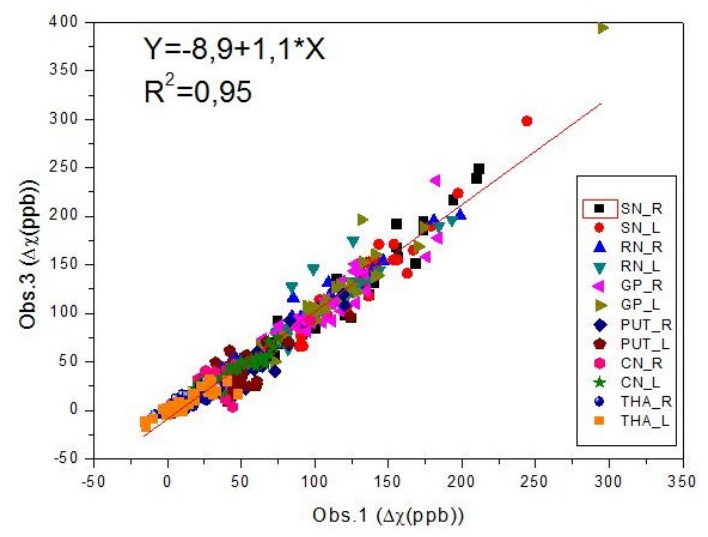

(b)

Figura 5.1: Análise inter-observador. Regressão linear para os valores de $\Delta \chi$ obtidos da segmentação realizada por dois observadores: (a) Observadores 1 e 2. (b) Observadores 1 e 3.

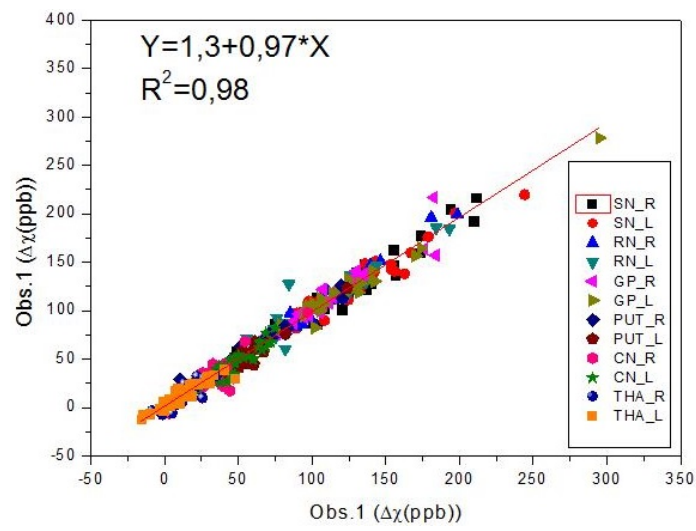

Figura 5.2: Análise intra-observador. Regressão linear para os valores de $\Delta \chi$ obtidos da segmentação realizada pelo observador 1 duas vezes.

Os coeficientes da regressão linear para análise inter-observador e intra-observador apresentaram ótima correlação, $\mathrm{R}^{2}$ próximo de 1 , validando o método de segmentação manual abordado.

A confiabilidade da segmentação analisada por coeficiente de correlação inter classe para inter-observador $(n=3)$ resultou em CCI igual a 0,970(0,964-0,975 com 95\% de confiança) que representa alta confiabilidade. Além disso, o coeficiente CCI determinado pela a análise intra-observador foi igual a 0,994(0,985-0,990 com 95\% de confiança), representando também 
alta confiabilidade. Sugerindo que mesmo existindo poucos pontos não correlacionados na Figura 5.1 e 5.2, a segmentação realizada pelos três pesquisadores e pelo pesquisador principal em duplicata apresentou pouca variabilidade da medida realizada.

Em resumo, consideramos que a segmentação manual adotada neste trabalho apresentou pouca variação dos resultados e pode ser usada para calcular os valores de R2, R2* e $\Delta \chi$. 


\subsection{Correlação linear entre R2, R2* e QSM com o acúmulo de ferro}

A concentração de ferro dos núcleos da base foi estimada de acordo com as curvas de acúmulo de ferro com o envelhecimento obtidas in vitro por Hallgren e Sourander (1958) (Tópico 2.3). Este trabalho tem sido a referência padrão para estimar a concentração de ferro in vivo e correlacionar com parâmetros de técnicas sensível ao acumulo de ferro (BARTZOKIS et al., 1993; XU; WANG; ZHANG, 2008; LANGKAMMER et al., 2010; LANGKAMMER et al., 2013). Abaixo apresentamos as curvas utilizadas por Hallgren e Sourander (1958) para estimar o conteúdo de ferro em certas regiões do cérebro:

$\begin{array}{lrl}\text { Globo Pálido } & y & =21,241-e^{(-0,09 x)}+0,37 \\ \text { Putâmen } & y & =14,621-e^{(-0,04 x)}+0,46 \\ \text { Núcleo Caudado } & y & =9,661-e^{(-0,05 x)}+0,33 \\ \text { Substância Branca } & y & =3,951-e^{(-0,10 x)}+0,31 \\ \text { Substância Cinzenta } & y & =21,241-e^{(-0,09 x)}+0,037\end{array}$

Onde " $y$ "representa valores de mg de Fe não heme por $100 \mathrm{~g}$ de peso fresco de tecido e " $x$ "é a idade em anos.

Contudo, para algumas regiões Hallgren e Sourander (1958) determinaram apenas o valor médio de concentração de ferro para todas as idades: Substância Negra 18,5( $\pm 6,5) \mathrm{mgFe} / 100 \mathrm{mg}$, Núcleo Rubro 19,5( $\pm 6,9) \mathrm{mgFe} / 100 \mathrm{mg}$ e Tálamo 4,8( $\pm 1,2) \mathrm{mgFe} / 100 \mathrm{mg}$.

A Figura 5.3, 5.4 e 5.5 mostra a correlação linear encontrada para os valores de R2, R2* e susceptibilidade magnética, respectivamente, com o acúmulo de ferro estimado para as regiões dos núcleos da base (esquerdo e direito) determinado para todos os sujeitos controles $(n=16)$. 


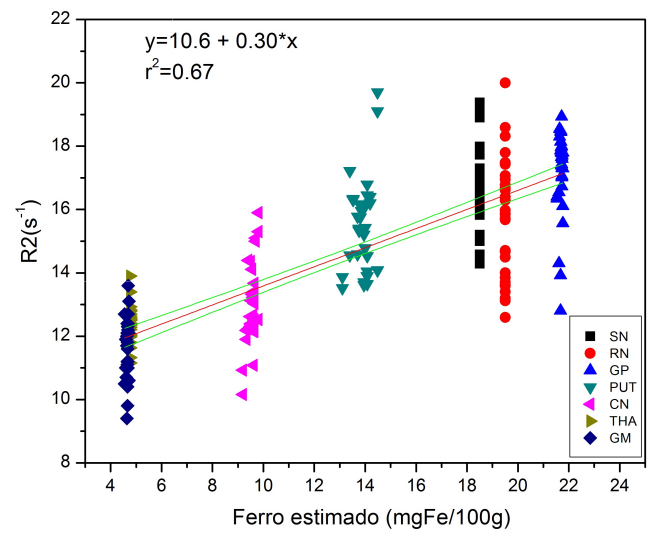

Figura 5.3: Correlação linear entre $R 2$ e acúmulo de ferro estimado considerando o efeito idade (HALLGREN; SOURANDER, 1958).

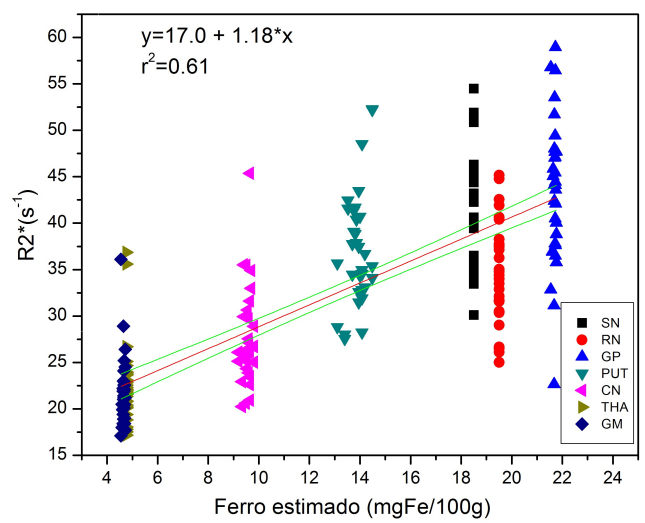

Figura 5.4: Correlação linear entre $R 2 *$ e acúmulo de ferro estimado considerando o efeito idade (HALLGREN; SOURANDER, 1958).

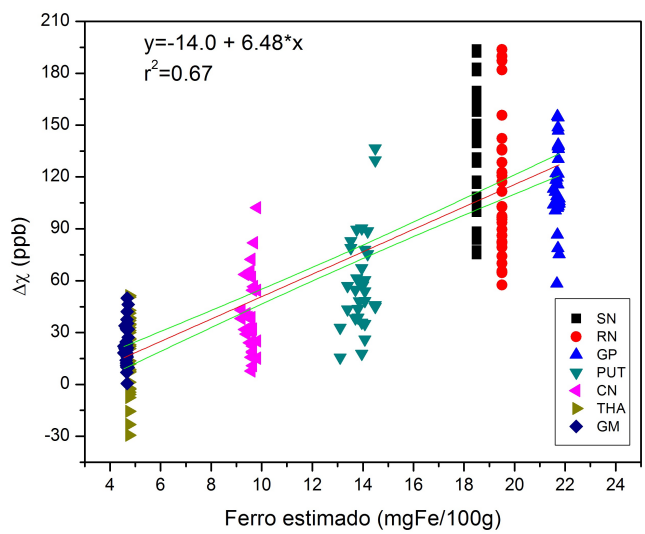

Figura 5.5: Correlação linear entre $\Delta \chi$ e acúmulo de ferro estimado considerando o efeito idade (HALLGREN; SOURANDER, 1958). 
A Tabela 5.1 permite comparar os coeficientes de regressão linear encontrados neste trabalho com vários achados da literatura. Em alguns dos estudos específicas regiões dos núcleos da base foram incluídas e outras excluídas. Para comparação de nossos resultados, determinamos os coeficientes de regressão com apenas regiões abordadas no estudo comparado.

\begin{tabular}{|c|c|c|c|c|c|c|c|}
\hline Estudo & Referência & $\begin{array}{l}\text { Coef. } \\
\text { Angular } \\
\end{array}$ & $\begin{array}{l}\text { Coef. } \\
\text { Linear }\end{array}$ & $\mathbf{r}^{2}$ & Regiões & $\begin{array}{l}\text { Campo } \\
\text { (T) }\end{array}$ & [Ferro] \\
\hline $\mathrm{R} 2$ & Vymazal et al. (1999) & 0,19 & 10,3 & 0,83 & $\begin{array}{l}\text { SN,RN,GP,PUT, } \\
\text { CN,THA,GM }\end{array}$ & 1,5 & HS \\
\hline $\mathrm{R} 2$ & Este trabalho & 0,30 & 10,6 & 0,67 & $\begin{array}{l}\text { SN,RN,GP,PUT, } \\
\text { CN,THA,GM }\end{array}$ & 3,0 & HS \\
\hline $\mathrm{R} 2$ & Langkammer et al. (2010) & 0,40 & 8,5 & 0,67 & $\begin{array}{l}\text { GP,PUT,CN,THA, } \\
\text { GM }\end{array}$ & 3,0 & ICP \\
\hline $\mathrm{R} 2$ & Este trabalho & 0,32 & 10,4 & 0,75 & $\begin{array}{l}\text { GP,PUT,CN,THA, } \\
\text { GM }\end{array}$ & 3,0 & HS \\
\hline $\mathrm{R} 2 *$ & $\begin{array}{l}\text { Martin, Wieler e Gee } \\
\text { (2008) }\end{array}$ & $1,0^{*}$ & 17,5 & 0,81 & $\begin{array}{l}\text { SN,RN,GP,PUT, } \\
\text { CN,WM }\end{array}$ & 3,0 & HS \\
\hline $\mathrm{R} 2 *$ & Este trabalho & $1,2 *$ & 17,4 & 0,55 & $\begin{array}{l}\text { SN,RN,GP,PUT, } \\
\text { CN,WM }\end{array}$ & 3,0 & HS \\
\hline $\mathrm{R} 2 *$ & Yao et al. (2009) & $1,2^{*}$ & 14,2 & 0,87 & GP,PUT,CN,THA & 3,0 & HS \\
\hline $\mathrm{R} 2 *$ & Este trabalho & $1,3 *$ & 16,6 & 0,63 & GP,PUT,CN,THA & 3,0 & HS \\
\hline $\mathrm{R} 2 *$ & Langkammer et al. (2010) & $2,7 *$ & 14,2 & 0,90 & $\begin{array}{l}\text { GP,PUT,CN,THA, } \\
\text { WM }\end{array}$ & 3,0 & ICP \\
\hline $\mathrm{R} 2 *$ & Este trabalho & $1,3^{*}$ & 16,3 & 0,69 & $\begin{array}{l}\text { GP,PUT,CN,THA, } \\
\text { WM }\end{array}$ & 3,0 & HS \\
\hline$\Delta \chi$ & Wharton e Bowtell (2010) & $7,5^{*}$ & -- & 0,96 & $\begin{array}{l}\text { SN,RN,GP,PUT, } \\
\text { CN,THA,GM }\end{array}$ & 3,0 & HS \\
\hline$\Delta \chi$ & Este trabalho & $6,5^{*}$ & 一- & 0,67 & $\begin{array}{l}\text { SN,RN,GP,PUT, } \\
\text { CN,THA,GM }\end{array}$ & 3,0 & HS \\
\hline$\Delta \chi$ & Langkammer et al. (2012) & $8,9 *$ & -- & 0,75 & GP,PUT,CN,THA & 3,0 & ICP \\
\hline$\Delta \chi$ & Este trabalho & $5,8^{*}$ & - & 0,70 & GP,PUT,CN,THA & 3,0 & HS \\
\hline
\end{tabular}

Tabela 5.1: Coeficientes de regressão linear obtidos e encontrados na literatura. A unidade do coeficiente angular de ambos $R 2$ and $R 2 *$ é $s^{-1} / m g F e / 100 g$ e para $\Delta \chi$ é $p p b / m g F e / 100 g .{ }^{*}$ Os coeficientes angular e linear foram estimados a partir do gráfico.

O valor do coeficiente angular para a regressão linear de R2 e ferro 
estimado encontrado neste estudo foi $0,30 \mathrm{~s}^{-1} / \mathrm{mgFe} / 100 \mathrm{~g}$. Valor muito maior quando comparado com o valor obtido por Vymazal et al. (1999) $\left(0,19 s^{-1} / m g F e / 100 g\right)$. A justificativa é devido a intensidade reduzida de campo $(1,5 T)$ utilizada no experimento de Vymazal et al. (1999). Fato que resulta em menores valores de R2 para todas as regiões devido à dependência direta da taxa de relaxação com a intensidade do campo. Quando nossos resultados são comparados com de Langkammer et al. (2010) (Tabela 5.1) em estudoin vitro da correlação linear dos valores de relaxometria e a concentração de ferro via espectroscopia de massa encontramos coeficientes de correlação linear muito próximos.

Encontramos coeficientes da regressão linear de R2* e concentração de ferro muito próximos dos resultados encontrados por Martin, Wieler e Gee (2008)e Yao et al. (2009) (Tabela 5.1). Diferentemente do estudo realizado com cérebros de cadáver por Langkammer et al. (2010), onde o acúmulo de ferro foi determinado por meio de espectroscopia de massa.

O coeficiente angular da regressão linear entre $\Delta \chi$ e concentração de ferro foi muito próximo ao de Wharton e Bowtell (2010) (Tabela 5.1). No estudo de Wharton e Bowtell (2010) foi utilizado a técnica mais acurada para quantificar susceptibilidade magnética: múltiplas orientações. Excluindo algumas regiões e comparando com os resultados de Langkammer et al. (2012) obtidos com cadáveres não fixados obtivemos valores de coeficiente angular muito próximos, onde a diferença pode ser justificada por nosso experimento ser realizado in vivo.

Os resultados obtidos neste tópico (5.2) foram publicados e apresentados no principal congresso da área: International Society for Magnetic Resonance in Medicine 20-26 de Abril de 2013 (Salt Lake City EUA) (BARBOSA et al., 2013). 


\subsection{Correlação linear entre R2 com QSM, R2* com QSM, R2 com R2* nos sujeitos controles}

A Figura 5.6 mostra a correlação linear encontrada para os valores de R2 e $\Delta \chi$ para as regiões dos núcleos da base (esquerdo e direito) determinado para os sujeitos controles $(n=16)$. Este estudo foi realizado apenas nos sujeitos controles com intuito de avaliar a correlação entre a técnica sem a implicação de outras variáveis.

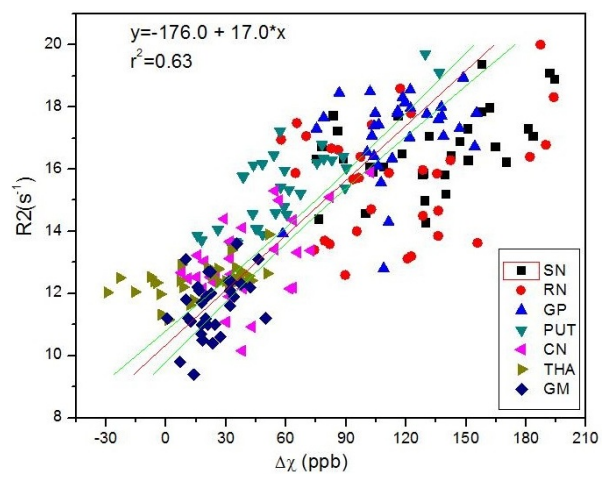

Figura 5.6: Correlação linear entre $R 2$ e $\Delta \chi$ nas diferentes regiões avaliadas neste estudo.

A Figura 5.7 mostra a correlação linear encontrada para os valores de $\mathrm{R}^{*}$ e $\Delta \chi$ para as regiões dos núcleos da base (esquerdo e direito) determinadas para os sujeitos controles $(n=16)$.

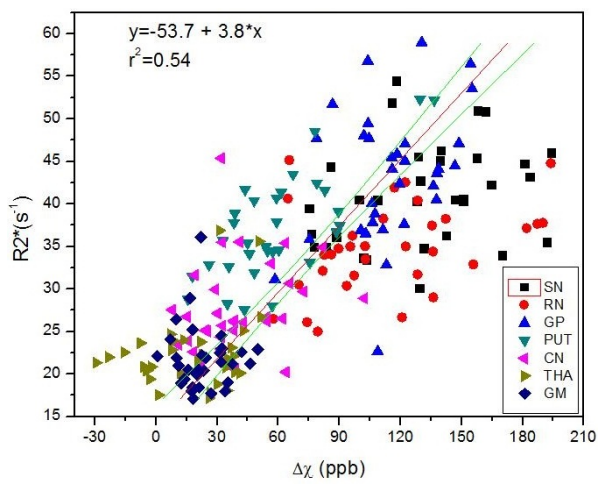

Figura 5.7: Correlação linear entre $R 2^{*}$ e $\Delta \chi$ nas diferentes regiões avaliadas neste estudo.

Obtemos valores medianos de coeficientes de regressão linear $r^{2}=0,63$ 
e $\mathrm{r}^{2}=0,54$ respectivamente para a correlação de $\mathrm{R} 2$ com $\Delta \chi$ e de R2* com $\Delta \chi$. Esses coeficientes podem ser justificados pelo fato da relaxometria não depender apenas da variação da susceptibilidade magnética do tecido, mas também com outros fatores como o conteúdo de água, o coeficiente de difusão da água e o tamanho médio dos vasos (KENNAN; ZHONG; GORE, 1994; WEISSKOFF et al., 1994; KISELEV; POSSE, 1999; TROPRèS et al., 2001). O sinal de RM decai com o efeito de difusão da água, porque as imagens de RM são adquiridas levando em conta o não movimento do spins nucleares. Portanto a difusão da água pode reduz o sinal e tornar baixa a dependência da relaxometria com a susceptibilidade. Já o tamanho dos vaso influencia em tecido muito vascularizado, visto que o sangue deoxigenado é paramagnético e, então, reduz a taxa de relaxometria abruptamente.

Com intuito de analisar a inter dependência das taxas de relaxometria de R2 e de R2* foi obtido à regressão linear entre os valores para as regiões dos núcleos da base (esquerdo e direito dos sujeitos controles $(n=16)$ ).

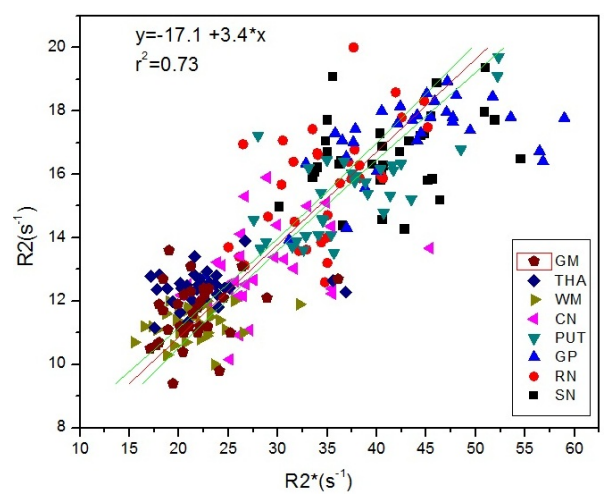

Figura 5.8: Correlação linear entre $R 2$ com $R 2^{*}$ nas diferentes regiões avaliadas neste estudo.

Foi observado maior coeficiente de regressão linear para a correlação de R2 com R2* do que R2 com $\Delta \chi$ e R2* com $\Delta \chi$. Indicando que os valores de R2 e R2* possuem maior relação em comum do que com susceptibilidade magnética. 


\subsection{Mapas de R2, R2* e QSM para controles e pacientes com doença de Parkinson}

Em geral, todos os mapas de R2 de controles e de pacientes apresentaram grande diferença de contraste para os núcleos da base em relação ao tecido vizinho (Figura 5.9).
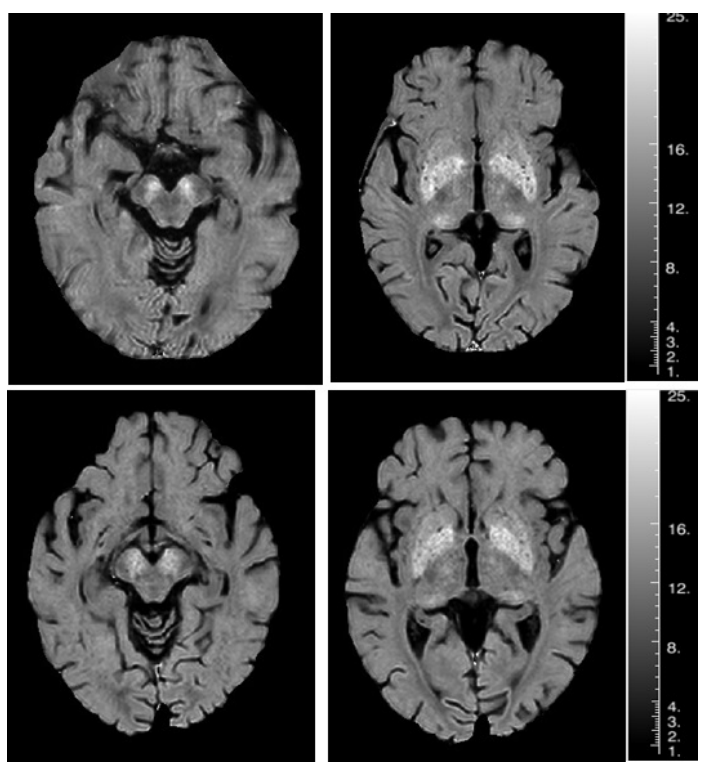

Figura 5.9: Exemplos de mapas de $R 2$ para sujeito controle (mulher com 61 anos na parte superior) e para sujeito paciente com doença de Parkinson (mulher com 60 anos na parte inferior). A unidade da escala dos mapas é $s^{-1}$.

No entanto, não houve diferença visível nos núcleos da base para os mapas de R2 dos controles e dos pacientes. Desta forma, foi necessário obter por segmentação os valores de cada região e calcular estatisticamente a diferença significativa.

Todos os mapas de R2*, controles e pacientes, apresentaram grande diferença de contraste para os núcleos da base em relação ao tecido ao redor (Figura 5.10). 


\section{4 - Mapas de R2, R2* e QSM para controles e pacientes com doença de Parkinson86}
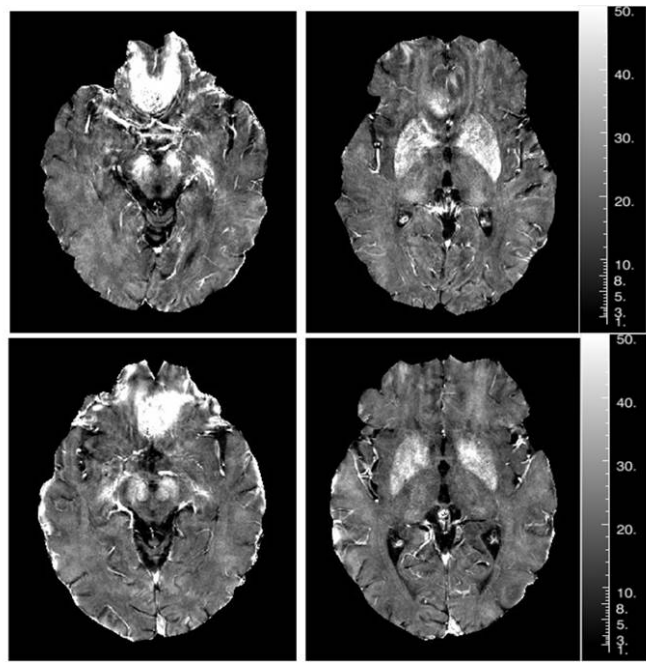

Figura 5.10: Exemplos de mapas de $R 2 *$ para sujeito controle (mulher com 61 anos na parte superior) e para sujeito paciente com doença de Parkinson (mulher com 60 anos na parte inferior). A unidade da escala dos mapas é $s^{-1}$.

Da mesma forma que nos mapas de R2, não houve diferença visível nos núcleos da base para os mapas de R2* dos controles e dos pacientes, necessitando também obter por segmentação os valores de cada região e calcular estatisticamente a diferença significativa. Além disso, nos mapas de R2* foram observados artefatos para a região dos seios nasais que possuem ar e tecido, fato justificado pela alta diferença de susceptibilidade magnética nesta região e, portanto aumento da taxa de relaxometria R2*. 
Os mapas quantitativos de susceptibilidade magnética para um controle e um paciente são mostrados na Figura 5.11.

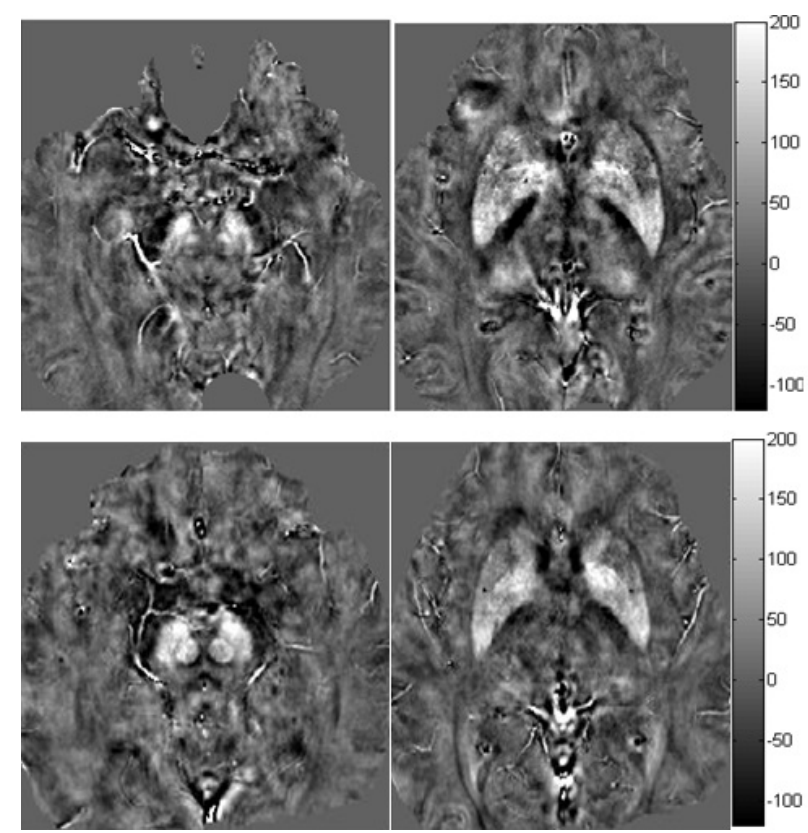

Figura 5.11: Exemplos de mapas de $\Delta \chi$ para sujeito controle (mulher com 61 anos na parte superior) e para sujeito paciente com doença de Parkinson (mulher com 60 anos na parte inferior). A unidade da escala dos mapas é ppb.

Embora no mapa quantitativo de susceptibilidade magnética tem sido visualizado alguns artefatos ao redor de algumas veias e dos seios nasais, foi observado um grande contraste entre os núcleos da base e o tecido ao redor. De forma semelhante aos nossos resultados preliminares com mapa QSM obtidos com filtro passa alta (BARBOSA; FILHO; SALMON, 2012). Porém, a análise visual não foi suficiente para diferenciar controles de pacientes, necessitando também do estudo da diferença significativa dos valores médios para cada região.

Em geral, os mapas de susceptibilidade magnética não apresentaram algumas regiões do cérebro como a parte mais externa e algumas partes dos seios nasais que foram excluídos para evitar a propagação de artefatos nos mapas de QSM. Já que estas regiões de interface (tecido e ar) possuem alta diferença de susceptibilidade magnética, constituindo assim uma limitação conhecida deste método. 


\section{4 - Mapas de R2, R2* e QSM para controles e pacientes com doença de Parkinson88}

Por meio de análise estatística, observamos que os valores médios de R2, R2* e $\Delta \chi$ para todas as regiões dos núcleos da base de todos os sujeitos controles e pacientes apresentaram distribuição normal de população por meio do teste de Kolmogorov-Smirnov. Portanto o grupo dos controles e dos pacientes contendo os valores de R2, R2* e $\Delta \chi$ puderam ser avaliados por meio do teste t de Student para determinar a existência de diferença significativa entre os grupos.

Primeiramente, avaliamos estatisticamente a influência da idade dos sujeitos nos valores quantitativos de relaxometria e susceptibilidade magnética. Os valores de R2, R2* e $\Delta \chi$ não apresentaram relação linear com a idade, porque todos os indivíduos tinham mais de 50 anos e o aumento da concentração de ferro é quase constante para idosos (HALLGREN; SOURANDER, 1958).

O valor médio e o desvio padrão de $\mathrm{R} 2, \mathrm{R} 2 *$ e $\Delta \chi$ para as regiões dos núcleos da base de todos os controles $(n=16)$ e de todos os pacientes $(n=14)$ estão nas Figura 5.12, 5.13, 5.14 e a Tabela 5.2.

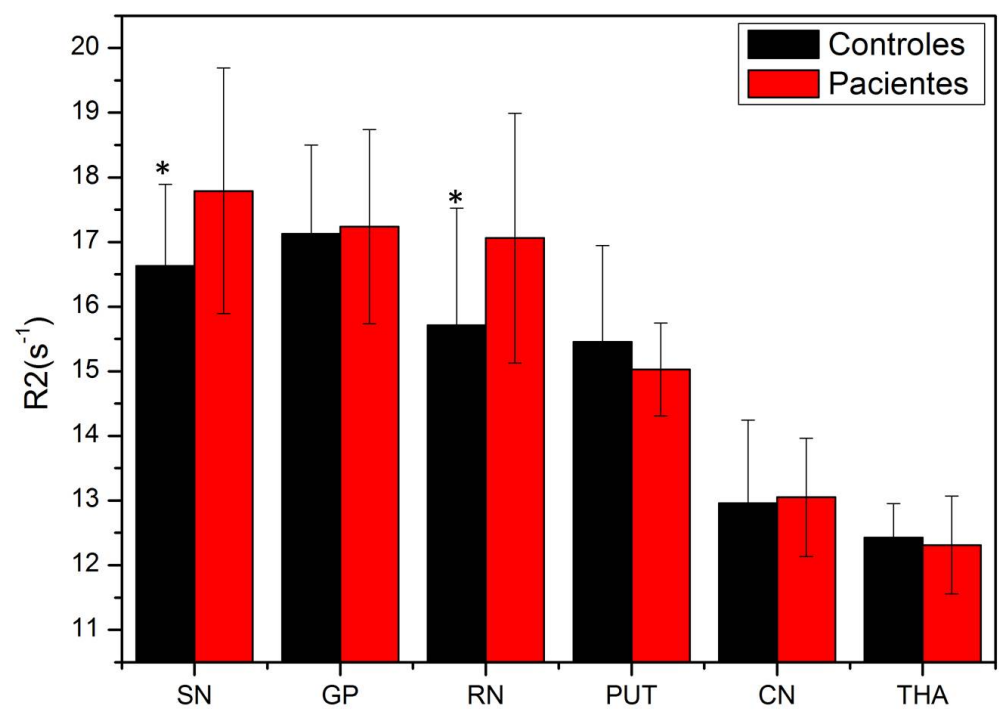

Figura 5.12: Valores médios e desvio padrão de $R 2$ dos controles e pacientes com doença de Parkinson. $*(p<0,01)$. 


\section{4 - Mapas de R2, R2* e QSM para controles e pacientes com doença de Parkinson89}

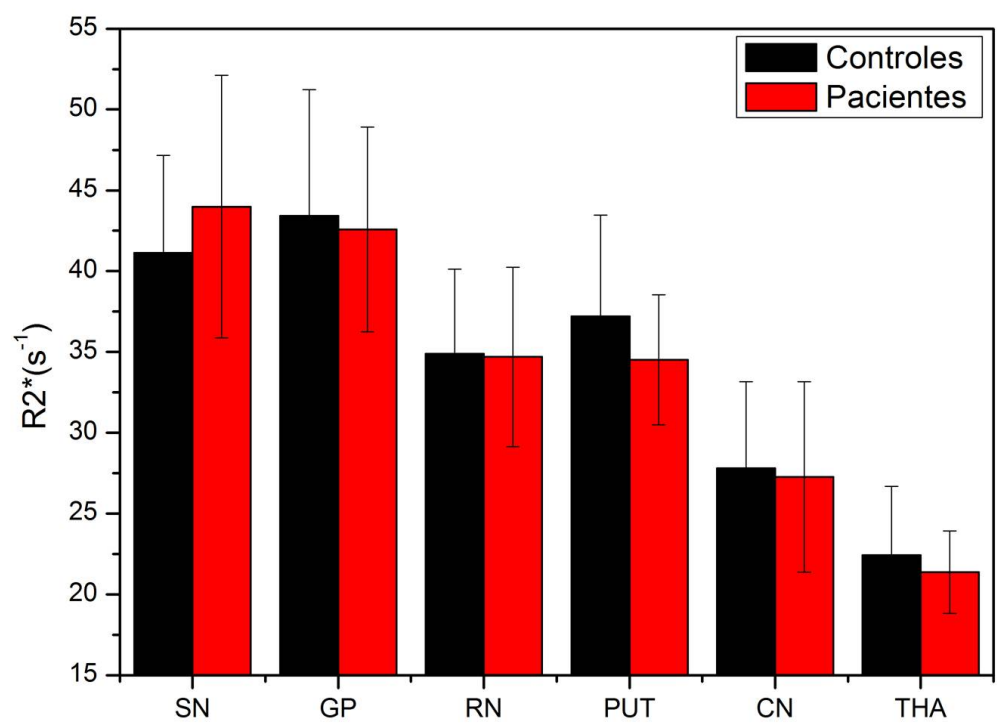

Figura 5.13: Valores médios e desvio padrão de $R 2^{*}$ dos controles e pacientes com doença de Parkinson.

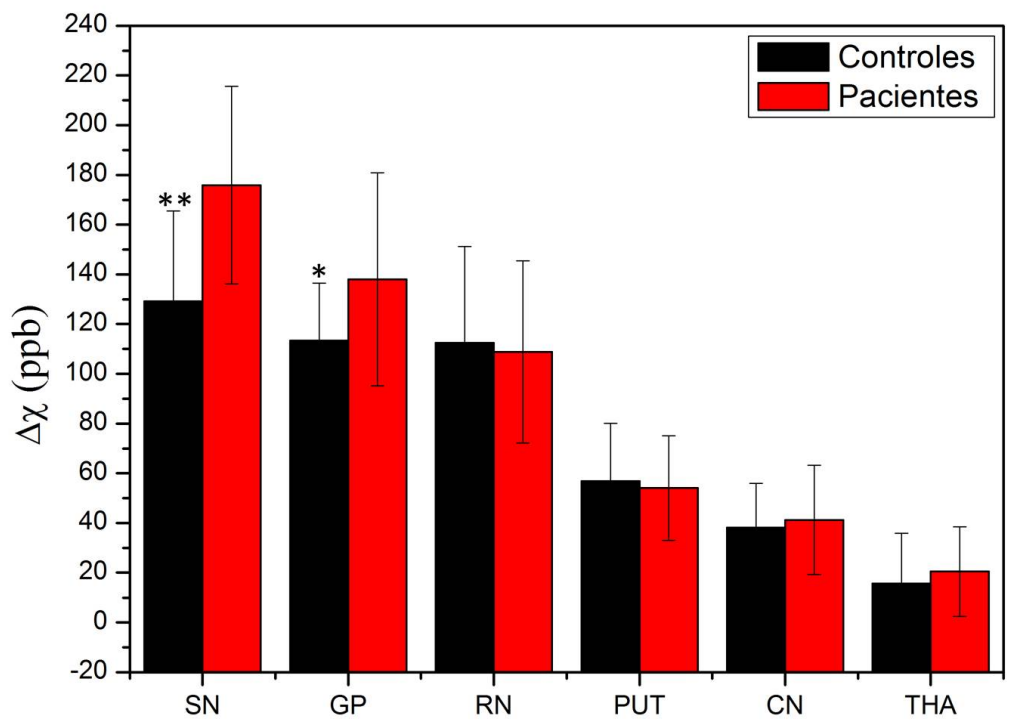

Figura 5.14: Valores médios e desvio padrão de $\Delta \chi$ dos controles e pacientes com doença de Parkinson. $*(p<0,01) * *(p<0,001)$. 
5.4 - Mapas de R2, R2* e QSM para controles e pacientes com doença de Parkinson90

\begin{tabular}{|c|c|c|c|c|}
\hline Мара & Região & Controles & Pacientes & Significância estatística \\
\hline R2 & Substância negra* & $16,6(1,3)$ & $17,8(1,9)$ & $\mathrm{p}=0,007 *$ \\
\hline R2 & Núcleo rubro* & $15,7(1,8)$ & $17,1(1,9)$ & $\mathrm{p}=0,007^{*}$ \\
\hline R2 & Globo pálido & $17,1(1,4)$ & $17,2(1,5)$ & $\mathrm{p}=0,77$ \\
\hline R2 & Putâmen & $15,4(1,5)$ & $15,0(0,7)$ & $p=0,17$ \\
\hline R2 & Núcelo caudado & $12,9(1,3)$ & $13,0(0,9)$ & $p=0,75$ \\
\hline R2 & Tálamo & $12,4(0,5)$ & $12,3(0,7)$ & $p=0,50$ \\
\hline $\mathrm{R} 2 *$ & Substância negra & $42,1(6,0)$ & $44,0(8,1)$ & $\mathrm{p}=0,12$ \\
\hline R2* & Núcleo rubro & $34,9(5,2)$ & $34,7(5,5)$ & $\mathrm{p}=0,89$ \\
\hline $\mathrm{R} 2 *$ & Globo pálido & $43,4(7,8)$ & $42,6(6,3)$ & $\mathrm{p}=0,65$ \\
\hline $\mathrm{R} 2 *$ & Putâmen & $37,2(6,3)$ & $34,5(4,0)$ & $\mathrm{p}=0,057$ \\
\hline $\mathrm{R} 2 *$ & Núcelo caudado & $27,8(5,3)$ & $27,3(5,9)$ & $\mathrm{p}=0,72$ \\
\hline $\mathrm{R} 2 *$ & Tálamo & $22,4(4,2)$ & $21,4(2,5)$ & $p=0,26$ \\
\hline$\Delta \chi$ & Substância negra** & $129,1(36,4)$ & $175,8(39,7)$ & $\mathrm{p}<0,001 * *$ \\
\hline$\Delta \chi$ & Núcleo rubro & $112,4(38,8)$ & $108,0(36,6)$ & $\mathrm{p}=0,71$ \\
\hline$\Delta \chi$ & Globo pálido* & $113,4(23,0)$ & $138(42,8)$ & $\mathrm{p}=0,007$ \\
\hline$\Delta \chi$ & Putâmen & $56,9(23,3)$ & $54,0(21,1)$ & $p=0,63$ \\
\hline$\Delta \chi$ & Núcelo caudado & $38,2(17,8)$ & $41,2(22,0)$ & $\mathrm{p}=0,55$ \\
\hline$\Delta \chi$ & Tálamo & $15,7(20,1)$ & $20,4(17,9)$ & $p=0,35$ \\
\hline
\end{tabular}

Tabela 5.2: Resultado do teste $t$ de Student para o grupo controle e de pacientes com doença de Parkinson. A unidade de ambos $R 2$ e $R 2 *$ é $s^{-1}$ e de $\Delta \chi$ é $p p b$. 
Dentre todas as técnicas apenas a relaxometria R2 e QSM encontraram diferenças significativas $(p=0,007$ e $p<0,001$ respectivamente) entre controles e pacientes para substância negra (Figura 5.12, 5.14 e a Tabela 5.2). Estes resultados estão de acordo com outros estudos in vivo que encontraram diferença significativa para a substância negra compacta com valores de R2 (RYVLIN et al., 1995; KOSTA et al., 2006) e com valores de $\Delta \chi$ (LOTFIPOUR et al., 2012). Além disso, nossos resultados também concordam com estudos de cérebros de cadáver que diferenciaram o acúmulo de ferro para controles saudáveis e para pacientes com doença de Parkinson na substância negra e substância negra compacta (DEXTER et al., 1987; SOFIC et al., 1988; DEXTER et al., 1989; GRIFFITHS et al., 1999). Estes estudos destacam que a doença de Parkinson apresenta mudanças químicas e físicas principalmente na substância negra: morte dos neurônios dopaminérgicos e acúmulo de ferro.

Diferentemente de Vymazal et al. (1999)nós encontramos diferença significativa $(p=0,007)$ para os valores de R2 do núcleo rubro (Figura 5.12) entre os grupos. A causa pode ser devido ao baixo campo usado por Vymazal et al. (1999), porque o valor de R2 aumenta quanto maior for campo e consequentemente a sensibilidade para diferenciar os grupos.

Pela literatura consultada acreditamos que por primeira vez está sendo reportado os valores de susceptibilidade magnética para todos os núcleos da base em ambos os grupos controles e pacientes com doença de Parkinson. Além da diferenciação entre os grupos através da SN, também encontramos diferença significativa para a região do globo pálido $(\mathrm{p}=0,007)$ (Figura 5.14). Este achado também concorda com estudos de cérebros de cadáver que diferenciaram o acúmulo de ferro para controles saudáveis e para pacientes com doença de Parkinson no globo pálido (GRIFFITHS et al., 1999).

O mapa de relaxometria $\mathrm{R} 2 *$ para todas as regiões dos núcleos da base não apresentou diferença significativa entre os grupos (Tabela 5.2), diferentemente de alguns trabalhos da literatura (GORELL et al., 1995; 
5.4 - Mapas de R2, R2* e QSM para controles e pacientes com doença de Parkinson92

GRAHAM; PALEY; GRüNEWALD, 2000; MARTIN; WIELER; GEE, 2008; BAUDREXEL et al., 2010; PERAN et al., 2010; DU et al., 2011). O valor de R2* pode ter sido influenciado pela a inomogeneidade do campo magnético não relacionado com o acúmulo de ferro (GROGER; BERG, 2012) e pelo efeito da difusão dos spins neste campo inomogênio (KENNAN; ZHONG; GORE, 1994). Outro fator que pode ter influenciado é não subdivisão da substância negra, que por exemplo, Martin, Wieler e Gee (2008) a dividiu em quatro regiões: SN compacta medial, SN compacta lateral, SN reticulada medial e SN reticulada lateral.

De acordo com a revisão da literatura existem resultados de R2 e R2* controversos para a diferenciação de grupo de pacientes com doença de Parkinson e grupo controle. Apenas 4 de 8 trabalhos com medida de R2 (RYVLIN et al., 1995; GORELL et al., 1995; BARTZOKIS et al., 1999; KOSTA et al., 2006; GRAHAM; PALEY; GRüNEWALD, 2000; VYMAZAL et al., 1999; MONDINO et al., 2002; ANTONINI et al., 1993) e 6 de 8 trabalhos com medida de R2* (GORELL et al., 1995; GRAHAM; PALEY; GRüNEWALD, 2000; MARTIN; WIELER; GEE, 2008; BAUDREXEL et al., 2010; PERAN et al., 2010; DU et al., 2011; BRAFFMAN et al., 1989; ORDIDGE et al., 1994) encontram diferença significativa entre os grupos para a região da substância negra. A inconsistência dos resultados da literatura pode ser justificada pela seleção de diferentes parâmetros para aquisição das imagens: tamanho da resolução da imagem, espessura do corte; segmentação: definição da região de interesse da substância negra e segmentação 2D ou 3D. Além disso, ainda não é conhecida a influência simultânea da perda celular e do acúmulo de ferro nas taxas de relaxação (GROGER; BERG, 2012).

Para mostrar o quanto é a dispersão dos resultados obtidos para as regiões determinadas com diferença significativa (R2: $\mathrm{SN}$ e $\mathrm{RN} ; \Delta \chi$ : $\mathrm{SN}$ e GP), plotamos os valores de R2 e $\Delta \chi$ em relação à idade (Figura 5.15 e 5.16). 


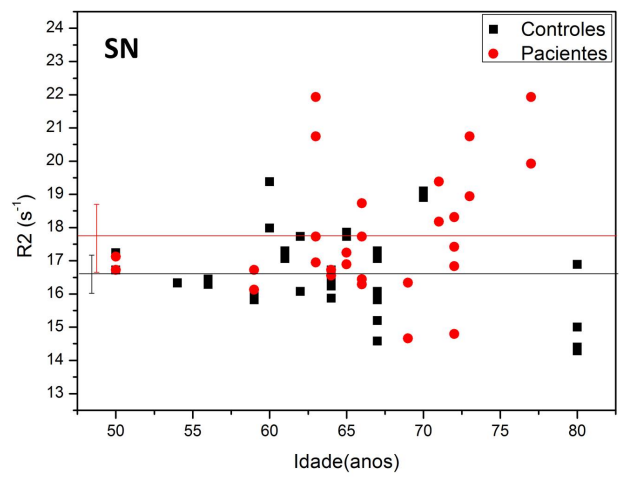

(a)

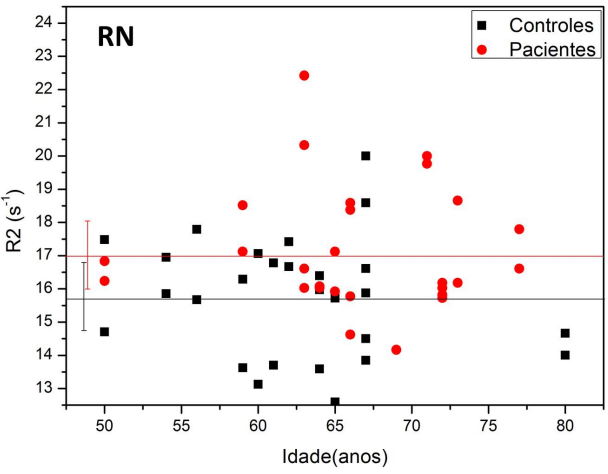

(b)

Figura 5.15: Valores de $R 2$ para a região da $S N$ (a) e $R N$ (b) para controles e pacientes em relação à idade. A linha vermelha indica o valor médio com $o$ respectivo desvio padrão para pacientes e a linha preta indica o mesmo para controles.

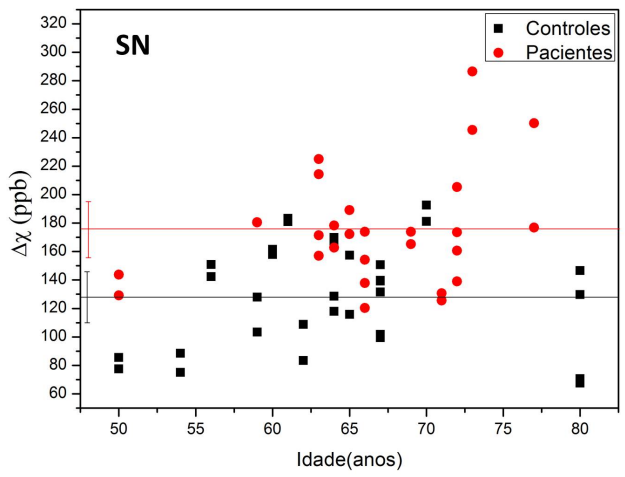

(a)

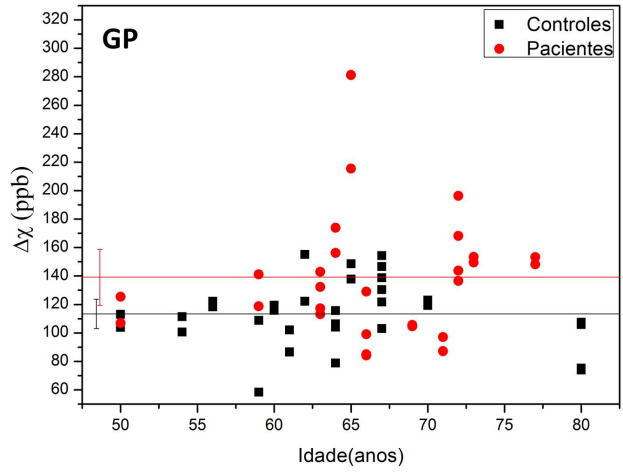

(b)

Figura 5.16: Valores de $\Delta \chi$ para a região da $S N$ (a) e GP (b) para controles e pacientes em relação a idade. A linha vermelha indica o valor médio com o respectivo desvio padrão para pacientes e a linha preta indica o mesmo para controles.

Em resumo, a diferença significativa encontrada entre os grupos para os valores de $\mathrm{R} 2$ e $\Delta \chi$ indica um possível acúmulo de ferro. Contudo, destacamos também que a mudança dos valores de R2 pode ser atribuída a uma mudança na concentração de água e ou na distribuição das moléculas de 


\section{4 - Mapas de R2, R2* e QSM para controles e pacientes com doença de Parkinson94}

água livre. Quando água livre se torna agua ligada o valor de R2 aumenta. Mudanças nos valores de $\Delta \chi$ também podem ser devido ao acúmulo de outros íons paramagnéticos $\left(\mathrm{Cu}^{+2}\right)$ mudança de estados de oxidação dos íons paramagnéticos e o acoplamento entre eles (LOTFIPOUR et al., 2012). Porém a forte correlação deste parâmetro com a concentração de ferro sugere que este metal seja o fator dominante.

Com intuito de determinar a técnica mais sensível e específica para a classificação de sujeitos controles e pacientes geramos algumas curvas ROC para os valores de R2, R2* e $\Delta \chi$ para as regiões que apresentaram diferença significativa entre os grupos controles e pacientes (figuras 5.17, 5.18 e 5.19).

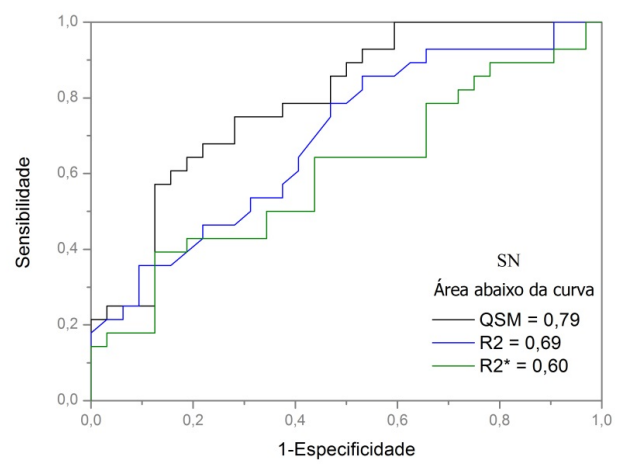

Figura 5.17: Curva ROC para os mapas de $R 2$, $R 2 *$ e $Q S M$ da região da substância negra (SN).

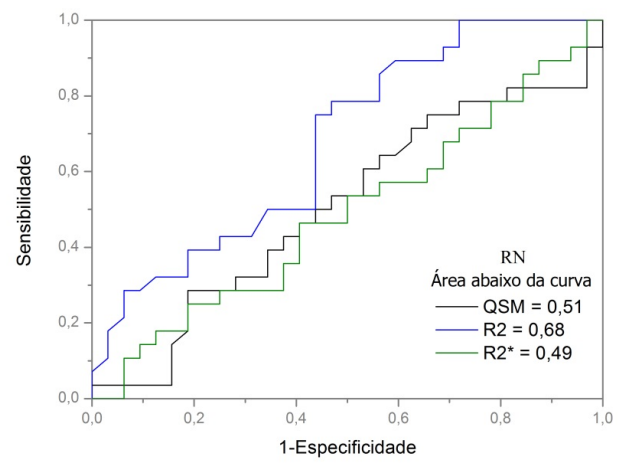

Figura 5.18: Curva $R O C$ para os mapas de $R 2$, $R 2 *$ e $Q S M$ da região do núcleo rubro $(R N)$. 


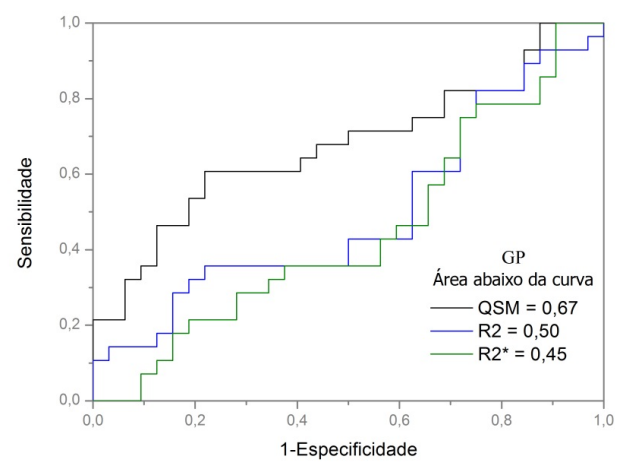

Figura 5.19: Curva ROC para os mapas de $R 2, R 2^{*}$ e $Q S M$ da região do globo pálido (GP).

A área sob a curva $R O C$ representa a probabilidade que tal técnica é capaz de diferenciar um paciente com doença e um controle como saudável. Desta forma, podemos dizer que para a região da SN o mapa QSM possui maior probabilidade de classificar como doença de Parkinson (área $=0,79$ ) do que o mapa de R2 (área=0,69) (Figura 5.17). Resultado concordante com a diferença dos valores de $\mathrm{p}$ para o test t de Studententre os grupos usando o mapa de $Q S M(\mathrm{P}<0,001)$ e $\mathrm{R} 2(\mathrm{p}=0,006)$.

O mapa de R2 apresentou área sob a curva ROC acima de 0,5 na região do núcleo rubro (Figura 5.18) e também o mapa QSM na região do globo pálido (Figura 5.19) porque foram as respectivas técnicas que determinaram diferença significativa entre os grupos.

Além dos resultados acima sobre diferença significativa entre os grupos controles e pacientes. Avaliamos também a assimetria dos valores de R2, R2* e $\Delta \chi$ dos núcleo da base direito em relação ao esquerdo separadamente para os controles e para os pacientes. Não foi encontrado diferença significativa $(p<0,05)$ entre os valores de R2, R2* e $\Delta \chi$ do lado direito em relação ao lado esquerdo para ambos os grupos. Resultado diferente de $\mathrm{Xu}$, Wang e Zhang (2008), que estudou o valor de fase e detectou maiores valores de mudança de fase do hemisfério esquerdo em certas regiões: putâmen, globo pálido, substância negra, tálamos e substância branca (tópico 2.3). A explicação da convergênica de nossos resultados com Xu, Wang e Zhang (2008) se deve aos 
autores terem usado a informação de fase e não os valores de R2, R2* e $\Delta \chi$. A fase possui dependência não local e pode ser influenciada por diversos fatores de pré processamento (desenrolamento e filtragem).

Nossas conclusões possuem algumas limitações relacionadas com detalhes do estudo. Numero de controles (16) e pacientes (14) não foi muito grande devido ao custo do exame. Os pacientes foram recrutados em ambulatório clinico que apresentavam predominantemente casos intermediários da doença (escala 2 ou 3 de $\mathrm{H} \& \mathrm{Yr}$ ). Pacientes com estágio da doença avançado (escala 4 ou 5 de $\mathrm{H} \& \mathrm{Y}$ ) apresentam muitos tremores, rigidez do corpo e debilitação física, fato que dificulta a aquisição do exame. Logo, não podemos obter conclusões para os casos mais avançados e pela pequena quantidade de pacientes não foi possível fazer uma analise de correlação entre os parâmetros quantitativos aqui estudados e o grau de gravidade da doença (por exemplo usando a escala de $\mathrm{H} \& \mathrm{Y}$ ). A segmentação dos núcleos da base foi realizada apenas no corte mais representativo da região de interesse e não em toda extensão do volume da região anatômica, fato que pode influenciar o valor médio de R2, R2* e $\Delta \chi$.

Os resultados obtidos neste tópico (5.4) foram aceitos para apresentação no principal congresso de susceptibilidade magnética: 2nd International Workshop on MRI Phase Contrast and Quantitative Susceptibility Mapping (QSM) 25-27 de Julho de 2013. Ithaca, Nova York EUA (BARBOSA et al., 2013). O resumo expandido (4 páginas) foi indicado pelo congresso para concorrer como melhor trabalho do evento, sendo o prêmio o financiamento da viagem para o congresso.

\subsection{Efeito da resolução da imagem no mapa de QSM}

A imagem com alta resolução $(0,5 \times 0,5 \times 2,0 \mathrm{~mm})$ foi adquirida em 2,8 minutos. A imagem de baixa resolução foi gerada a partir da imagem de alta resolução (Tópico 4.3.2). Se fossemos adquirir a imagem de baixa resolução 
(1,0x1,0x2,0mm) seriam necessários 0,9 minutos.

Os mapas de QSM processados a partir das imagens com diferentes resoluções não apresentaram qualitativamente muitas diferenças. Na figura abaixo é mostrado os mapas de QSM para um controle e um paciente gerados a partir de imagens com diferentes resoluções.

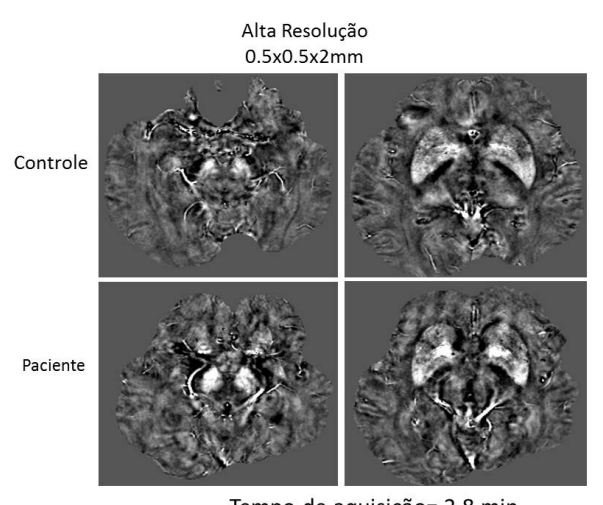

Tempo de aquisição= $2.8 \mathrm{~min}$

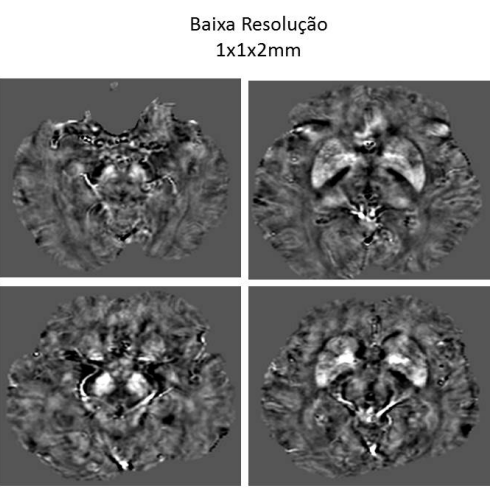

Tempo de aquisição= $0.9 \mathrm{~min}$

Figura 5.20: Mapas de QSM obtidos de imagens com alta e baixa resolução para um controle e um paciente com doença de Parkinson.

Os valores de $\Delta \chi$ obtidos das imagens com baixa resolução para todas as regiões dos núcleos da base foram plotados em função dos valores das imagens com alta resolução. Gerando coeficientes de correlação linear e angular próximo de 1, fato que indica muito pouca variação nos valores de $\Delta \chi$.

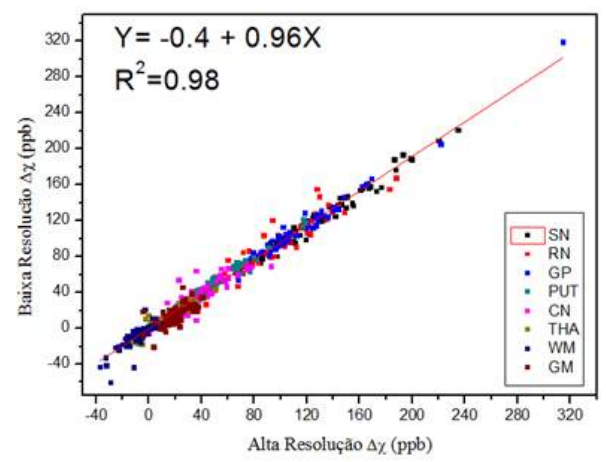

Figura 5.21: Correlação linear entre valores médios de susceptibilidade magnética dos núcleos da base por meio do processamento de imagens com baixa e alta resolução.

O resultado do teste t de Student entre valores de $\Delta \chi$ para controles e 
pacientes se manteve o mesmo em alta e baixa resolução (Figura 5.22).

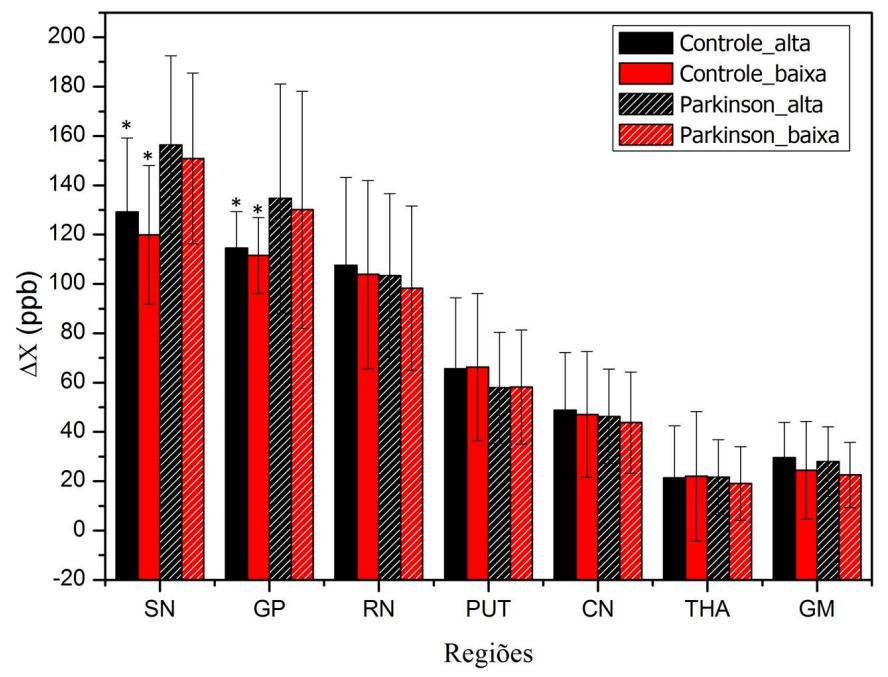

Figura 5.22: Valores médios e desvio padrão dos valores de susceptibilidade magnética. ${ }^{*}(p<0,05)$.

Em resumo os mapas de $Q S M$ de alta resolução apresentaram maiores detalhes da anatomia como a presença de pequenos vasos, no entanto os mapas de QSM de baixa resolução apresentaram pouca mudança nos valores de susceptibilidade magnética para as regiões segmentadas. Os pequenos vasos não influenciaram no valor médio medido das regiões, porque são muito pequenos em relação ao tamanho da região de interesse e o valor de susceptibilidade magnética das regiões são muito superiores ao valores de susceptibilidade dos vasos. Portanto sugerimos para a quantificação da susceptibilidade magnética dos núcleos da base na aplicação clínica a aquisição de imagens de baixa resolução $(1,0 \times 1,0 \times 2,0)$ por motivos de menor tempo de aquisição.

Os resultados obtidos neste tópico (5.5) foram apresentados em inglês e de forma oral no XXXVI Encontro Nacional de Física da Matéria Condensada nos dias 13 a 17 de Maio de 2013. Águas de Lindóia, São Paulo.(BARBOSA; SALMON, 2013). 


\subsection{Análise de diferentes valores de T2}

A Figura 5.23 e 5.24 mostra os resultados da análise de múltiplos T2 para um controle e um paciente. 

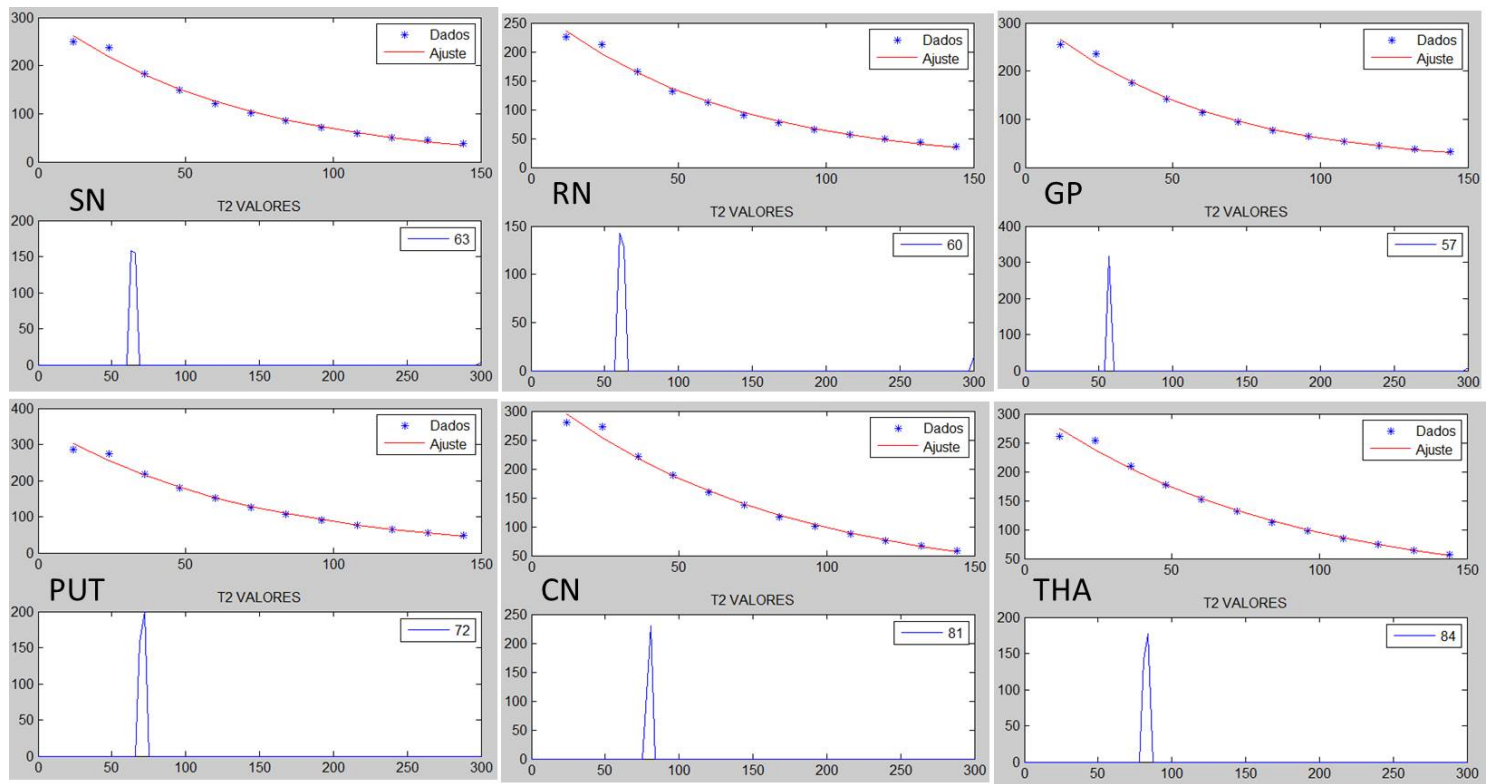

Figura 5.23: Análise de múltiplos $T 2$ para sujeito controle (67 anos). Eixo das ordenadas contem intensidade do sinal (u.a.) e ponderação (u.a.) no gráfico acim e abaixo respectivamente. Eixo das abscissas contem TE (ms) e T2 (ms) respectivamente.
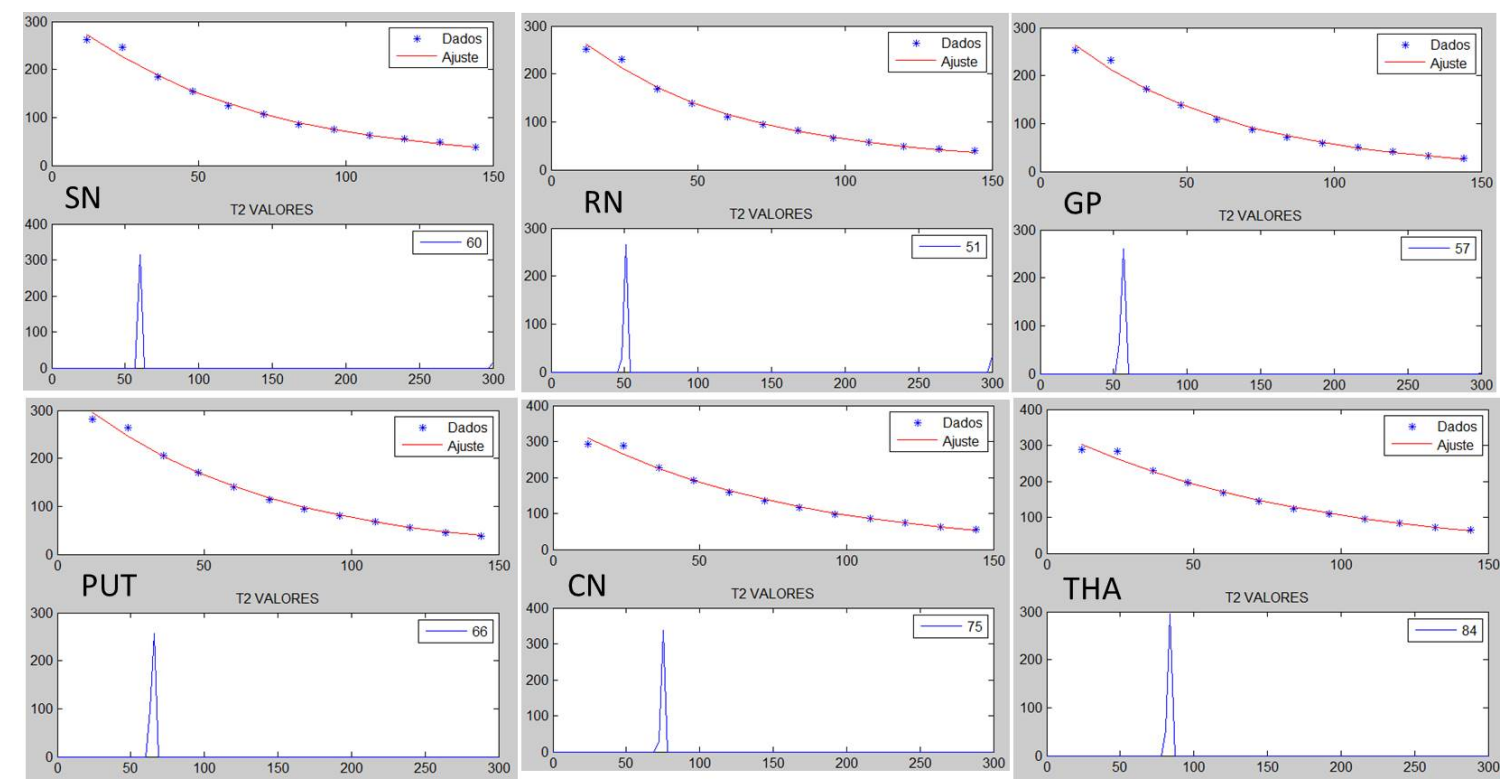

Figura 5.24: Análise de múltiplos $T 2$ para pacientes com doença de Parkinson (60 anos). Eixo das ordenadas contem intensidade do sinal (u.a.) e ponderação (u.a.) no gráfico acim e abaixo respectivamente. Eixo das abscissas contem TE (ms) e T2 (ms) respectivamente.

Em todos os sujeitos controles e pacientes com doença de Parkinson 
foi observado apenas um valor de T2 para o estudo de relaxometria dos núcleos da base. Estes resultados não concordam com os reportados na tese de doutorado de Silva (2013), que foi observado um comportamento bi exponencial dos valores de T2 para os núcleos da base. Nossos resultados poderiam ser justificados pela baixa acurácia da técnica de ajuste construída. As simulações desta técnica mostra uma grande dependência com relação sinal ruído para determinar os valores de T2. Na Figura 5.25 apresenta os resultados encontrados para dois valores de $\mathrm{T} 2$ simulados $\mathrm{T} 2=20 \mathrm{~ms}$ e $\mathrm{T} 2=100 \mathrm{~ms}(\mathrm{~S}=50 * \exp (-\mathrm{TE} / 100)+50 * \exp (-\mathrm{TE} / 20)$ com valores de TE iguais 12 , $24,36,48,60,72,84,96,108,120,132$ e 144ms) e os respectivos valores de ruído em porcentagem para o sinal de $\mathrm{TE}=12 \mathrm{~ms}$.

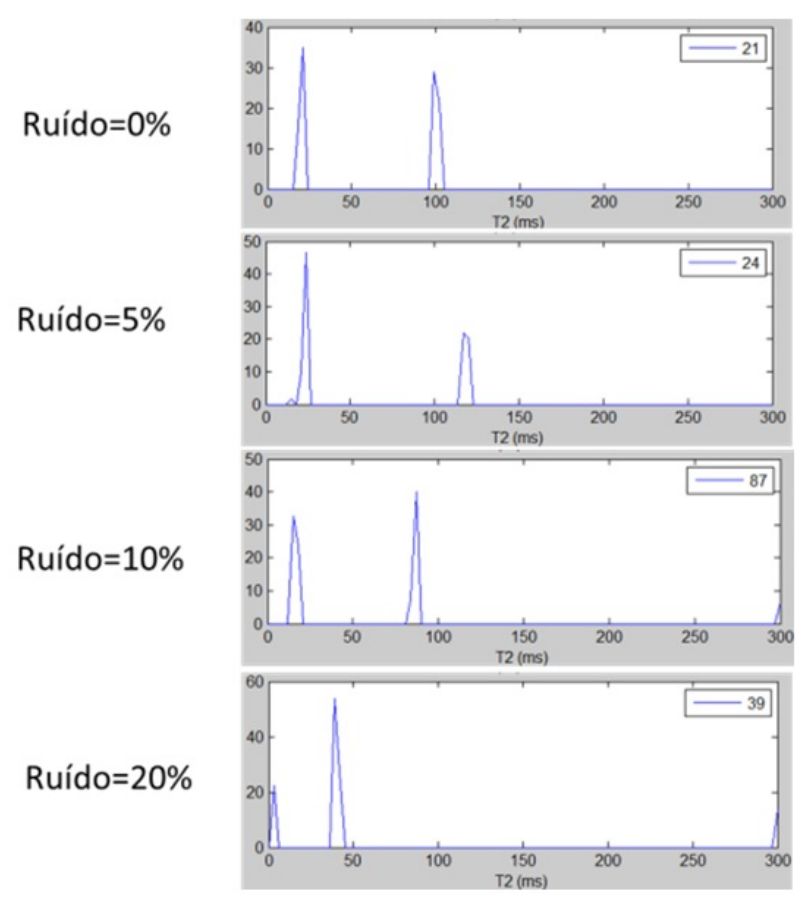

Figura 5.25: Dependência do cálculo de múltiplos T2 para de determinação dois valores de T2 simulados. Eixo das ordenadas contem ponderação (u.a.). Eixo das abscissas contem valores de T2 (ms) respectivamente.

Portanto com esta abordagem não foi possível identificar a existência de mais de um valor de T2 tanto para controles quanto para pacientes. Acreditamos que seja devido à dependência da técnica com a relação sinal ruído. 


\section{Capítulo}

\section{Conclusões}

A alta correção linear entre as técnicas R2, R2* e QSM com o acumulo de ferro estimado nas regiões dos núcleos da base sugere que elas podem ser utilizadas como medidas indiretas da deposição de ferro no cérebro. Além disso, os resultados de analise de intercorrelação entre as técnicas: $\mathrm{R} 2 \& Q S M\left(\mathrm{r}^{2}=0,63\right), \mathrm{R} 2 * \& Q S M\left(\mathrm{r}^{2}=0,54\right)$ e $\mathrm{R} 2 \& \mathrm{R} 2 *\left(\mathrm{r}^{2}=0,73\right)$ permitiu concluir que apesar de uma depedência razoável, cada técnica responde diferentemente com a deposição de íons paramagnéticos em tecidos cerebrais. Como sugerido pela literatura, os valores de relaxometria também podem depender da inomogeneidade do campo estático, da difusão do tecido e de outros fatores relacionados a compartimentalização de íons paramagnéticos (KENNAN; ZHONG; GORE, 1994; WEISSKOFF et al., 1994; KISELEV; POSSE, 1999; TROPRèS et al., 2001). Os valores de susceptibilidade magnética também são sensíveis ao acumulo de outras substâncias paramagnéticas ou diamagnéticas, à mudança de estados de oxidação dos íons paramagnéticos e ao acoplamento entre eles (LOTFIPOUR et al., 2012).

Observamos que a relaxometria R2 e o mapa de susceptibilidade magnética apresentaram sensibilidade e especificidade razoável para diferenciar sujeitos controles de pacientes com doença de Parkinson principalmente para a região da substância negra. Devido à doença de Parkinson apresentar mudanças químicas e físicas principalmente na substância negra: morte dos neurônios dopaminérgicos e acúmulo de ferro. Com maior sensibilidade e especificidade para o mapa de suscepetibilidade 
como descrito pela curva ROC.

Concluímos que o mapa QSM gerado com imagens de baixa resolução $(1,0 \times 1,0 \times 2,0 \mathrm{~mm})$ apresenta valores de $\Delta \chi$ das regiões dos núcleos da base muito próximos dos mapas gerados com imagem de alta resolução $(0,5 \times 0,5 \times 2,0 \mathrm{~mm})$. Como o tempo de aquisição de imagens com baixa resolução é reduzido 70\%, sugerimos a aquisição de imagens com baixa resolução para grandes estudos e na aplicação clinica.

O método de analise de múltiplos T2 abordado neste estudo não verificou comportamento multi exponencial. Não houve mais de um valor de T2 para as regiões dos núcleos da base tanto para controles quanto para pacientes. Este resultado foi aparentemente afetado pela relação sinal ruído.

Como perspectivas futuras deste trabalho, elaboramos algumas perguntas que podem guiar estudos futuros: Qual é o estado de ionização do ferro que estamos detectando com as técnicas quantitativas de ressonância magnética in vivo? Além disso, quais são os outros íons paramagnéticos e moléculas que contribuem ou competem com os valores de relaxometria e susceptibilidade magnética? De forma aplicada, o ferro é causa ou consequência do acúmulo de ferro na doença de Parkinson? É possível verificar in vivo o acúmulo de ferro durante a doença? 


\section{Referências Bibliográficas}

AISEN, P.; WESSLING-RESNICK, M.; LEIBOLD, E. A. Iron metabolism. Current opinion in chemical biology, v. 3, n. 2, p. 200-6, 1999.

ANDREWS, N. C. Disorders of iron metabolism. The New England journal of medicine, v. 341, n. 26, p. 1986-95, 1999.

ANTONINI, A. et al. T2 relaxation time in patients with Parkinson's disease. Neurology, v. 43, p. 697-700, 1993.

AQUINO, D. et al. Age-related iron deposition in the basal ganglia: quantitative analysis in healthy subjects. Radiology, v. 252, n. 1, p. 165-72, 2009.

BAFFA, O. Estudos estruturais das mioglobinas de Aplysia Brasiliana e Dermochelis Coriacea por técnicas ópticas e ressonância paramagnética eletrônica. Tese (Doutorado) - University of Sao Paulo, 1984.

BARBOSA, J. H. O.; FILHO, A. C. S. S.; SALMON, C. E. G. Mapas de R2, R2* e susceptibilidade magnética de depósitos de ferro nos gânglios da base. In: Congresso Brasileiro em Engenharia Biomedica. Porto de Galinhas - PE: [s.n.], 2012.

BARBOSA, J. H. O. et al. Correlation of R2 and R2* with Quantitative Susceptibility Maps in Healthy Elderly Controls. In: ISMRM. Salt Lake City USA: [s.n.], 2013.

BARBOSA, J. H. O.; SALMON, C. E. G. Study about susceptibility mapping with different images resolutions. In: XXXVI Encontro de Física da Matéria Condensada. Águas de Lindóia - SP: [s.n.], 2013. Disponível em: $<$ http://www.sbf1.sbfisica.org.br/eventos/enfmc/xxxvi/sys/resumos/R0532-2.pdf >.

BARBOSA, J. H. O. et al. Are transverse relaxation rates and susceptibility maps equivalent in detecting changes in iron content in Parkinson's disease? In: 2nd International Workshop on MRI Phase Contrast and Quantitative Susceptibility Mapping (QSM). Ithaca - USA: [s.n.], 2013. p. 4.

BARTON, J. C. et al. Handbook of Iron Overload Disorders. [S.l.]: Cambridge University Press, 2010. 376 p. 
BARTZOKIS, G. et al. Field dependent transverse relaxation rate increase may be a specific measure of tissue iron stores. Magnetic resonance in medicine, v. 29, n. 4, p. 459-64, 1993.

BARTZOKIS, G. et al. MRI evaluation of brain iron in earlier and later onset Parkinson's disease and normal subjects. Magnetic Resonance Imaging, v. 17, n. 2, p. 213-222, 1999.

BARTZOKIS, G. et al. Brain ferritin iron may influence age e gender related risks of neurodegeneration. Neurobiol. Aging, v. 28, p. 414-423, 2007.

BAUDREXEL, S. et al. Quantitative mapping of T1 and T2* discloses nigral and brainstem pathology in early Parkinson's disease. Neuroimage, 2010.

BEARD, J. L.; CONNOR, J. R.; JONES, B. C. Iron in the Brain. Nutrition Reviews, v. 51, n. 6, p. 157-170, 1993.

BERG, D. In vivo detection of iron and neuromelanin by transcranial sonography a new approach for early detection of substantia nigra damage. Journal of neural transmission, 2006.

BERG, D.; HOCHSTRASSER, H. Iron metabolism in Parkinsonian syndromes. Movement disorders, v. 21, n. 9, p. 1299-310, 2006.

BORTEN, O. et al. Effects of dietary restriction and metal supplementation on the accumulation of iron-laden glial inclusions in the aging rat hippocampus. Biogerontology, v. 5, p. 81-88, 2004.

BOTHWELL, T. H. et al. Iron metabolism in man. St. Louis: Blackwell Scientific Publications., 1979. 576 p.

BRAFFMAN, B. H. et al. MR imaging of Parkinson disease with spin-echo and gradient-echo sequences. American journal of roentgenology, v. 152, p. 159-65, 1989.

BROOKS, D. J. et al. Does signal-attenuation on high-field T2-weighted MRI of the brain reflect regional cerebral iron deposition? Observations on the relationship between regional cerebral water proton $\mathrm{T} 2$ values and iron levels. Journal of neurology, neurosurgery, and psychiatry, v. 52, n. 1, p. 108-11, 1989.

CARNEIRO, A. A. O. Sistema para medidas da magnetização remanente intragástrica. 123 p. Tese (Doutorado) - Universidade de Sao Paulo, 2001.

CHEN, J.; HARDY, P. MR of human postmortem brain tissue: correlative study between T2 and assays of iron and ferritin in Parkinson and Huntington disease. American journal Neuroradiol, v. 14, n. 2, p. 275-281, 1993. 
CHEN, J. C. et al. MR of human postmortem brain tissue: correlative study between T2 and assays of iron and ferritin in Parkinson and Huntington disease. American journal of neuroradiology, v. 14, n. 2, p. 275-81, 1989.

CONNOR, J. R. et al. Iron and iron management proteins in neurobiology. Pediatric neurology, v. 25, n. 2, p. 118-29, 2001.

CONNOR, J. R. et al. Cellular distribution of transferrin, ferritin, and iron in normal and aged human brains. Journal of neuroscience research, v. 27, n. 4, p. 595-611, 1990.

CONNOR, J. R. et al. A histochemical study of iron, transferrin, and ferritin in Alzheimer's diseased brains. Journal of neuroscience research, v. 31, n. 1, p. 75-83, 1992.

CONNOR, J. R. et al. A quantitative analysis of isoferritins in select regions of aged, parkinsonian, and Alzheimer's diseased brains. Journal of neurochemistry, v. 65, n. 2, p. 717-24, ago. 1995.

CONNOR, J. R. et al. Regional distribution of iron and iron-regulatory proteins in the brain in aging and Alzheimer's disease. Journal of neuroscience research, v. 31, n. 2, p. 327-35, 1992.

CONNOR, R. J.; BOESHORE, K. L.; BENKOVIC, S. A. Isoforms of ferritin have a distinct cellular distribuition in the brain. Mol Biol Cell, v. 3, p. 84A, 1992.

CRICHTON, R. R.; DEXTER, D. T.; WARD, R. J. Brain iron metabolism and its perturbation in neurological diseases. Journal of neural transmission, v. 118, n. 3, p. 301-14, 2011.

De Arriba Zerpa, G. A. et al. Alternative splicing prevents transferrin secretion during differentiation of a human oligodendrocyte cell line. Journal of neuroscience research, v. 61, n. 4, p. 388-95, 2000.

De la Fuente-Femeez, R. et al. Nigrostriatal dopamine system e motor lateralization. Brain Res., v. 112, p. 63-68, 2000.

DEISTUNG, A. et al. NeuroImage Toward in vivo histology : A comparison of quantitative susceptibility mapping ( QSM ) imaging at ultra high magnetic field strength with magnitude, phase, and R2*. v. 65, p. 299-314, 2013.

DEXTER, D. et al. Alterations in the levels of iron, ferritin and other trace metals in Parkinson's disease and other neurodegenerative diseases affecting the basal ganglia. Brain : a journal of neurology, v. 114, p. 1953-75, 1991.

DEXTER, D. et al. Increased nigral iron content in postmortem parkinsonian brain. Lancet, v. 2, n. 8569, p. 1219-20, 1987. 
DEXTER, D. T. et al. Increased nigral iron content and alterations in other metal ions occurring in brain in Parkinson's disease. Journal of neurochemistry, v. 52, n. 6, p. 1830-6, 1989.

DRAYER, B. et al. MRI of brain iron. AJR. American journal of roentgenology, v. 147, n. 1, p. 103-10, 1986.

DU, G. et al. Combined R2* and diffusion tensor imaging changes in the substantia nigra in Parkinson's disease. Movement disorders, v. 26, p. 1627-32, 2011.

DURIEUX, A. et al. Superficial siderosis of the central nervous system. Revue neurologique, v. 155, n. 3, p. 201-7, 1999.

DUYN, J. H. et al. High field MRI of brain cortical substructure based on signal phase. Proceedings of the National Academy of Sciences of the United States of America, v. 104, n. 28, p. 11796-801, 2007.

FAUCHEUX, B. A. et al. Autoradiographic localization and density of [125I] ferrotransferrin binding sites in the basal ganglia of control subjects, patients with Parkinson's disease and MPTP-lesioned monkeys. Brain research, v. 691, n. 1-2, p. 115-24, 1995.

FERNANDEZ, L.; BARBOSA, L. H. T.; Schroder, M. V., N. Ferro e neurodegeneração. Scientia Medica, v. 17, n. 4, p. 218-224, 2007.

FINCH, C. A.; HUEBERS, H. Perspectives in iron metabolism. The New England journal of medicine, v. 306, n. 25, p. 1520-8, 1982.

FLEMING, D. et al. Aspirin intake and the use of serum ferritin as a measure of iron status. Am J Clin Nutr, v. 74, p. 219-226, 2001.

GELMAN, N. et al. MR imaging of human brain at 3.0 T: preliminary report on transverse relaxation rates and relation to estimated iron content. Radiology, v. 210, n. 3, p. 759-67, 1999.

GHUGRE, N. R. et al. Mechanisms of tissue-iron relaxivity: nuclear magnetic resonance studies of human liver biopsy specimens. Magnetic resonance in medicine, v. 54, n. 5, p. 1185-93, 2005.

GLICK, S.; ROSS, D.; HOUGH, L. Lateral asymmetry of neurotransmitters in human brain. Brain research, v. 234, p. 53-63, 1982.

GORELL, J. M. et al. Increased iron-related MRI contrast in the substantia nigra in Parkinson's disease. Neurology, v. 45, p. 1138-43, 1995.

GöTZ, M. E. et al. The relevance of iron in the pathogenesis of Parkinson's disease. Annals of the New York Academy of Sciences, v. 1012, p. 193-208, 2004. 
GRAHAM, J.; PALEY, M.; GRüNEWALD, R. Brain iron deposition in Parkinson's disease imaged using the PRIME magnetic resonance sequence. Brain research, 2000.

GRIFFITHS, P. D. et al. Iron in the basal ganglia in Parkinson's disease. An in vitro study using extended $\mathrm{X}$ ray absorption fine structure and cryo electron microscopy. Brain : a journal of neurology, v. 122, p. 667-73, 1999.

GROGER, A.; BERG, D. Does structural neuroimaging reveal a disturbance of iron metabolism in Parkinson's disease? Implications from MRI and TCS studies. Journal of neural transmission, v. 119, n. 12, p. 1523-8, 2012. ISSN 1435-1463.

GUPTA, D. et al. Utility of susceptibility weighted MRI in differentiating Parkinsons disease and atypical parkinsonism. Neuroradiology, v. 52, n. 12, p. 1087-94, 2010.

HAACKE, E. et al. Magnetic Resonance Imaging: Physical Principles and Sequence Design. [S.l.]: Wiley, 1999.

HAACKE, E.; REICHENBACH, J. R. Susceptibility Weighted Imaging in MRI: Basic Concepts and Clinical Applications. [S.l.]: John Wiley and Sons, 2011. $416 \mathrm{p}$.

HAACKE, E. M. Susceptibility weighted imaging. Patent.US 6,658,280 B1. 2002.

HAACKE, E. M. et al. Imaging iron stores in the brain using magnetic resonance imaging. Magnetic resonance imaging, v. 23, n. 1, p. 1-25, 2005.

HAACKE, E. M. et al. Characterizing iron deposition in multiple sclerosis lesions using susceptibility weighted imaging. Journal of magnetic resonance imaging : JMRI, v. 29, n. 3, p. 537-544, 2009.

HAACKE, E. M. et al. Susceptibility weighted imaging: technical aspects and clinical applications, part 1. AJNR. American journal of neuroradiology, v. 30, n. 1, p. 19-30, 2009.

HAACKE, E. M. et al. Susceptibility mapping as a means to visualize veins and quantify oxygen saturation. Journal of magnetic resonance imaging, v. 32, n. 3, p. 663-76, 2010.

HAACKE, E. M. et al. Susceptibility weighted imaging (SWI). Magnetic resonance in medicine :, v. 52, n. 3, p. 612-8, 2004.

HALLGREN, B.; SOURANDER, P. THE EFFECT OF AGE ON THE NON-HAEMIN IRON IN THE HUMAN BRAIN. Journal of Neurochemistry, v. 3, n. 1, p. 41-51, 1958. 
HARRISON, P. The ferritins: molecular properties, iron storage function and cellular regulation. Biochimica et Biophysica Acta (BBA) - Bioenergetics, v. 1275 , n. 3, p. 161-203, 1996.

HEBBRECHT, G.; MAENHAUT, W.; REUCK, J. D. Brain trace elements and aging. Nuclear Instruments and Methods in Physics Research Section B, v. 150, n. $1-4$, p. 208-213, 1999.

HENTZE, M. W.; MUCKENTHALER, M. U.; ANDREWS, N. C. Balancing acts: molecular control of mammalian iron metabolism. Cell, v. 117, n. 3, p. 285-97, 2004.

HIRSCH, E. C. et al. Iron and aluminum increase in the substantia nigra of patients with Parkinson's disease: an X-ray microanalysis. Journal of neurochemistry, v. 56, n. 2, p. 446-51, 1991.

HIRSCH, E. C.; GRAYBIEL, A. M.; AGID, Y. Melanised dopaminergic neurons are differently susceptible to degeneration in Parkinson's disease. Nature, v. 334, p. 345-348, 1988.

JELLINGER, K. A. Pathology of Parkinson's disease. Changes other than the nigrostriatal pathway. Molecular and chemical neuropathology / sponsored by the International Society for Neurochemistry and the World Federation of Neurology and research groups on neurochemistry and cerebrospinal fluid, v. 14 , n. 3, p. 153-97, 1991.

JENKINSON, M.; WILSON, J. L.; JEZZARD, P. Perturbation method for magnetic field calculations of nonconductive objects. Magnetic resonance in medicine, v. 52, n. 3, p. 471-7, 2004.

JENSEN, J. Tissue Iron Detection \& Quantification with MRI. cds.ismrm.org, 2011.

Jr. Wagner, H. et al. Imaging dopamine receptors in the human brain by positron emission tomography. Science, v. 221, p. 1264-1266, 1983.

KAMMAN, R. et al. Nuclear magnetic resonance relaxation in experimental brain edema: effects of water concentration, protein concentration, and temperature. Magnetic Resonance in Medicine, 1988.

KAUSHANSKY, K. et al. Williams Hematology, Eighth Edition. [S.l.]: McGraw-Hill Education, 2010. 2460 p.

KENNAN, R. P.; ZHONG, J.; GORE, J. C. Intravascular susceptibility contrast mechanisms in tissues. Magnetic resonance in medicine, v. 31, n. 1, p. 9-21, 1994. 
KISELEV, V.; POSSE, S. Analytical Model of Susceptibility Induced MR Signal Dephasing: Effect of Diffusion in a Microvascular Network. Magnetic Resonance Imaging, v. 41, p. 499-509, 1999.

KOSTA, P. et al. MRI evaluation of the basal ganglia size and iron content in patients with Parkinson's disease. Journal of neurology, 2006.

LANGKAMMER, C. et al. Quantitative MR imaging of brain iron: a postmortem validation study. Radiology, v. 257, n. 2, p. 455-62, 2010.

LANGKAMMER, C. et al. Susceptibility induced gray white matter MRI contrast in the human brain. NeuroImage, Elsevier Inc., v. 59, n. 2, p. 1413-1419, 2012.

LANGKAMMER, C. et al. Quantitative susceptibility mapping in multiple sclerosis. Radiology, v. 267, n. 2, p. 551-9, 2013.

LANGKAMMER, C. et al. Quantitative susceptibility mapping (QSM) as a means to measure brain iron? A post mortem validation study. NeuroImage, Elsevier Inc., v. 62, n. 3, p. 1593-1599, 2012.

LEVEUGLE, B. et al. Cellular distribution of the iron-binding protein lactotransferrin in the mesencephalon of Parkinson's disease cases. Acta neuropathologica, v. 91, n. 6, p. 566-72, 1996.

LI, L.; LEIGH, J. S. High precision mapping of the magnetic field utilizing the harmonic function mean value property. Journal of magnetic resonance, v. 148 , n. 2 , p. $442-8,2001$.

LILL, R.; MUHLENHOFF, U. Iron sulfur protein biogenesis in eukaryotes: components and mechanisms. Annual review of cell and developmental biology, v. 22, p. 457-86, 2006.

LIU, T. et al. Calculation of susceptibility through multiple orientation sampling (COSMOS): a method for conditioning the inverse problem from measured magnetic field map to susceptibility source image in MRI. Magnetic resonance in medicine, v. 61, n. 1, p. 196-204, 2009.

LOK, C. N.; LOH, T. T. Regulation of transferrin function and expression: review and update. Biological signals and receptors, v. 7, n. 3, p. 157-78, 1998.

LOTFIPOUR, A. K. et al. High resolution magnetic susceptibility mapping of the substantia nigra in Parkinson's disease. Journal of magnetic resonance imaging, v. 35, n. 1, p. 48-55, 2012.

MAI, J.; PAXINOS, G.; VOSS, T. Atlas of the human brain. [S.l.]: Academic Press, 2008. (Academic Press). 
MARQUES, J.; BOWTELL, R. Application of a Fourier based method for rapid calculation of field inhomogeneity due to spatial variation of magnetic susceptibility. Concepts in Magnetic Resonance Part B: Magnetic Resonance Engineering, v. 25B, n. 1, p. 65-78, 2005.

MARTIN, W. R. W.; WIELER, M.; GEE, M. Midbrain iron content in early Parkinson disease: a potential biomarker of disease status. Neurology, v. 70, n. 16 Pt 2, p. 1411-7, 2008.

MCCREA, R. P. E. et al. A comparison of rapid scanning X ray fluorescence mapping and magnetic resonance imaging to localize brain iron distribution. European journal of radiology, v. 68, n. 3 Suppl, p. S109-13, 2008.

MITTAL, S. et al. Susceptibility-weighted imaging: technical aspects and clinical applications, part 2. AJNR. American journal of neuroradiology, v. 30, n. 2, p. 232-52, 2009.

MONDINO, F. et al. Magnetic resonance relaxometry in Parkinson's disease. Neurological sciences, v. 23(2), p. 87-8, 2002.

MORRIS, C. M. et al. Transferrin receptors in the parkinsonian midbrain. Neuropathology and applied neurobiology, v. 20, n. 5, p. 468-72, 1994.

MOUSSA, B. et al. Iron Deficiency and Overload. Totowa, NJ: Humana Press, 2010.

NEELAVALLI, J. et al. Removing background phase variations in susceptibility-weighted imaging using a fast, forward-field calculation. Journal of magnetic resonance imaging : JMRI, v. 29, n. 4, p. 937-48, 2009.

NELSON, D. L.; COX, M. M. Lehninger Principles of Biochemistry, 3ed Edition. [S.1.]: W. H. Freeman, 2000. 1200 p.

ORDIDGE, R. J. et al. Assessment of relative brain iron concentrations using T2-weighted and T2*-weighted MRI at 3 Tesla. Magnetic resonance in medicine, v. 32, p. 335-41, 1994.

ORDWAY, G. A.; GARRY, D. J. Myoglobin: an essential hemoprotein in striated muscle. The Journal of experimental biology, v. 207, p. 3441-6, 2004.

PELL, G. S. et al. Optimized clinical T2 relaxometry with a standard CPMG sequence. Journal of magnetic resonance imaging, v. 23, n. 2, p. 248-52, 2006.

PENKE, L. et al. Brain iron deposits are associated with general cognitive ability and cognitive aging. Neurobiology of aging, v. 33, n. 3, p. 510-517.e2, 2012. 
PERAN, P. et al. Magnetic resonance imaging markers of Parkinson's disease nigrostriatal signature. Brain research, v. 133, p. 3423-33, 2010.

PERL, M. No Title. Virchows Arch Pathol Anat., p. 39:42, 1867.

PONKA, P.; BEAUMONT, C.; RICHARDSON, D. R. Function and regulation of transferrin and ferritin. Seminars in hematology, v. 35, n. 1, p. 35-54, 1998.

QUINTANA, C. et al. Study of the localization of iron, ferritin, and hemosiderin in Alzheimer's disease hippocampus by analytical microscopy at the subcellular level. Journal of structural biology, v. 153, n. 1, p. 42-54, 2006.

QUINTANA, C.; COWLEY, J. M.; MARHIC, C. Electron nanodiffraction and high-resolution electron microscopy studies of the structure and composition of physiological and pathological ferritin. Journal of structural biology, v. 147, n. 2, p. 166-78, ago. 2004.

RIEDERER, P. et al. Transition metals, ferritin, glutathione, and ascorbic acid in parkinsonian brains. Journal of neurochemistry, v. 52, n. 2, p. 515-20, 1989.

RILEY, K.; HOBSON, M.; BENCE, S. Mathematical Methods for Physics and Engineering. 3ed. ed. New York: Cambridge University Press, 2006.

ROCHEFORT, L. de et al. Quantitative MR susceptibility mapping using piece wise constant regularized inversion of the magnetic field. Magnetic resonance in medicine, v. 60, n. 4, p. 1003-1009, 2008.

ROCHEFORT, L. de et al. Quantitative susceptibility map reconstruction from MR phase data using bayesian regularization: validation and application to brain imaging. Magnetic resonance in medicine, v. 63, n. 1, p. 194-206, 2010.

ROSSI, M. et al. Brain iron deposition and sequence characteristics in Parkinsonism: comparison of SWI, T2star maps, T2 weighted, and FLAIR SPACE. Investigative radiology, v. 45, n. 12, p. 795-802, 2010.

ROUAULT, T. A. Systemic iron metabolism: a review and implications for brain iron metabolism. Pediatric Neurology, v. 25, n. 2, p. 130-137, 2001.

ROY, K. K. Potential Theory in Applied Geophysics. In: Potential Theory in Applied Geophysics, by Kalyan Kumar Roy. Berlin: Springer, 2008. Berlin: Springer, 2008. -1, cap. 10, p. 307-328.

RYVLIN, P. et al. Magnetic resonance imaging evidence of decreased putamenal iron content in idiopathic Parkinson's disease. Archives of neurology, v. 52, n. 6, p. 583-8, 1995. 
SAINI, S. et al. Magnetism: a primer and review. AJR. American journal of roentgenology, v. 150, n. 4, p. 735-43, 1988.

SCHENCK, J. F. Health and Physiological Effects of Human Exposure to Whole Body Four Tesla Magnetic Fields during MRI. Annals New York Academiy of Sciences, v. 649, p. 285-301, 1993.

SCHENCK, J. F. The role of magnetic susceptibility in magnetic resonance imaging: MRI magnetic compatibility of the first and second kinds. Medical Physics, v. 23, n. 6, p. 815-850, 1996.

SCHENCK, J. F. Magnetic resonance imaging of brain iron. Journal of the neurological sciences, v. 207, n. 1-2, p. 99-102, 2003.

SCHWESER, F. A Novel Approach for Separation of Background Phase in SWI Phase Data Utilizing the Harmonic Function Mean Value Property. In: ISMRM meeting. Stockholm, Sweden: [s.n.], 2010.

SCHWESER, F. et al. Quantitative imaging of intrinsic magnetic tissue properties using MRI signal phase : An approach to in vivo brain iron metabolism? NeuroImage, Elsevier Inc., v. 54, n. 4, p. 2789-2807, 2011.

SELDEN, C. et al. Studies on the concentration and intracellular localization of iron proteins in liver biopsy specimens from patients with iron overload with special reference to their role in lysosomal disruption. British journal of haematology, v. 44, n. 4, p. 593-603, 1980.

SENGSTOCK, G. J. et al. Iron induces degeneration of nigrostriatal neurons. Brain research bulletin, v. 28, n. 4, p. 645-9, 1992.

SHMUELI, K. et al. Magnetic susceptibility mapping of brain tissue in vivo using MRI phase data. Magnetic resonance in medicine, v. 62, n. 6, p. 1510-1522, 2009.

SILVA, M. Avaliação da utilidade da Ultrasonografia para o diagnóstico da doença de Parkinson e análise da concordância com a relaxometria por Ressonância Magnética. Tese (Doutorado) - Universidade Sao Paulo, 2013.

SMITH, S.; JENKINSON, M.; WOOLRICH, M. Advances in functional and structural MR image analysis and implementation as FSL. NeuroImage, v. 23, p. 208-219, 2004.

SOFIC, E. et al. Selective increase of iron in substantia nigra zona compacta of parkinsonian brains. Journal of neurochemistry, v. 56, n. 3, p. 978-82, 1991.

SOFIC, E. et al. Increased iron (III) and total iron content in post mortem substantia nigra of parkinsonian brain. Journal of neural transmission, v. 74, n. 3, p. 199-205, 1988. 
SPATZ, H. Uber Den Eisennachweis im Gehrin, besonders in Zentren des extrapyrimidal-motorishcen systems. Z Ges Neuronal Psychiat Berl, p. 77:261, 1922.

STANKIEWICZ, J. et al. Iron in chronic brain disorders: imaging and neurotherapeutic implications. Neurotherapeutics : the journal of the American Society for Experimental NeuroTherapeutics, v. 4, n. 3, p. 371-86, 2007.

SUPPRIAN, T. et al. MRI T2 relaxation times of brain regions in schizophrenic patients e control subjects. Psychiatry Res., v. 75, p. 173-182, 1997.

TANG, J. et al. Improving susceptibility mapping using a threshold based $\mathrm{K}$ space image domain iterative reconstruction approach. Magnetic resonance in medicine, v. 69, n. 5, p. 1396-407, 2013.

THOMAS, L. O. et al. MR detection of brain iron. AJNR. American journal of neuroradiology, v. 14, n. 5, p. 1043-8, 1993.

TOFTS, P. Quantitative MRI of the Brain. Chichester, UK: John Wiley Sons, Ltd, 2003.

TRINDER, D.; MORGAN, E. Uptake of transferrin-bound iron by mammalian cells In: In: Molecular and Cellular Iron Transport. New York: Marcel Dekker, 2001. cap. 17, p. 427-449.

TROPRèS, I. et al. Vessel size imaging. Magnetic resonance in medicine : official journal of the Society of Magnetic Resonance in Medicine / Society of Magnetic Resonance in Medicine, v. 45, n. 3, p. 397-408, 2001.

VOET, D.; VOET, J. G.; PRATT, C. W. Fundamentos de bioquímica. [S.l.]: Artmed, 2000. 931 p.

VYMAZAL, J. et al. T1 and T2 in the brain of healthy subjects, patients with Parkinson disease, and patients with multiple system atrophy: relation to iron content. Radiology, v. 211, n. 2, p. 489-95, 1999.

VYMAZAL, J.; URGOSÍK, D.; BULTE, J. W. Differentiation between hemosiderin- and ferritin-bound brain iron using nuclear magnetic resonance and magnetic resonance imaging. Cellular and molecular biology (Noisy-le-Grand, France), v. 46, n. 4, p. 835-42, 2000.

WARD, R. J. et al. Does the haemosiderin iron core determine its potential for chelation and the development of iron-induced tissue damage? Journal of inorganic biochemistry, v. 79, n. 1-4, p. 311-7, 2000.

WEIR, M. P.; GIBSON, J. F.; PETERS, T. J. No Title. Cell Biochem, Funct. 2, p. 186-194, 1984. 
WEISSKOFF, R. M. et al. Microscopic susceptibility variation and transverse relaxation: theory and experiment. Magnetic resonance in medicine, v. 31, n. 6, p. 601-10, 1994.

WHARTON, S.; BOWTELL, R. Whole brain susceptibility mapping at high field: a comparison of multiple and single orientation methods. NeuroImage, Elsevier Inc., v. 53, n. 2, p. 515-525, 2010.

WHARTON, S.; SCHAFER, A.; BOWTELL, R. Susceptibility mapping in the human brain using threshold based $\mathrm{k}$ space division. Magnetic resonance in medicine, v. 63, n. 5, p. 1292-304, 2010.

WHITTALL, K. P.; MACKAY, A. L. Quantitative interpretation of NMR relaxation data. Journal of Magnetic Resonance, v. 84, n. 1, p. 134-152, 1989. WIJAYANTI, N.; KATZ, N.; IMMENSCHUH, S. Biology of heme in health and disease. Current medicinal chemistry, v. 11, n. 8, p. 981-6, 2004.

WOOD, J. C.; GHUGRE, N. Magnetic resonance imaging assessment of excess iron in thalassemia, sickle cell disease and other iron overload diseases. Hemoglobin, v. 32, n. 1-2, p. 85-96, 2008.

XU, X.; WANG, Q.; ZHANG, M. Age, gender, and hemispheric differences in iron deposition in the human brain: an in vivo MRI study. NeuroImage, v. 40, n. 1, p. 35-42, 2008.

YAO, B. et al. Neuro Image Susceptibility contrast in high field MRI of human brain as a function of tissue iron content. NeuroImage, Elsevier B.V., v. 44, n. 4, p. 1259-1266, 2009.

YOUDIM; M.B.H. Brain Iron: Neurochemical e Behavioral Aspects. 1. ed. Ney York: Taylor e Francis, 1988. 25-66 p.

ZAKIN, M. M. Regulation of transferrin gene expression. FASEB journal : official publication of the Federation of American Societies for Experimental Biology, v. 6, n. 14, p. 3253-8, 1992.

ZATTA, P. Metal Ions and Neurodegenerative Disorders. [S.l.]: World Scientific, 2003. $511 \mathrm{p}$. 


\section{Apêndice}

\section{Processamento da imagem SWI}

Para se realizar o processamento da imagem SWI é necessário adquirir a imagem de magnitude e de fase em uma sequencia Gradiente Eco com certo tempo ao eco. Posteriormente processar a imagem de fase, criar a máscara de fase e multiplicá-la pela imagem de magnitude para gerar a imagem $S W I$.

\section{Aquisição de imagem por sequência Gradiente Echo}

Para a aquisição SWI é necessário utilizar a sequência Gradiente Eco. Esta sequência é visualizada na Figura A.1. A magnetização de equilíbrio, longitudinal $\left(\mathrm{M}_{0}\right)$, é transformada, parcialmente ou totalmente, em magnetização transversal através da aplicação de um pulso de rádio frequência específico (rf). Posteriormente, ocorre relaxação da magnetização transversal, fato que é intensificado pela defasagem dos spins nucleares. No entanto, utiliza-se uma composição de gradientes na direção de leitura (Gr) para refocalizar os spins nucleares (A.2) e recuperar um pouco a magnetização transversal e obter a leitura do sinal no tempo ao eco. 


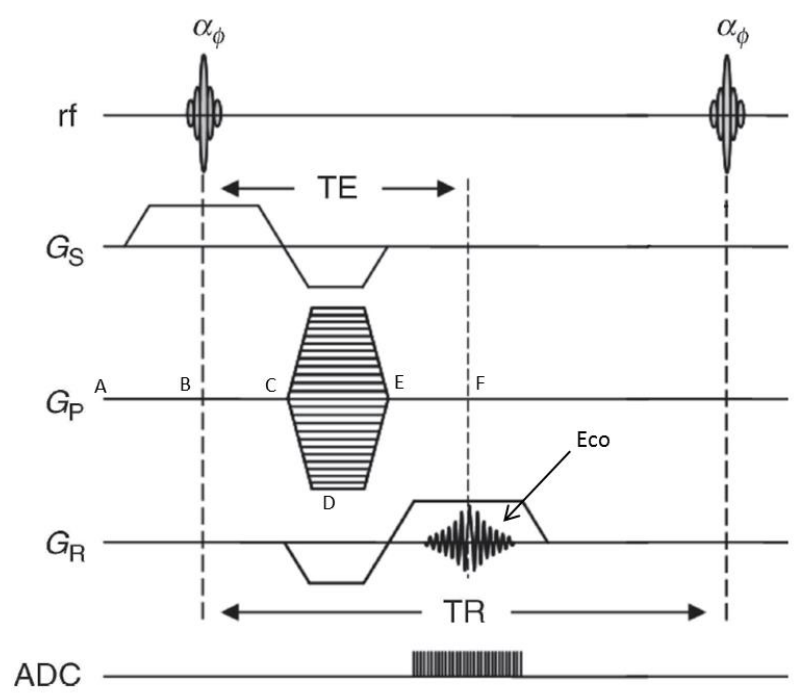

Figura A.1: Esboço da sequência de Gradiente Eco. TE refere-se ao intervalo de tempo ao eco, TR é o tempo entre dois pulsos de rádio frequência e as letras $A, B, C, D, E$, F indicam o tempo para representação dos spins na Figura A.2. Imagem adaptada de Haacke e Reichenbach (2011).

A
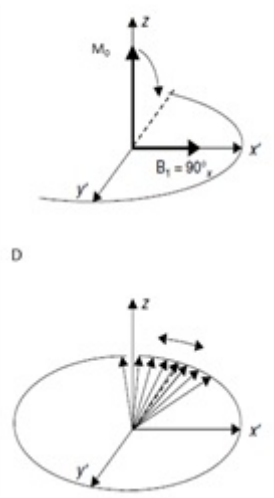

B

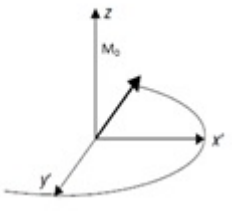

E

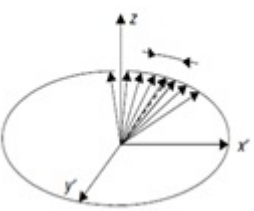

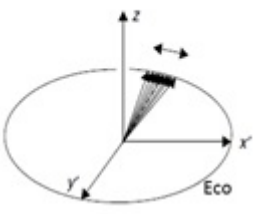

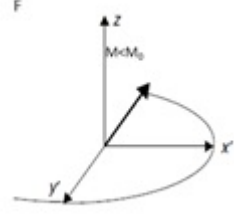

Figura A.2: Diagrama da evolução dos spins durante uma sequência de Gradiente Eco. Imagem Adaptada de Tofts (2003).

O sinal adquirido no experimento de Ressonância Magnética é complexo (Equação A.1 e Figura A.3). Apresenta parte real e imaginária, que pode gerar tanto a imagem de fase quanto a de magnitude:

$$
\rho_{\text {sinal }}=e^{-i \varphi} \cdot \rho(x)
$$

As imagens de fase e magnitude são formadas pelo sinais $\varphi$ e $|\vec{M}|$ 


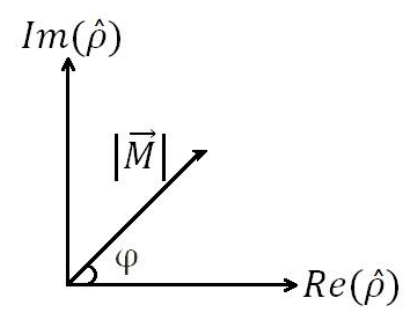

Figura A.3: Representação do sinal complexo.

respectivamente:

$$
\begin{gathered}
\varphi=\tan ^{-1}\left(\frac{\operatorname{Im}\left(\rho_{\text {sinal }}(x)\right)}{\operatorname{Re}\left(\rho_{\text {sinal }}(x)\right)}\right) \\
|\vec{M}|=\sqrt{\left(\operatorname{Im}\left(\rho_{\text {sinal }}(x)\right)\right)^{2}+\left(\operatorname{Re}\left(\rho_{\text {sinal }}(x)\right)\right)^{2}}
\end{gathered}
$$

A intensidade do sinal de magnitude é denominado como uma função $\left(\varphi_{m}(\theta)\right)$, que apresenta a seguintes dependências quando obtido em um tempo TE:

$$
\rho_{m}(\theta)=\frac{\rho_{0} \sin (\theta) e^{\left(\frac{-T E}{T 2 *}\right)}\left(1-e^{\left(\frac{-T R}{T 1}\right)}\right)}{\left(1-\cos (\theta) . e^{\left(\frac{-T R}{T 1}\right)}\right)}
$$

Onde $\varphi_{0}$ é a densidade de spin do tecido, TR é o tempo de repetição de cada aquisição de dados, T1 e T2 são o tempo de relaxação longitudinal e transversal do tecido respectivamente, $\theta$ é o ângulo formado entre a magnetização longitudinal antes do pulso de RF com a magnetização transversal após o pulso de RF.

A intensidade do sinal de fase apresenta dependência com as seguintes variáveis:

$$
\Delta \varphi=-\gamma g \Delta \chi B_{0} T E
$$

Onde $\gamma$ é a constante razão giromagnética, $g$ fator geométrico, $\Delta \chi$ diferença de susceptibilidade magnética local do tecido e $B_{0}$ é a intensidade do campo 
estático.

\section{Processamento da Imagem de fase}

A imagem de fase adquirida em sequência Gradiente Echo possui alguns enrolamentos e artefatos causados por alta diferença de susceptibilidade magnética e inomogeneidade do campo externo. Para o processamento da imagem de fase é necessário aplicar um filtro para remover estes artefatos.

Haacke et al. (2004) sugerem a aplicação do filtro passa alta para atenuar ou eliminar as componentes de baixa frequência. Essas componentes são responsáveis pelas características que variam lentamente na imagem, tais como o contraste total e a intensidade média. O efeito resultante da filtragem passa alta é uma aparente agudização das bordas e outros detalhes finos.

De forma simplificada, iremos exemplificar o filtro espacial passa alta sugerido por Haacke et al. (2004). Primeiramente é aplicado um filtro passa baixa (Figura A.4) em uma imagem de 9 x 9 (Figura A.5).

Sendo a máscara de filtro espacial genérica 3 x 3 pixels:

\begin{tabular}{|l|l|l|}
\hline W1 & W2 & W3 \\
\hline W4 & W5 & W6 \\
\hline W7 & W8 & W9 \\
\hline
\end{tabular}

Figura A.4: Máscara de filtro espacial com coeficientes arbitrários (pesos).

\begin{tabular}{|c|c|c|c|c|c|c|c|c|}
\hline Z1 & Z2 & Z3 & Z4 & Z5 & Z6 & Z7 & Z8 & Z9 \\
\hline Z10 & Z11 & Z12 & Z13 & Z14 & Z15 & Z16 & Z17 & Z18 \\
\hline Z19 & Z20 & Z21 & Z22 & Z23 & Z24 & Z25 & Z26 & Z27 \\
\hline Z28 & Z29 & Z30 & Z31 & Z32 & Z33 & Z34 & Z35 & Z36 \\
\hline Z37 & Z38 & Z39 & Z40 & Z41 & Z42 & Z43 & Z44 & Z45 \\
\hline Z46 & Z47 & Z48 & Z49 & Z50 & Z51 & Z52 & Z53 & Z54 \\
\hline Z55 & Z56 & Z57 & Z58 & Z59 & Z60 & Z61 & Z62 & Z63 \\
\hline Z64 & Z65 & Z66 & Z67 & Z68 & Z69 & Z70 & Z71 & Z72 \\
\hline Z73 & Z74 & Z75 & Z76 & Z77 & Z78 & Z79 & Z80 & Z81 \\
\hline
\end{tabular}

Figura A.5: Imagem de $9 \times 9$ pixels, com os respectivos valores de intensidade. 
O centro da máscara do filtro (W5) é posicionado sobre o pixel de interesse da imagem e multiplicam-se os coeficientes das máscaras por todos os pixels da imagem sobrepostos pela máscara. Então se o centro da máscara estiver em uma posição $(i, j)$ na imagem, a intensidade da imagem em $(i, j)$ será substituído por R:

$$
R=w 1 z 1+w 2 z 2+\ldots+w 9 z 9
$$

A máscara é então movida para a próxima posição de pixel na imagem e o processo se repete. Isso continua até que todas as posições de pixels tenham sido cobertas. Além disso, é comum criar uma nova imagem para armazenar os valores de R (imagem de fase filtrada passa baixa), em vez de alterar os valores dos pixels da imagem original.

A imagem de fase filtrada passa alta é obitida pela divisão da imagem de fase original $\left(\rho_{0}(x)\right)$ e pela imagem de fase filtrada passa baixa $\left(\rho_{\text {passabaixa }}(x)\right)$ :

$$
\rho_{\text {passaalta }}(x)=\frac{\rho_{0}(x)}{\rho_{\text {passabaixa }}(x)}
$$

O uso de filtro passa alta é mostrado na Figura A.6. O valor real da fase decresce de acordo com o tamanho da máscara usada (HAACKE et al., 2009b).

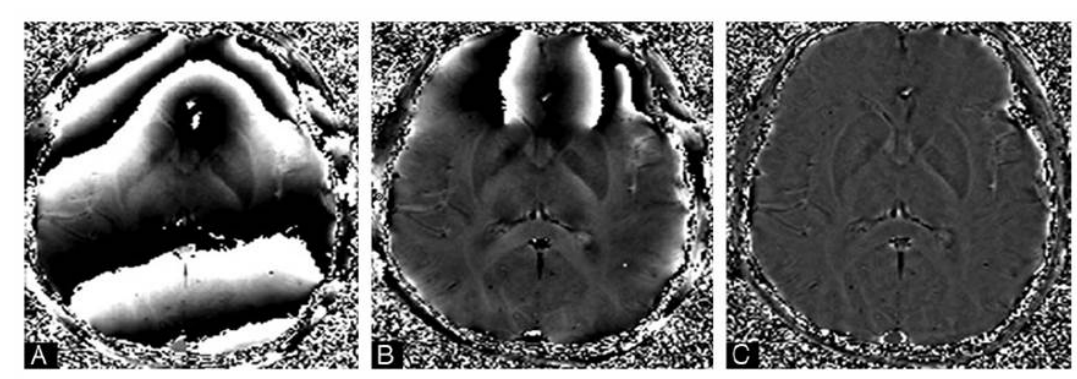

Figura A.6: Aplicação de filtro espacial passa alta. A, Imagem de fase enrolada. B imagem filtrada passa alta com filtro $32 \times 32$. C, Imagem filtrada passa alta com filtro 64x64. Imagem obtida de Haacke et al. (2009b). 


\section{Máscara de fase}

Embora a imagem de fase filtrada por filtro passa alta (Figura A.6) apresente diferentes contrastes de susceptibilidade magnética, a imagem de fase filtrada passa alta pode gerar uma máscara multiplicativa sobre a imagem de magnitude para aumentar o contraste de susceptibiliade mangética (HAACKE et al., 2009b). Quando não há características de fase que queremos melhorar, os pixels da máscara de fase são definidos como 1. Caso contrário, a máscara de fase destina-se a suprimir a intensidade de sinal em áreas onde a fase assume determinados valores (Figura A.7). Por exemplo, se a fase de interesse é negativa, a máscara será $\mathrm{f}(\mathrm{x})$ :

$$
\begin{gathered}
f(x)=[\pi+\varphi(x)] / \pi, \text { para }-\pi<\varphi(x)<0 \\
f(x)=1, \operatorname{para} \varphi(x)>0
\end{gathered}
$$

Uma vez que a máscara é elevada à quarta potência, a veia que tem uma fase de $-\pi / 2$ e um valor de máscara de 0,5 será $1 / 16$ e, portanto, essa veia será suprimida. 


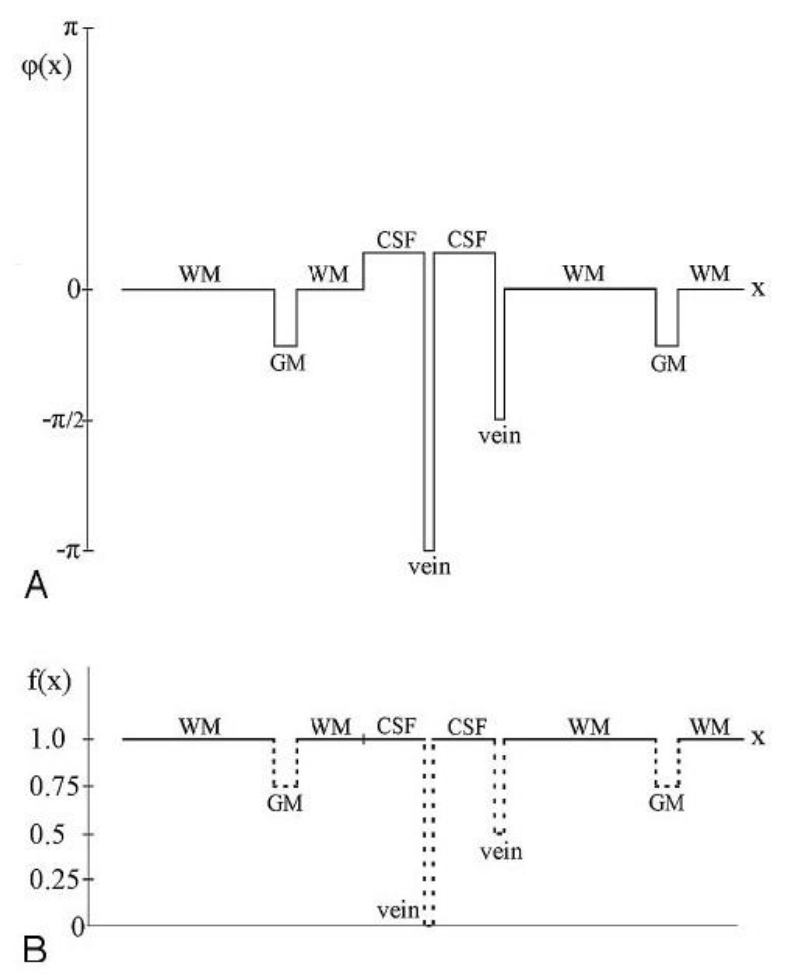

Figura A.7: Representação pictórica do processo de geração da máscara da fase. A)Perfil de fase de uma imagem de fase filtrada. B) Perfil correspondente da máscara criada a partir de A. GM indica que a substância cinzenta, WM a substância branca, CSF o líquido encéfalo raquidiano e vein uma veia. Imagem obtida de Haacke et al. (2009b).

\section{Casando-se imagens de magnitude e de fase}

A máscara de fase pode ser aplicada qualquer número de vezes à imagem original de magnitude $r h o_{m a g}(x)$ para criar a imagem de SWI.

$$
S W I(x)=f^{m} \rho_{\text {mag }}(x)
$$

O número $\mathrm{m}$ de multiplicações da máscara de fase é escolhido de maneira a otimizar a relação contraste ruído da imagem SWI . A Figura A.8 apresenta a obtenção da imagem $S W I$ com o uso de uma máscara negativa m igual 4 . 

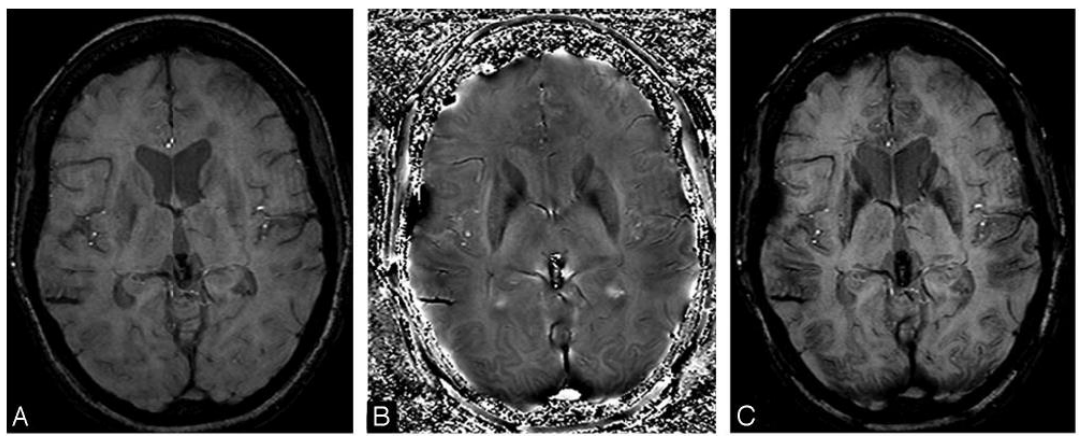

Figura A.8: Obtenção da imagem SWI. A, imagem de magnitude. B, imagem de fase filtrada passa alta. $C$, imagem de SWI $(m=4)$. Imagem obtida de Haacke et al. (2009b).

Finalmente, caso queira visualizar o sistema vascular pode-se fazer a projeção de intensidade mínima (mIP). Consiste na escolha de um limiar de intensidade de sinal para realizar a projeção de vários cortes sobre um resultante. Na Figura A.9 mostra os dados de projeção em relação a imagem original de magnitude e as imagens processadas SWI.
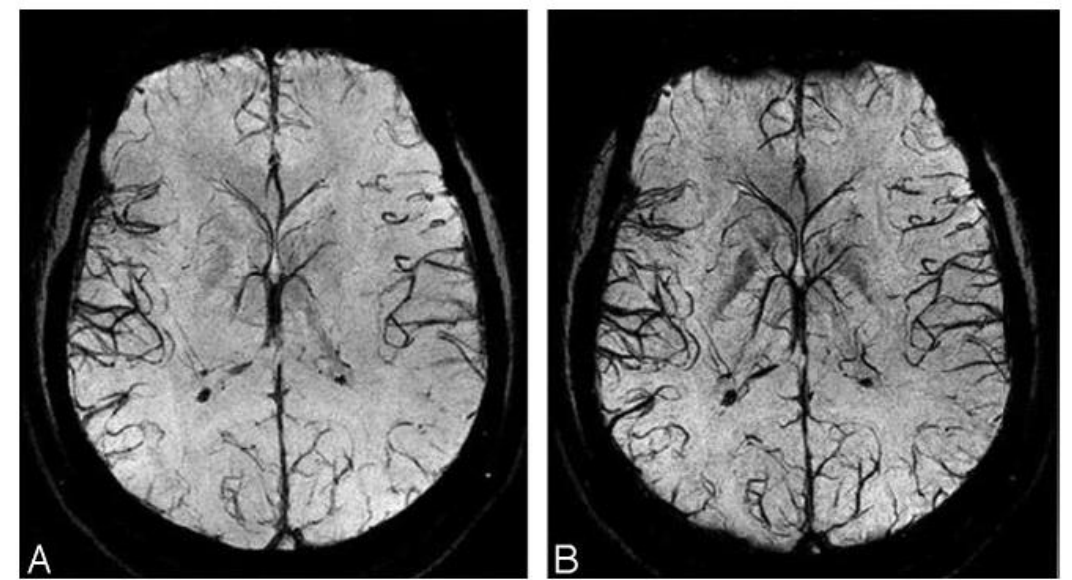

Figura A.9: Imagem mIP das imagens de magnitude e SWI. mIP realizado ao longo de 7 seções (14 milímetros). Há uma perda da intensidade do sinal na parte frontal do cérebro, mas por outro lado a visibilidade das veias é muito melhor em B. Imagem obtida de Haacke et al. (2009b). 
A Figura A.10 resume o processamento da imagem SWI:

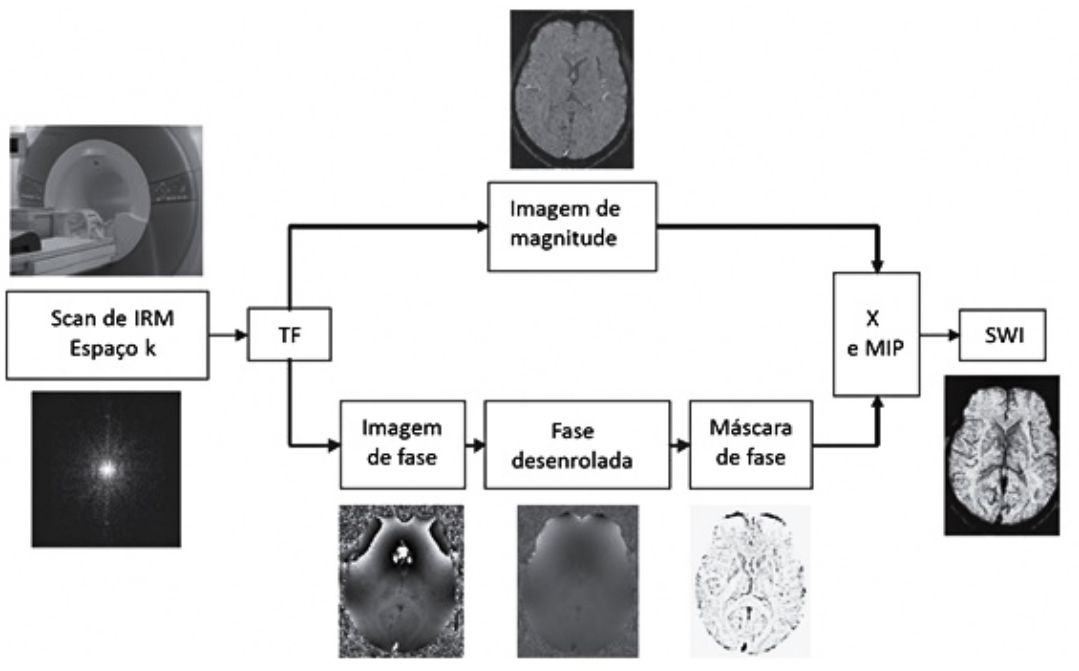

Figura A.10: Diagrama das etapas do processamento da imagem de SWI. Imagem modificada de Haacke e Reichenbach (2011). 


\section{Apêndice}

\section{Teorema da Convolução}

Dada as funções $f(x), g(y)$ e a respectiva convolução $h(z)$ :
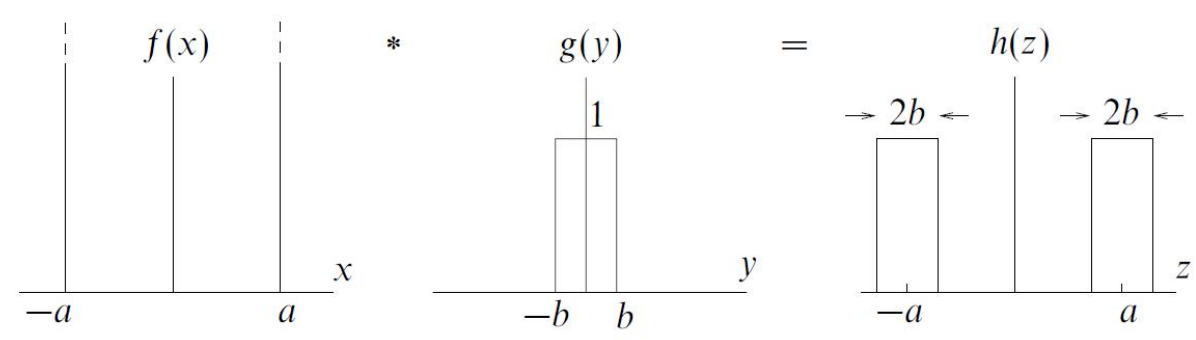

Figura B.1: A convolução de duas funções $f(x)$ e $g(x)$.

A convolução de $f(x)$ e $g(x)(f(x) * g(x))$ pode ser escrita como a integral abaixo:

$$
h(z)=\int_{-\infty}^{\infty} f(x) g(z-x) d x
$$

A transformada de Fourier da convolução $\mathrm{f}(\mathrm{x})^{*} \mathrm{~g}(\mathrm{x})$, é dada por $\mathrm{h}(\mathrm{k})\left(^{\prime}\right)$ :

$$
\begin{aligned}
& h^{\prime}(k)=\frac{1}{\sqrt{ }(2 \pi)} \int_{-\infty}^{\infty} d z e^{-i k z}\left(\int_{-\infty}^{\infty} f(x) g(z-x) d x\right) \\
& h^{\prime}(k)=\frac{1}{\sqrt{ }(2 \pi)} \int_{-\infty}^{\infty} d x f(x)\left(\int_{-\infty}^{\infty} g(z-x) e^{-i k z} d z\right)
\end{aligned}
$$

Tomando $\mathrm{u}=\mathrm{z}$ - $\mathrm{x}$ na segunda integral, temos:

$$
h^{\prime}(k)=\frac{1}{\sqrt{ }(2 \pi)} \int_{-\infty}^{\infty} d x f(x)\left(\int_{-\infty}^{\infty} g(u) e^{-i k(u+x)} d u\right)
$$




$$
\begin{gathered}
h^{\prime}(k)=\frac{1}{\sqrt{ }(2 \pi)} \int_{-\infty}^{\infty} f(x) e^{-i k x} d x \int_{-\infty}^{\infty} g(u) e^{-i k u} d u \\
h^{\prime}(k)=\frac{1}{\sqrt{ }(2 \pi)} x \sqrt{ }(2 \pi) f^{\prime}(k) x(\sqrt{ } 2 \pi) g^{\prime}(k)=\sqrt{ }(2 \pi) f^{\prime}(k) g^{\prime}(k) \\
h^{\prime}(k)=\sqrt{ }(2 \pi) f^{\prime}(k) g^{\prime}(k) \\
h^{\prime}(k)=T F[f(x) g(x)] \\
T F[f(x) * g(x)]=\sqrt{ }(2 \pi)) f^{\prime}(k) g^{\prime}(k)
\end{gathered}
$$

Portanto a transformada de Fourier da convolução das funções é igual o produto das transformadas de Fourier das funções separadamente e multiplicado por $(2 \pi) 1 / 2$, este resultado é descrito como teorema da convolução. A forma inversa também pode ser provada, onde a transformada de Fourier do produto das funções resulta no seguinte:

$$
T F[f(x) g(x)]=\frac{1}{\sqrt{ }(2 \pi)} f^{\prime}(k) * g^{\prime}(k)
$$

Todo o texto acima foi construído com base no livro de (RILEY; HOBSON; BENCE, 2006). 


\section{Termo de consentimento livre e esclarecido para sujeito controle}

\section{TERMO DE CONSENTIMENTO LIVRE E ESCLARECIDO (PARA SUJEITO SAUDÁVEL)}

Este documento é um termo de consentimento, no qual são abordadas todas as informações sobre o estudo abaixo. Sinta-se a vontade para fazer perguntas; caso concorde em participar, por favor, assine.

Título da Pesquisa: Quantificação de Deposição de Ferro no Cérebro usando Ressonância Magnética

Físico Médico: Jeam Haroldo Oliveira Barbosa. Departamento de Física, Faculdade de Filosofia Ciências e Letras de Ribeirão Preto, Universidade de São Paulo. Telefone: 16-3602-3721 Telefone do Comitê de Ética em Pesquisa: 16-3602-4811

Antes de receber as informações sobre o estudo, é importante tomar conhecimento das seguintes condições:

- A sua participação é completamente voluntária.

- É livre para decidir ou não participar do estudo quando quiser sem perder o direito de receber os cuidados médicos de rotina ou quaisquer outros benefícios aos quais tenha direito na assistência médica regular na clínica habitual qualquer que seja sua decisão.

Você está sendo convidado a participar de uma pesquisa que tem como objetivo determinar a técnica de Imagem de Ressonância Magnética mais 
sensível para quantificar acúmulo de ferro no cérebro.

Pesquisas científicas comprovam que as pessoas acumulam ferro ao longo da vida, além disso, pacientes com Parkinson acumulam ferro em maiores concentrações do que pessoas saudáveis. Como dito acima, esta pesquisa irá determinar a técnica de exame de Ressonância Magnética mais sensível para acúmulo de ferro no cérebro e, portanto o seu perfil pertence a um dos grupos a ser pesquisado: sujeitos saudáveis ou de pacientes com Parkinson, ambos com idade acima de 50 anos. No seu caso, você pertence ao grupo de sujeitos saudáveis.

Caso decida participar do estudo, você precisará comparecer ao Hospital das Clínicas de Ribeirão Preto apenas uma vez, em um dia a combinar, que dependerá principalmente da disponibilidade do técnico que fará o exame e da máquina de Ressonância Magnética do Hospital das Clínicas para o estudo.

Realizará um exame de ressonância magnética normal de duração total de 20 minutos. Este exame é realizado por uma máquina de ressonância magnética, que produz um campo magnético que passa pelo corpo sem causar efeitos. Durante o exame não se sente dor. O exame não traz nenhum prejuízo para a sua saúde.

Durante o estudo, você deverá permanecer imóvel dentro da máquina de Ressonância Magnética Nuclear. Os desconfortos previstos são: eventuais incômodos devido ao seu posicionamento e cansaço devido ao barulho durante a realização do exame. Você poderá solicitar o encerramento do exame a qualquer momento. Dependendo da roupa que você estiver usando (se ela possuir botões ou zíper) deverá trocar por um roupão do hospital para garantir o seu conforto e não gerar nenhum artefato (falha) na aquisição das imagens. Durante o exame, a máquina fará um barulho relativamente alto. Será fornecido um protetor auricular a fim de reduzir esse barulho.

Você não terá nenhum benefício direto ao participar desta pesquisa e não receberá laudo médico que traga qualquer informação sobre seu 
estado de saúde. O benefício esperado com a realização desta pesquisa é a produção de novos conhecimentos científicos. Ambos os sujeitos, saudáveis e pacientes, terão acesso ao resultado final da pesquisa por meio de notificação (e-mail, telefone, ou carta) da publicação em algum veículo de divulgação e comunicação de acesso livre. Ressaltando que haverá sigilo total dos dados pessoais dos participantes.

Esses dados serão vistos e analisados apenas pelos pesquisadores responsáveis por este estudo. Os resultados poderão ser comunicados a outros pesquisadores, mas sua identidade será mantida em sigilo. Nenhum dado que possa revelar sua identidade estará disponível para quaisquer pessoas ou em quaisquer textos ou publicações.

Os dados deste estudo são mantidos em um banco de dados do CENTRO DE CIÊNCIAS DAS IMAGENS DA FÍSICA MÉDICA, caso estes dados sejam consultados para outros estudos o CEP será consultado para ver a necessidade de se assinar um novo termo de consentimento ou não.

Caso você tenha perguntas, dúvidas ou qualquer outra informação a respeito deste estudo procurar o pesquisador Jeam Haroldo Oliveira Barbosa, tel. 3602-3721. Sobre questões éticas procurar o Comitê de Ética em Pesquisa tel. 3602-4811. 


\section{ASSINATURAS}

Os detalhes deste estudo foram explicados e relato que tive a oportunidade de fazer todas as perguntas aos pesquisadores. Li o Termo de Consentimento Livre e Esclarecido e entendi as informações nele contidas, portanto concordo voluntariamente em participar deste estudo e assino abaixo:

Nome do Sujeito Saudável

Assinatura do Sujeito Saudável

(impresso ou em letra de forma)

Data:

Nome da Testemunha

Assinatura da Testemunha

(impresso ou em letra de forma)

Data:

Declaração do Pesquisador Principal

Declaro que revisei este estudo e o formulário de consentimento com o participante. Segundo meu entendimento, ele compreendeu os objetivos, os procedimentos, riscos e benefícios do estudo.

Nome do Pesquisador Principal

Assinatura do Pesquisador Principal

(impresso ou em letra de forma)

Data: 


\section{Termo de consentimento livre e esclarecido para sujeito paciente}

\section{TERMO DE CONSENTIMENTO LIVRE E ESCLARECIDO (PARA SUJEITO PACIENTE)}

Este documento é um termo de consentimento, no qual são abordadas todas as informações sobre o estudo abaixo. Sinta-se a vontade para fazer perguntas; caso concorde em participar, por favor, assine.

Título da Pesquisa: Quantificação de Deposição de Ferro no Cérebro usando Ressonância Magnética

Físico Médico: Jeam Haroldo Oliveira Barbosa. Departamento de Física, Faculdade de Filosofia Ciências e Letras de Ribeirão Preto, Universidade de São Paulo. Telefone: 16-3602-3721 Telefone do Comitê de Ética em Pesquisa: 16-3602-4811

Antes de receber as informações sobre o estudo, é importante tomar conhecimento das seguintes condições:

- A sua participação é completamente voluntária.

- É livre para decidir ou não participar do estudo quando quiser sem perder o direito de receber os cuidados médicos de rotina ou quaisquer outros benefícios aos quais tenha direito na assistência médica regular na clínica habitual qualquer que seja sua decisão.

Você está sendo convidado a participar de uma pesquisa que tem como objetivo determinar a técnica de Imagem de Ressonância Magnética mais 
sensível para quantificar acúmulo de ferro no cérebro.

Pesquisas científicas comprovam que as pessoas acumulam ferro ao longo da vida, além disso, pacientes com Parkinson acumulam ferro em maiores concentrações do que pessoas saudáveis. Como dito acima, esta pesquisa irá determinar a técnica de exame de Ressonância Magnética mais sensível para acúmulo de ferro no cérebro e, portanto o seu perfil pertence a um dos grupos a ser pesquisado: sujeitos saudáveis ou de pacientes com Parkinson, ambos com idade acima de 50 anos. No seu caso, você pertence ao grupo de pacientes com Parkinson.

Caso decida participar do estudo, você precisará comparecer ao Hospital das Clínicas de Ribeirão Preto apenas uma vez, em um dia a combinar, que dependerá principalmente da disponibilidade do técnico que fará o exame e da máquina de Ressonância Magnética do Hospital das Clínicas para o estudo.

Realizará um exame de ressonância magnética normal de duração total de 20 minutos. Este exame é realizado por uma máquina de ressonância magnética, que produz um campo magnético que passa pelo corpo sem causar efeitos. Durante o exame não se sente dor. O exame não traz nenhum prejuízo para a sua saúde.

Durante o estudo, você deverá permanecer imóvel dentro da máquina de Ressonância Magnética Nuclear. Os desconfortos previstos são: eventuais incômodos devido ao seu posicionamento e cansaço devido ao barulho durante a realização do exame. Você poderá solicitar o encerramento do exame a qualquer momento. Dependendo da roupa que você estiver usando (se ela possuir botões ou zíper) deverá trocar por um roupão do hospital para garantir o seu conforto e não gerar nenhum artefato (falha) na aquisição das imagens. Durante o exame, a máquina fará um barulho relativamente alto. Será fornecido um protetor auricular a fim de reduzir esse barulho.

Você terá como benefício a aquisição da imagem do exame de Ressonância Magnética Nuclear, porém não receberá laudo, que poderá ser 
anexado ao meu prontuário do Hospital das Clínicas da FMRP, sendo um dado a mais para o médico considerar em seu diagnóstico, tratamento e prognóstico. Ambos os sujeitos, saudáveis e pacientes, terão acesso ao resultado final da pesquisa por meio de notificação (e-mail, telefone, ou carta) da publicação em algum veículo de divulgação e comunicação de acesso livre. Ressaltando que haverá sigilo total dos dados pessoais dos participantes.

Esses dados serão vistos e analisados apenas pelos pesquisadores responsáveis por este estudo. Os resultados poderão ser comunicados a outros pesquisadores, mas sua identidade será mantida em sigilo. Nenhum dado que possa revelar sua identidade estará disponível para quaisquer pessoas ou em quaisquer textos ou publicações.

Os dados deste estudo são mantidos em um banco de dados do CENTRO DE CIÊNCIAS DAS IMAGENS DA FÍSICA MÉDICA, caso estes dados sejam consultados para outros estudos o CEP será consultado para ver a necessidade de se assinar um novo termo de consentimento ou não.

Caso você tenha perguntas, dúvidas ou qualquer outra informação a respeito deste estudo procurar o pesquisador Jeam Haroldo Oliveira Barbosa, tel. 3602-3721. Sobre questões éticas procurar o Comitê de Ética em Pesquisa tel. 3602-4811. 


\section{ASSINATURAS}

Os detalhes deste estudo foram explicados e relato que tive a oportunidade de fazer todas as perguntas aos pesquisadores. Li o Termo de Consentimento Livre e Esclarecido e entendi as informações nele contidas, portanto concordo voluntariamente em participar deste estudo e assino abaixo:

Nome do Paciente

(impresso ou em letra de forma)

Data:

Nome da Testemunha

(impresso ou em letra de forma)

Data:

Declaração do Pesquisador Principal

Declaro que revisei este estudo e o formulário de consentimento com o participante. Segundo meu entendimento, ele compreendeu os objetivos, os procedimentos, riscos e benefícios do estudo.

Nome do Pesquisador Principal Assinatura do Pesquisador Principal

(impresso ou em letra de forma)

Data: 
Anexo

\section{Aceite do Comitê de Ética da FFCLRP}


Universidade de São Paulo

Faculdade de Filosofia, Ciências e Letras de Ribeirão Preto

Comitê de Ética em Pesquisa

Of.CEtP/FFCLRP-USP/081/-jsI

Campus de Ribeirão Preto

Ribeirão Preto, 15 de junho de 2012

Prezado Pesquisador,

Comunicamos V. Sa. que o projeto de pesquisa intitulado "QUANTIFICAÇÃo de DEPOSIÇÃo de FERRO No CÉREBRo USANDO RESSONÂNCIA MAGNÉTICA" foi reanalisado pelo Comitê de Ética em Pesquisa da FFCLRP-USP, e enquadrado na categoria: APROVADO (CAAE - 01396712.0.0000.5407).

Solicitamos que eventuais modificações ou emendas ao projeto de pesquisa sejam apresentadas ao CEP, de forma sucinta, identificando a parte do projeto a ser modificada e suas justificativas, e que, ao término do estudo, um relatório final seja entregue, via Plataforma Brasil (icone 'Notificação').

Atenciosamente,

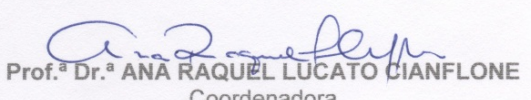

Ao Senhor

Jeam Haroldo Oliveira Barbosa

Mestrando do Programa de Pós-Graduação em Física Aplicada à Medicina e Biologia da FFCLRP USP

Com cópia para o orientador:

Prof. Dr. Carlos Ernesto Garrido Salmon

Departamento de Fisica da FFCLRP USP

CEP - Cormité de Ética em Pesquisa da FFCLRP

Fone: (16) $3602-4811$

Homepage heirantes, 3900 - bloco 3 - sala 16- $14040-901$ - Ribeirăo Preto - SP - Brasil

Homepage: hittp://mww. ffcliro. usp. br - e-mail: coetp@fffcirp. usp.br

Figura C.1: Aceite do comitê de ética da FFCLRP 
Anexo

D

Aceite do Comitê de Ética do Hospital das Clínicas 
HOSPITAL DAS CLINIICAS DA FACULDADE DE MEDICINA DE RIBEIRĀO PRETO DA UNIVERSIDADE DE SÄO PAULO

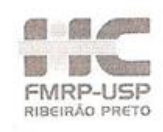

Ribeirão Preto, 06 de julho de 2012

Projeto de pesquisa: "Quantificação de deposição de ferro no cérebro usando ressonância magnética"

Pesquisadores responsáveis: Jeam Haroldo Oliveira Barbosa e Prof. Dr. Carlos Ernesto Guarrido Salmon

Instituição Proponente: Faculdade de Filosofia, Ciências e Letras de Ribeirão Preto - USP.

"O CEP do HC e da FMRP-USP concorda com o parecer ético emitido pelo CEP da Instituição Proponente, que cumpre as Resoluções Éticas Brasileiras, em especial a Resolução CNS 196/96. Diante disso, o HCFMRP-USP, como instituição co-participante do referido projeto de pesquisa, está ciente de suas co-responsabilidades e de seu compromisso no resguardo da segurança e bemestar dos sujeitos desta pesquisa, dispondo de infra-estrutura necessária para a garantia de tal segurança e bem-estar".

Ciente e de acordo:

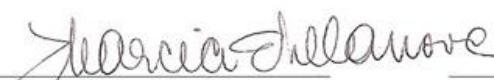

Dir Marcia Guimarães Villanova

Coordenadora do Comitê de Ética

em Pesquisa - HCFMRP-USP

Coordenador Técríco Científico da Unidade de Pesquisa Clingica - HCFMRP-USP

Figura D.1: Aceite do comitê de ética do HC 